Portland State University

PDXScholar

Civil and Environmental Engineering Faculty

Publications and Presentations

Civil and Environmental Engineering

9-2013

\title{
Improving the Representation of the Pedestrian Environment in Travel Demand Models, Phase I
}

Kelly J. Clifton

Portland State University, kclifton@pdx.edu

Patrick Allen Singleton

Portland State University, singletonpa@gmail.com

Christopher Devlin Muhs

Portland State University, cdmuhs@gmail.com

Robert J. Schneider

University of Wisconsin - Milwaukee

Peter Lagerwey

Follow this and additional works at: https://pdxscholar.library.pdx.edu/cengin_fac

Part of the Engineering Commons, Transportation Commons, Urban Studies Commons, and the Urban Studies and Planning Commons

Let us know how access to this document benefits you.

Citation Details

Clifton, K. J., Singleton, P. A., Muhs, C. D., Schneider, R. J., \& Lagerwey, P. Improving the Representation of the Pedestrian Environment in Travel Demand Models, Phase I. OTREC-ED-510. Portland, OR:

Transportation Research and Education Center (TREC), 2013. http://dx.doi.org/10.15760/trec.120

This Report is brought to you for free and open access. It has been accepted for inclusion in Civil and Environmental Engineering Faculty Publications and Presentations by an authorized administrator of PDXScholar. Please contact us if we can make this document more accessible: pdxscholar@pdx.edu. 


\section{S)OTREC}

FINAL REPORT

\section{Improving the Representation of the Pedestrian}

\section{Environment in Travel Demand Models - Phase I}

\section{OTREC-ED-5 10}

September 2013 



\title{
IMPROVING THE REPRESENTATION OF THE PEDESTRIAN ENVIRONMENT IN TRAVEL DEMAND MODELS - PHASE I
}

\author{
FINAL REPORT \\ OTREC-RR-510
}

by

Professor Kelly J. Clifton

Patrick A. Singleton

Christopher D. Muhs

Robert J. Schneider

Peter Lagerwey

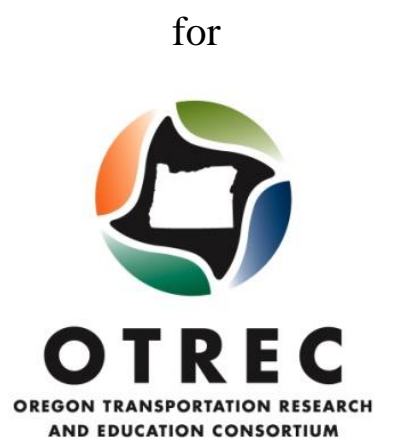

P.O. Box 751

Portland, OR 97207

September 2013 



\section{Technical Report Documentation Page}

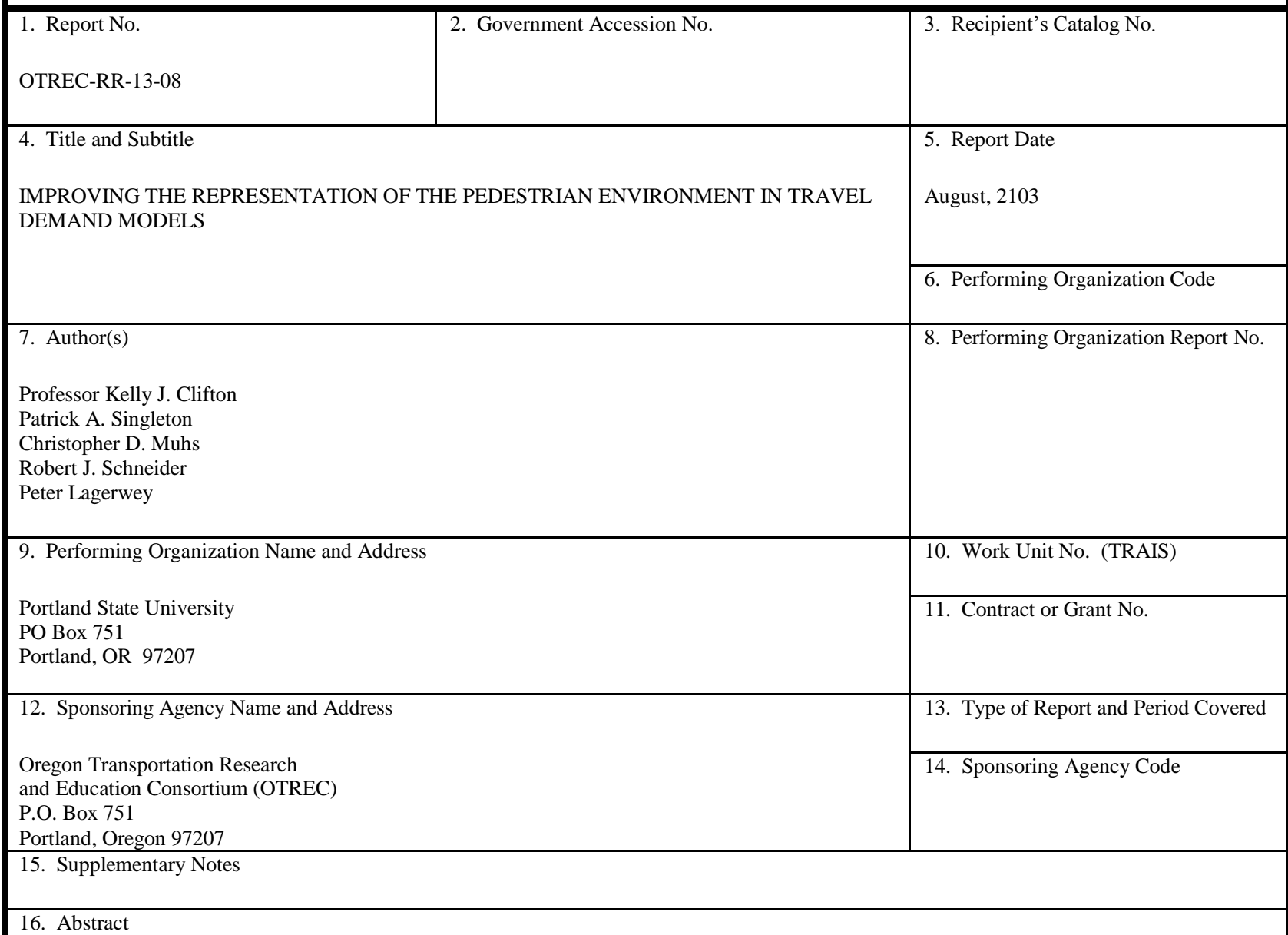

16. Abstract

There is growing support for improvements to the quality of the walking environment, including more investments to promote pedestrian travel. Metropolitan planning organizations (MPOs) are improving regional travel demand forecasting models to better represent walking and bicycling and to expand the evaluative capacity of models to address policy-relevant issues like air quality, public health, and the smart allocation of infrastructure and other resources. This report describes an innovative, spatially disaggregate method to integrate walking activity into trip-based travel models. Using data for the Portland, OR, metropolitan area, the method applies trip generation at a new micro-scale spatial unit: a 264-foot-by-264-foot (80-meters-by-80-meters) pedestrian analysis zone (PAZ). Next, a binary logit walk mode split model—using a new pedestrian environment measure - estimates the number of walk trips generated. Non-walk trips are then aggregated up to larger transportation analysis zones (TAZs) for destination choice, mode choice, and traffic assignment. Finally, there are opportunities for choosing destinations and for routing of the PAZ pedestrian trips. This method improves travel models' sensitivity to policy- and investment-related walking influences, and it could operate as a standalone tool for rapid scenario analysis. Care must be taken when applying this method with respect to scalability, forecasting, and operational challenges.

\section{Key Words}

Walking, pedestrians, travel demand forecasting, four-step models
18. Distribution Statement

No restrictions. Copies available from OTREC: www.otrec.us

\begin{tabular}{l|l}
\hline 19. Security Classification (of this report) & 20. Security Classification (of this page) \\
Unclassified & Unclassified
\end{tabular}

21. No. of Pages

102 


\section{ACKNOWLEDGEMENTS}

This project was funded by the Oregon Transportation Research and Education Consortium (OTREC) and Metro, the regional government for the Portland, OR, metropolitan area. The authors thank colleagues from Metro, Portland State University, Toole Design Group, and the University of Wisconsin, Milwaukee, for their insights and interest in this topic.

\section{DISCLAIMER}

The contents of this report reflect the views of the authors, who are solely responsible for the facts and the accuracy of the material and information presented herein. This document is disseminated under the sponsorship of the U.S. Department of Transportation University Transportation Centers Program and Portland State University in the interest of information exchange. The U.S. Government and Portland State University assume no liability for the contents or use thereof. The contents do not necessarily reflect the official views of the U.S. Government or Portland State University. This report does not constitute a standard, specification, or regulation. 


\section{TABLE OF CONTENTS}

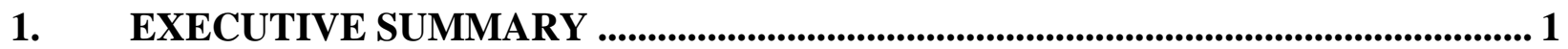

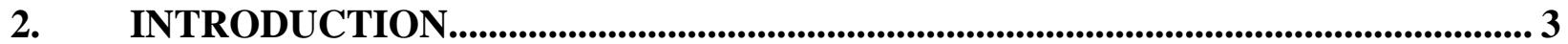

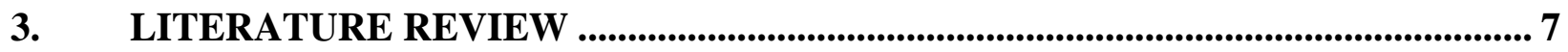

3.1 KEY FINDINGS FROM THE REVIEW OF THE BUILT ENVIRONMENT AND

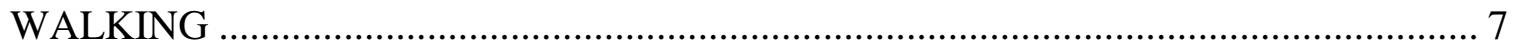

3.2 KEY FINDINGS FROM THE REVIEW OF PEDESTRIANS IN REGIONAL TRAVEL DEMAND MODELS..... 8

4. WALK TRIP MODEL: DATA \& METHODS ............................................................. 11

4.1 GEOGRAPHY SELECTION .............................................................................. 11

4.2 OREGON HOUSEHOLD ACTIVITY SURVEY DATA ...................................... 12

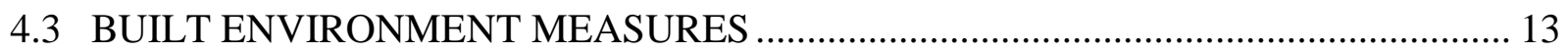

4.3.1 Metro Context Tool.............................................................................................. 13

4.3.2 Pedestrian Index of the Environment................................................................ 15

5. WALK TRIP MODEL: ESTIMATION RESULTS AND VALIDATION .............. 23

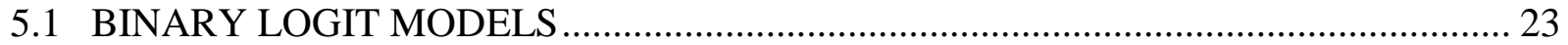

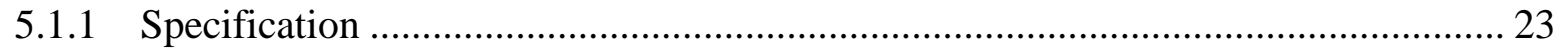

5.1.2 Estimation and Results................................................................................ 26

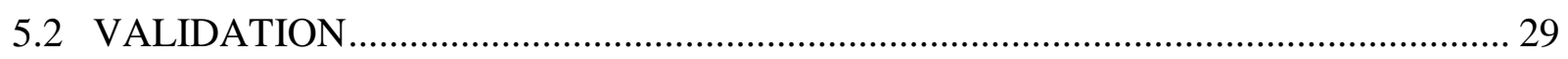

6. WALK TRIP MODEL: APPLICATION IN METRO'S FOUR-STEP MODEL ... 31

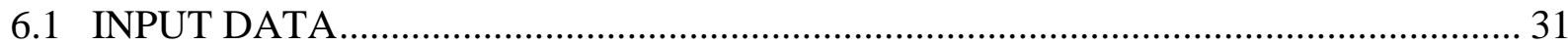

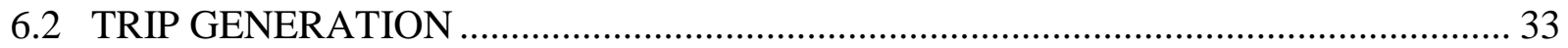

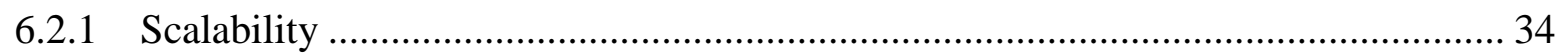

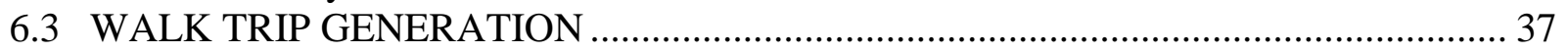

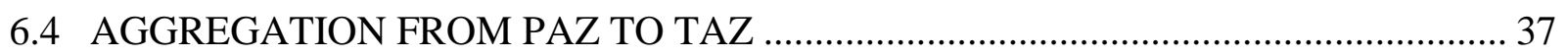

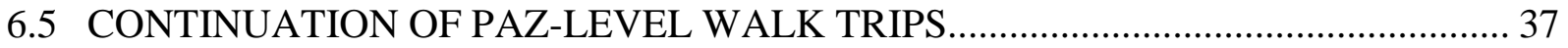

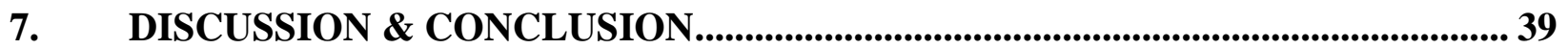

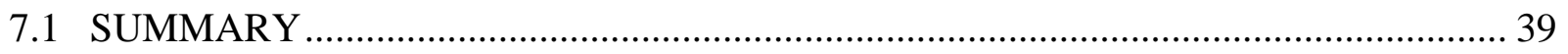

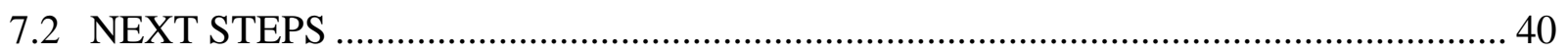

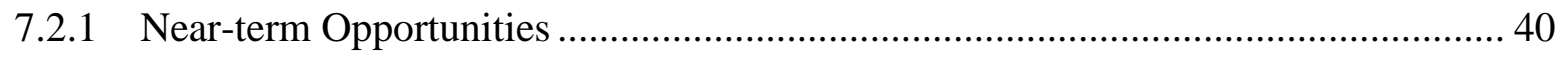

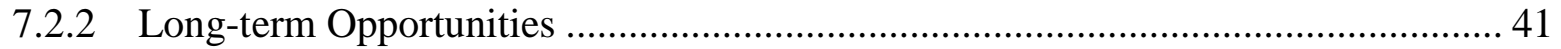

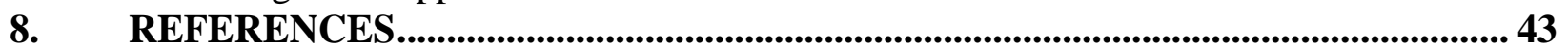
APPENDIX A. THE RELATIONSHIP BETWEEN THE BUILT ENVIRONMENT AND PEDESTRIAN TRAVEL BEHAVIOR ....................................................................... A-1

A.1 CLASSIFYING URBAN FORM AND BUILT ENVIRONMENT "INDEPENDENT"

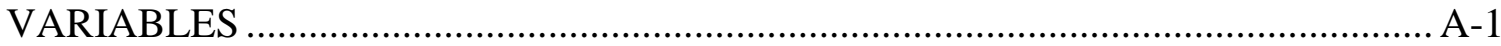

A.2 CLASSIFYING TRAVEL BEHAVIOR AND TRAVEL OUTCOME "DEPENDENT" VARIABLES …........................................................................................ A

A.3 DESCRIBING THE RELATIONSHIP BETWEEN BUILT ENVIRONMENT AND

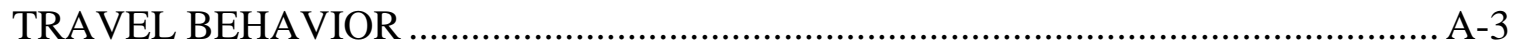

A.4 THE INFLUENCE OF SCALE AND AGGREGATION ..................................... A-8 


\section{A.5 BUILT ENVIRONMENT VARIABLES THAT INFLUENCE PEDESTRIAN TRAVEL}

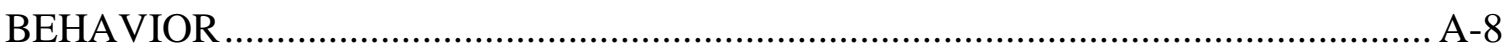

A.5.1 Intensity / Density Variables.......................................................................... A-8

A.5.2 Land Use Mix / Diversity Variables ............................................................ A-11

A.5.3 Network / Connectivity Variables …………………......................................... A-13

A.5.4 Mobility and Accessibility Variables................................................................. A-15

A.5.5 Street and Other Urban Design Variables...................................................... A-17

A.5.6 Pedestrian Environment Factor ....................................................................... A-19

A.5.7 Attitudes and Perceptions .......................................................................... A-21

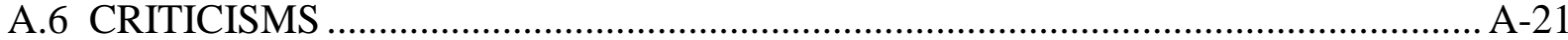

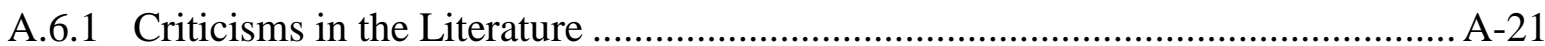

A.6.2 Criticisms from the Research Team............................................................. A-23

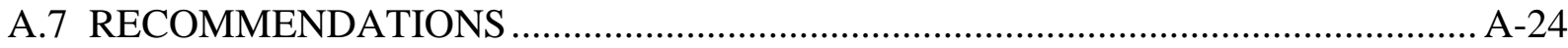

APPENDIX B. REPRESENTING PEDESTRIAN TRAVEL IN REGIONAL TRAVEL DEMAND FORECASTING MODELS.............................................................................. B-1

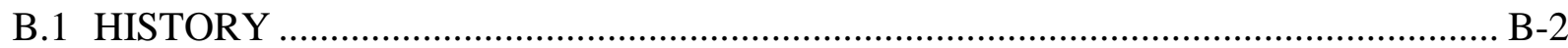

B.2 REVIEW METHODOLOGY …........................................................................... B-3

B.3 MODELING FRAMEWORKS, MODEL STRUCTURES, AND VARIABLES ......... B-3

B.3.1 Detailed Descriptions of Frameworks, Structures, and Variables .......................... B-4

B.3.2 Other Considerations ............................................................................... B-11

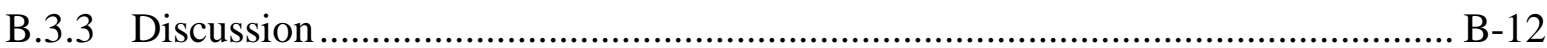

B.4 BARRIERS TO REPRESENTING NON-MOTORIZED AND/OR WALK TRAVEL . B13

B.4.1 Travel Survey Records........................................................................... B-144

B.4.2 Data Collection Resources .................................................................. B-14

B.4.3 Model Development Resources .......................................................... B-14

B.4.4 Decision-Maker Interest........................................................................ B-14

B.4.5 Other Considerations ……………………........................................... B-14

B.5 CURRENT AND FUTURE INNOVATIONS ……………………………..... B-155

B.5.1 Adding Modes or Modifying the Mode Choice Model ...................................... B-15

B.5.2 Pedestrian Environment Data ………………................................................ B-15

B.5.3 Smaller Spatial Analysis Units …………….......................................... B-166

B.5.4 Activity-Based Modeling Activities …………......................................... B-16

B.5.5 Non-Motorized Network Assignment............................................................ B-16

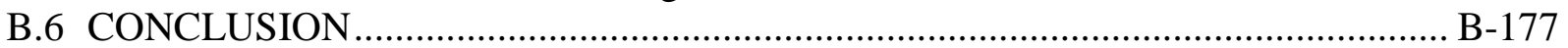




\section{LIST OF FIGURES}

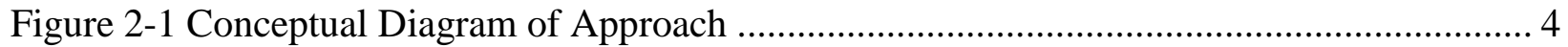

Figure 4-1 TAZ and PAZ Boundary Example.................................................................. 12

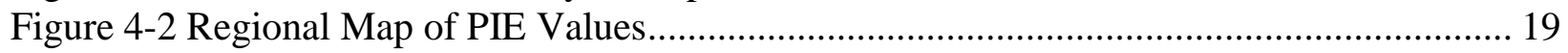

Figure 4-3 Examples of PIE Values in the Portland Region ............................................... 20

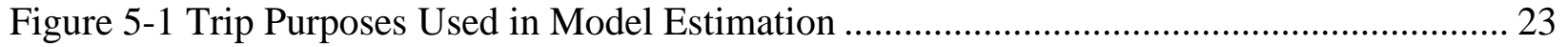

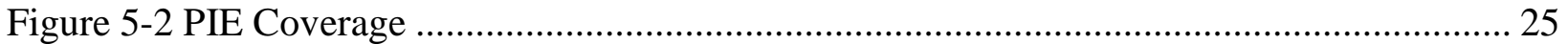

Figure 6-1 PAZ-level Home-Based Work Trip Productions .................................................. 35

Figure 6-2 TAZ-level Home-Based Work Trip Productions ................................................. 36

Figure 8-1 Pedestrian Modeling Frameworks..................................................................... B-5

Figure 8-2 Barriers to Representing Non-Motorized and/or Walk Travel ........................... B-13 Figure 8-3 Current and Future Innovations in Representing Non-Motorized and/or Walk Travel

\section{LIST OF TABLES}

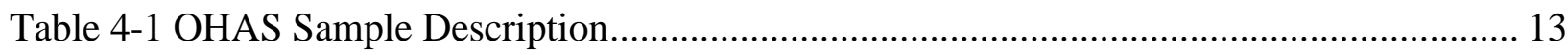

Table 4-2 Metro Context Tool Data Sources ......................................................................... 14

Table 4-3 Seven Binary Logit Models of Context Tool Components ...................................... 17

Table 4-4 Weights Assigned to Components of the PIE ........................................................ 18

Table 5-1 Variables Used in Model Estimation....................................................................... 26

Table 5-2 Model Results ................................................................................................ 28

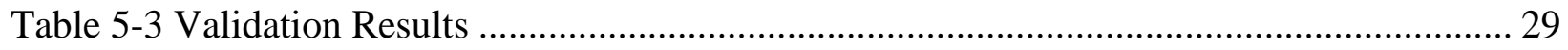

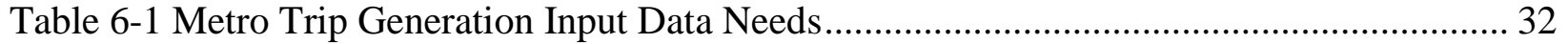

Table B-1 Large MPOs and their Pedestrian Modeling Frameworks.................................... B-6

Table B-2 Variables and their Frequency of Use, by Modeling Framework.......................... B-8 


\section{EXECUTIVE SUMMARY}

Despite recent attention paid to the importance of active transportation for public health and environmental concerns as well as transportation policies that seek to reduce automobile use and encourage walking, cycling, and transit, extant modeling tools suffer from a lack of spatial acuity and behavioral sensitivity to the preferences of non-motorized travelers. Accurate prediction of the likely responses of travelers to land use changes, parking management, pricing, and other policies that would encourage non-motorized travel and thereby reduce emissions also requires a more explicit representation of the pedestrian travel environment.

There is a need for analytical modeling tools that can predict likely traveler responses at a smaller level of detail, including behaviors now obscured by the larger transportation analysis zones (TAZs) used in most travel demand modeling systems. This is critically important for assessing the impacts of land uses or transportation system components that are attractors of pedestrian travel, such as mixed-use developments or transit stations. Perhaps more fundamentally, there are few analytical models of pedestrian behavior that can gauge traveler preferences and evaluate the tradeoffs they are willing to make between distance and the quality of the walking environment.

This project helps fill these gaps by developing more robust pedestrian planning tools for use in regional travel demand models. This applied research improves the mode choice capabilities with respect to pedestrian trips of the existing trip-based model used by Metro, the regional metropolitan planning organization for Portland, OR. The research design uses existing data resources including a recent regional household travel survey, pedestrian count data, and built environment attributes to develop a more appropriate measure of the pedestrian environment. This will ultimately result in better model performance.

The following information summarizes the pedestrian planning methodology developed in this research project. First, the spatial unit of analysis for trip generation is changed from TAZs to 264-foot-by-264-foot gridded pedestrian analysis zones (PAZs). After calculating total trips generated at this smaller geographic scale, a new binary logistic walk trip mode split model predicts the number of walk trips produced by each PAZ. The key to this walk trip model is a new variable: the pedestrian index of the environment (PIE). The PIE, a factor of six different measures of the built environment, is calibrated to best represent the aspects of the pedestrianscale built environment that influence walking behavior. Trips by other modes are finally aggregated back up to TAZs and then proceed through the remaining travel model stages. This innovative method allows for detailed consideration of walking trips within a four-step travel model without adding significant additional complexity or data requirements. 
The key takeaways from this project are the following:

1. The method uses data that are available to Metro.

2. The units of analysis (PAZs) are at a finer-grained spatial scale than the existing TAZs, which is better for capturing and representing short walking trips.

3. The weighted PIE improves upon previous regional measures for evaluating "walkability."

4. The parameters in the walk trip models are statistically significant and generally have expected relationships with the probability of walking.

5. Despite being integrated with travel demand modeling structures, the walk trip model can operate as a stand-alone pedestrian planning tool separate from the rest of the travel model.

This project is a partnership between the Oregon Modeling Collaborative, Metro, and Toole Design Group. The project has value in its direct application to Metro's upcoming planning efforts as well as the possible integration into trip-based travel demand models in other urban areas across the country. It builds on the principal investigators' previous and current work in non-motorized model development. 


\section{INTRODUCTION}

The state of the practice in regional travel forecasting models utilizes relatively coarse spatial units, transportation analysis zones (TAZs), to provide a convenient data structure for aggregating neighborhood-level details into a single area. The use of TAZs evolved pragmatically in an era focused on highway investment decisions and with relatively low computing power. Accordingly, the current practice of modeling pedestrian travel is either to leave walk trips out of the model altogether or, at best, to represent them as a mode choice option, influenced by the distance of a proposed trip and maybe basic attributes related to the quality of the pedestrian environment. Unfortunately, distance is relatively poorly measured for shorter trips because the TAZ system obscures variability in intra-zonal travel. This has resulted in widely applied rules-of-thumb, such as two-thirds the distance to the nearest neighboring zone, measured from center to center, as a measure of intra-zonal trip distance. Once trips have been allocated to the "walk" mode, they are not typically analyzed further other than to report their existence.

However, as transportation modeling practice has evolved, models have been increasingly relied upon to answer more complex questions related to transit system planning and air pollutant emissions. Planners have also sought to use models to analyze urban design proposals such as transit-oriented developments and similar compact land development strategies. Proper analysis of transit proposals and supporting land use policies and plans must consider pedestrian accessibility and catchment areas. Accurate prediction of the likely responses of travelers to land use changes, parking management, pricing, and other policies that would encourage nonmotorized travel and thereby reduce emissions also requires a nuanced representation of the pedestrian travel environment. Indeed, recent greenhouse gas emissions legislation, such as Oregon SB 1059 (Courtney, 2010), Oregon HB 2001 (Beyer et al., 2009), and California SB 375 (Steinberg, 2008) require upgrades to modeling tools to better reflect travel behavior at much finer spatial and temporal scales.

There is a long history of research that documents the relationships between walking and environmental conditions (Saelens and Handy, 2008). In practice, recent growth in local and national pedestrian and bicycle data collection efforts (Schneider et al., 2005; AMEC E\&I, Inc. and Sprinkle Consulting Inc., 2011), combined with innovative modeling approaches, have advanced the state of knowledge. Yet, these advances have not been incorporated into practice in the form of reliable, predictive methods for regional travel forecasting. This project aims to fill this gap by building on the body of literature and capitalizing on new data resources to develop innovative ways to represent the pedestrian environment and capture its influences in travel demand models.

The overarching goal of this research is to improve transportation decision making by incorporating new measures of the pedestrian environment that better reflect traveler choices. Specific objectives of this work include: 
1. Reviewing the literature of the relationship between walking for transportation and the built environment and how walking is integrated into regional travel forecasting models;

2. Developing state-of-the-art measures of the pedestrian environment;

3. Testing associations of these measures with traveler decisions; and

4. Developing an approach for integration into travel demand modeling technology for Portland Metro and other urban areas.

In this report, we introduce a method to integrate walk trips into the Portland Metro's existing four-step travel model at a 264-foot-by-264-foot grid cell resolution. We refer to the grid cells as pedestrian analysis zones (PAZs). Working with PAZs provides a much finer geographic scale than the existing TAZ framework. Figure 2-1 illustrates our approach. We perform the trip generation at the PAZ level for all person trips, then run a binary walk mode split model based on socio-demographic and built environment characteristics to estimate the PAZ-specific walk share of all person trips. Once the pedestrian trip ends have been identified, they can be matched in trip distribution. The non-pedestrian trips can then be aggregated up to the TAZ level and the remaining destination choice, mode choice, and trip assignment models can be performed per Metro's typical four-step framework.

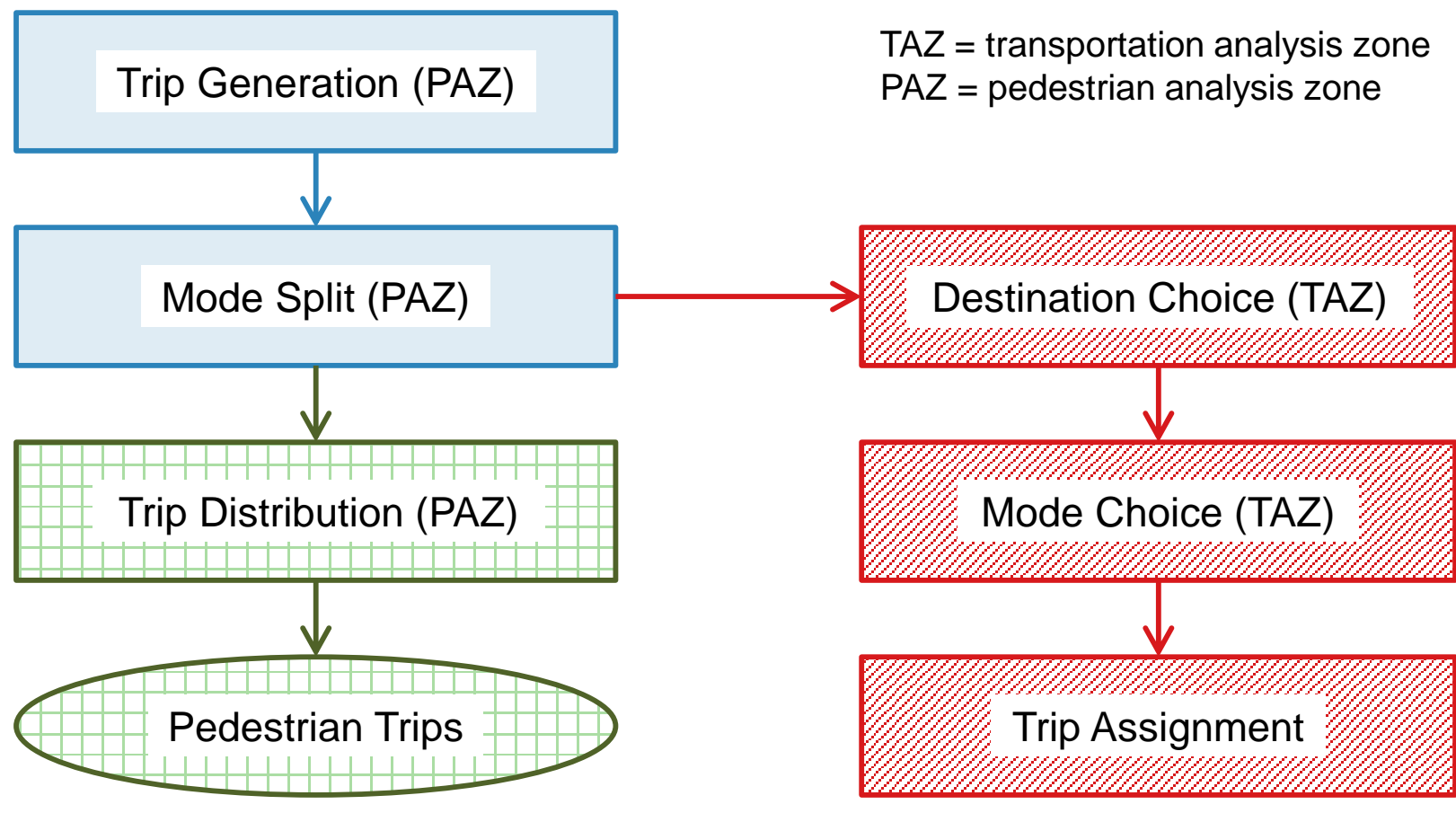

$\square$ All Person Trips $\quad \square$ Pedestrian Trips $\quad \square$ Other Mode Trips

Figure 2-1 Conceptual Diagram of Approach

The resulting measures and modeling approach are useful in Oregon, communities across the U.S., and internationally. Specifically, the research findings and products developed here are 
important for understanding connections between the environment and pedestrian choices, planning for non-motorized travel, and estimating and forecasting pedestrian demand.

This report documents Phase I of the project. The work here covers the objectives enumerated above, but the project itself will continue into a second phase to integrate the processes from Phase I into Metro's four-step model.

The report is organized as follows: In the next chapter, a literature review summarizes research on walking and the built environment, and documents how pedestrian travel is analyzed in regional travel demand models. We then describe the data assembly and analysis methods used for our walk trip model, followed by model estimation and validation results. We conclude with a conceptual discussion of integrating this work in the four-step modeling process and the next steps for Phase II of the project. 


\section{LITERATURE REVIEW}

A large component of this project was to review the literature on the relationships between the built environment and walking as well as the current state of the practice of analyzing walking in regional travel demand models. We performed two comprehensive reviews which are included in their entirety in Appendix A and Appendix B. Here we summarize the key findings and takeaways from these literature reviews.

\subsection{KEY FINDINGS FROM THE REVIEW OF THE BUILT ENVIRONMENT AND WALKING}

1. The factors consistently related to walk mode choice, walk trip frequency, and levels of walking include the following:

- Distances between trip origins and destinations;

- Value of time;

- Economic status of a person or a household;

- Vehicle ownership and availability;

- Demographics and life situation (e.g., primary school student, working adult, elderly retiree);

- Attitudes and preferences (e.g., some people may walk more simply because they want to); and

- Metrics of the built environment.

But, many of these factors have relationships between them. For example, higher economic status is associated with increased likelihood of vehicle ownership.

2. There are many categorizations of and ways to measure the built environment. The common categorizations of built form measures are the following:

- Intensity and density variables;

- Land use mix and diversity variables;

- Network and route connectivity variables;

- Mobility and accessibility variables;

- Street and other urban design variables; and

- Compound pedestrian environmental variables, which combine several attributes together in a score or index to avoid statistical issues when many individual attributes are highly correlated.

In the literature, built form is typically measured at various distances around a certain point of analysis, which can include points of trip origins, destinations, or locations along a route. Evidence suggests that the geographic scales for a particular measure's influence differ depending on the mode of travel and the built environment measure. Still, it is not completely certain which scales of geography are appropriate to use as a basis for assessing pedestrian behavior. The appropriate scale to evaluate walking behavior is 
likely much smaller than the TAZ or other large (greater than a half-mile) buffer scales commonly used to analyze other modes of transportation. However, there is not consistent or sufficient evidence to support the use of specific geography at this time.

3. Several shortcomings exist in the current understanding of pedestrian behavior and the built environment.

In general, aspects of the built environment tend to be measured differently across studies despite a comprehensive call for standardization (Forsyth, 2010), which may account for differences in results. Built environment variables tend to be highly correlated with one another, and researchers have used different statistical methods to address this issue. This is another source of discrepancy in results and a large barrier to detailed understanding of the relationships between particular measures of the built environment and walking.

Data availability for walking has historically been low, and the cross-sectional nature of nearly all studies of pedestrian travel behavior has prevented causal inferences to be drawn between the built form and walking. Many researchers have called for longitudinal studies, but very few have been performed. In addition, most research on walking occurs in specific local areas or regions. It is uncertain whether the results of particular studies are transferable between regions, and little work has been performed to assess transferability. Finally, there is disagreement among researchers on how to explain and analyze walking. Some researchers choose a derived demand framework based on economic utility theory, while others have highlighted flaws in those methods and prefer models that integrate psychological theories.

This review of walking and the built environment serves as a useful standalone summation of the current state of the knowledge on the topic. It also guides the selection of variables to include in analysis. Particularly, the review emphasizes the importance of controlling for demographic, socioeconomic, and vehicle ownership characteristics when evaluating relationships between the built environment and walking. The review also poses research questions that need to be addressed in advancing the understanding of walking and the built environment.

\subsection{KEY FINDINGS FROM THE REVIEW OF PEDESTRIANS IN REGIONAL TRAVEL DEMAND MODELS}

1. The practice of representing walking in regional travel demand models is still evolving. A number of different modeling frameworks and mathematical structures are used. Among the metropolitan planning organizations (MPOs) serving the 48 largest urban areas in the U.S.:

- Eighteen (38\%) exclude pedestrian and bicycle travel from their models;

- Two (4\%) use a separate cross-classification process to generate non-motorized trips;

- Five (10\%) use a model to split off non-motorized trips after trip generation;

- Five (10\%) use a pre-mode choice binary logit model to split off non-motorized trips; 
- Eighteen (38\%) include walk or non-motorized mode in the multinomial or nested logit mode choice model, of which:

- Four (8\%) use one non-motorized alternative for mode choice, and

- Fourteen (29\%) use separate walk and bicycle alternatives for mode choice; and

- None assign pedestrian trips to the network.

Trip-based (four-step) modeling practice is generally transitioning towards using walk as a mode separate from bicycle for mode choice. Most activity-based models include walk or non-motorized alternatives in their mode choice stages.

2. A number of different variables are used in travel demand models to determine the number or percentage of walking trips. Among the most common are:

- Level-of-service variables (used in $95 \%$ of relevant models), including trip distance and travel time;

- Demographic and socioeconomic variables (used in $88 \%$ of models), including household size, income, and vehicle ownership;

- Density variables (used in $85 \%$ of models), including residential density, employment density, and area type;

- Design variables (used in $38 \%$ of models), including block or intersection density, non-motorized path density, network connectivity, and pedestrian indices;

- Diversity variables (used in 19\% of models), including land use mix; and

- Accessibility variables (used in $8 \%$ of relevant models).

In general, mode choice and pre-mode choice models within the four-step framework distinguish walking and non-walking travel with a greater number of variablesincluding policy-relevant measures of the built environment - than earlier four-step model stages. However, this is not true for all MPO mode choice models; some predict walking solely based on travel time and a combination of the three density variables.

3. The biggest barriers to representing non-motorized and/or walk travel in regional travel demand forecasting models are:

- Insufficient travel survey records for walking or non-motorized travel;

- Limited resources for collecting environmental and/or pedestrian data;

- Limited resources for model development and staffing; and

- Limited decision-maker interest.

Representing walking in regional travel models first and foremost requires the collection of a sufficient sample of pedestrian trip data in order to estimate even a simple model. Next, detailed environmental data can help agencies develop more sophisticated and policy-sensitive formulations. Such developments require sufficient levels of funding and/or staffing expertise to develop, maintain, and run these models. Trying to better represent walking in travel demand models can be a futile exercise if policymakers are 
not interested in using the improved tools for transportation planning and decision making.

4. Efforts are underway to modify how travel demand models represent walking. Among the most likely and promising innovations are:

- Developing activity-based and integrated travel models;

- Collecting better data on the pedestrian environment;

- Using smaller spatial analysis units; and

- Implementing non-motorized network assignment/route choice.

The development of tour- and activity-based models often coincides with updated and improved activity/travel surveys which may capture more short walking trips. More detailed measures of the pedestrian-scale environment imbue models with increased sensitivity and policy relevance. Smaller spatial analysis units are more on the scale of shorter walking trips and can better capture variations in the built environment. Bicycle route choice models have been integrated with travel demand models in recent years; it is only a matter of time until the same can be said for walk trip assignment.

This literature review of how regional travel demand forecasting models represent pedestrian travel informs the current project in several ways. Despite recent trends towards including walk as an alternative in mode choice models, other modeling frameworks are possible, especially tools that capitalize on walking's unique attributes: shorter travel that may be more influenced by the local environment. In order to develop explanatory and policy-relevant modeling tools, a greater number of walking trips must be observed, more detailed built environment data should be collected, and much smaller spatial analysis units must be used. These takeaways were key considerations during the development, estimation, and application of the walk trip models described in the following sections. 


\section{WALK TRIP MODEL: DATA \& METHODS}

To execute our approach of developing a walk mode split model that better represents pedestrian travel in the existing four-step framework, we simply changed the spatial unit in the trip generation stage and then added one step — a binary pedestrian mode choice model — before continuing on to the destination choice, mode choice, and trip assignment stages (Figure 2-1). This chapter discusses the data and methods for the binary pedestrian mode choice model step.

\subsection{GEOGRAPHY SELECTION}

As informed by the literature review, the transportation analysis zone (TAZ) is usually not an adequate spatial geography for representing walking in regional travel forecasting models. An important step in this research was selecting a geographical unit for pedestrian trips.

The three options considered were: (1) using 264-feet-by-264-feet raster grid cells or pedestrian analysis zones (PAZs); (2) segmenting existing TAZs into smaller subareas suitable for walking trips; and (3) operating at the parcel level. Option 1 had already been developed by Metro for previous projects. Option 2 would have required the development of a procedure to split TAZs into smaller units. Option 3 would be perhaps the most spatially accurate method, since Options 1 and 2 both aggregate data to a hypothetical centroid point to conduct trip generation. Both household and employment data at the parcel level were incomplete for the entire metropolitan region at the time of the project.

Option 1 was chosen because the grid cells were hypothesized to be small enough to capture fine-grained attributes of households and the physical environment, as well as variation within those attributes, in order to accurately represent walking. Urban areas conducive to walking tend to have smaller TAZs due to higher densities of people and destinations, but there are exceptions in which some smaller cities and towns are swallowed within larger, predominately rural, zones. The greater spatial resolution offered by PAZs is consistent with the trend toward using smaller spatial analysis units - smaller TAZs or even parcels - in the operation of activity-based models. The 264-foot (0.05-mile) grid cell dimension represents an approximate one-minute walking distance at three mph. There are 2,147 TAZs and 1,465,252 PAZs within the four-county Metro model region. Figure 4-1 shows an example of the differences between TAZ and PAZ geographies in a section of Portland's downtown. 


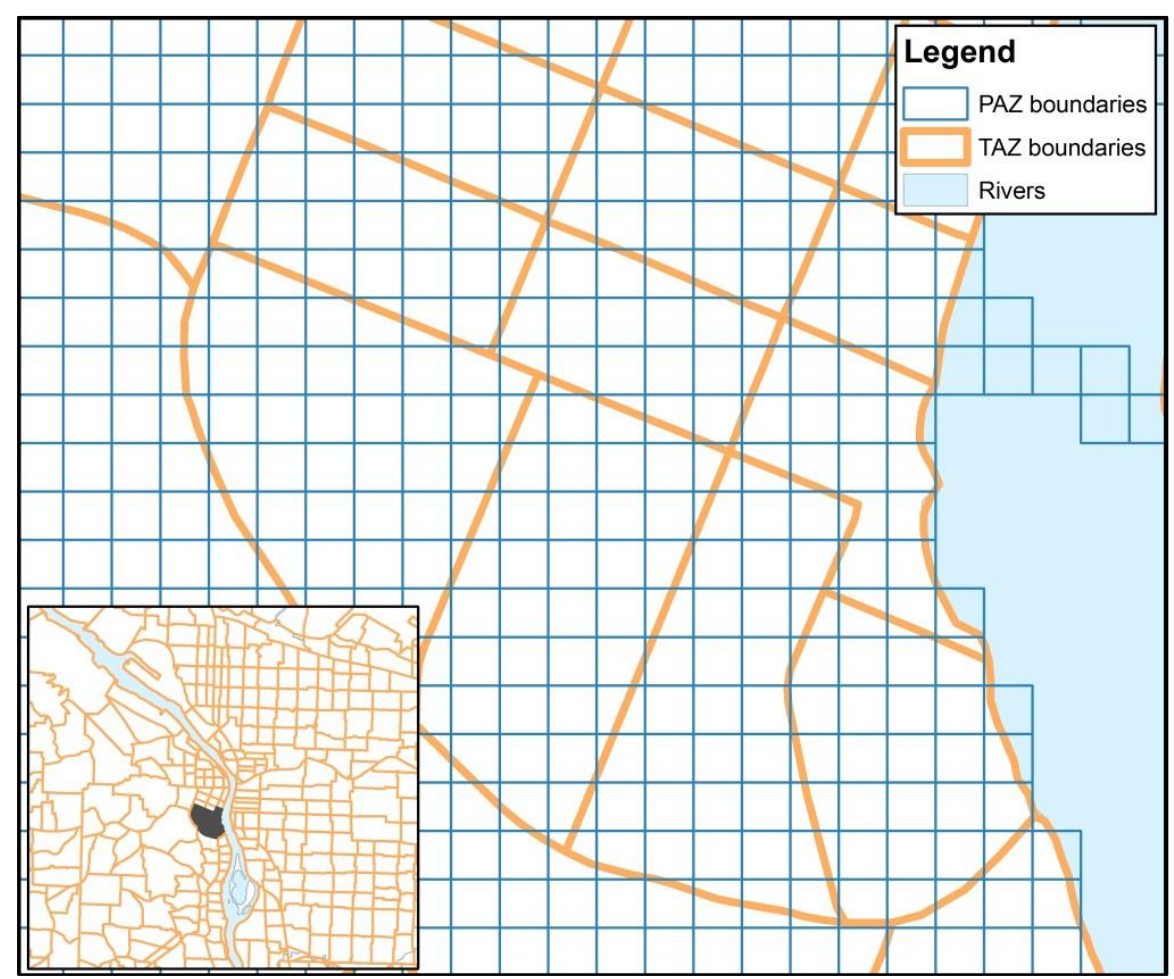

Figure 4-1 TAZ and PAZ Boundary Example

Note: A bridge spans the river where several PAZs extend into the water. These PAZs generate no trips.

\subsection{OREGON HOUSEHOLD ACTIVITY SURVEY DATA}

To estimate the walk mode split model, we used data from the 2011 Oregon Household Activity Survey (OHAS) for the Portland region (Oregon Metro and Oregon Department of Transportation, 2011). The variables of interest used from the dataset are described in Table 4-1. Demographic and socioeconomic variables included age of head of household, household size, number of workers, number of children, household income, and vehicle availability. Because Metro's model deals with multimodal walk trips to access other modes (e.g., transit) using a separate process, only single-mode or full walk trips were analyzed. 
Table 4-1 OHAS Sample Description

\begin{tabular}{lrrr}
\hline \multicolumn{1}{c}{ Variable } & N & Mean & S.D. \\
\hline Database summary & & & \\
Households in sample & 6,108 & & \\
Persons in households & 13,418 & & \\
All trips & 55,878 & & \\
All trips involving walking & 6,654 & & \\
Single-mode walk trips only & 4,511 & & \\
Household demographics and socioeconomics & & & \\
Household size & 6,108 & 2.4 & 1.3 \\
Household income category* & 5,700 & 5.1 & 1.9 \\
Age of head of household & 6,005 & 54.0 & 13.7 \\
Number of workers in household & 6,108 & 1.4 & 0.8 \\
Number of children & 6,108 & 0.5 & 0.9 \\
Number of vehicles & 6,108 & 2.0 & 1.1 \\
\hline
\end{tabular}

* Income categories: $1=\$ 0$ to $\$ 14,999 ; 2=\$ 15,000$ to $\$ 24,999 ; 3=\$ 25,000$ to $\$ 34,999$;

$4=\$ 35,000$ to $\$ 49,999 ; 5=\$ 50,000$ to $\$ 74,999 ; 6=\$ 75,000$ to $\$ 99,999 ; 7=\$ 100,000$ to $\$ 149,999$;

$8=\$ 150,000$ or more.

The full Portland-region OHAS dataset ( $\mathrm{N}=55,878$ trips) was partitioned for the modeling and validation steps described in the following sections. We used $90 \%$ of the OHAS trips $(\mathrm{N}=$ $50,271)$ to estimate the models and retained the other $10 \%$ of the data $(\mathrm{N}=5,607)$ for model validation. The $90 \%$ estimation and $10 \%$ validation samples were stratified within walk/nonwalk trips and within each of the three trip purpose categories: home-based work, home-based other and non-home-based.

\subsection{BUILT ENVIRONMENT MEASURES}

Initially, built environment variables were calculated for PAZs and tested at several different geographic scales. Associations between built environment measures and walking trips were tested at scales of eighth-mile, quarter-mile, half-mile, and one-mile circular buffers. These associations were also tested using variables summarized at the TAZ level.

\subsubsection{Metro Context Tool}

The Context Tool, developed by Metro, is an index of the built environment that encompasses the following seven dimensions: bicycle access, block size, access to parks, people per acre (population and employment density), sidewalk density, transit access, and urban living infrastructure ${ }^{1}$. Each of these seven dimensions is quantified on a scale of one to five for individual raster grid cells, coincident with PAZs, in the Portland region. Therefore, the Context Tool illustrates the character of the urban environment through measured objective conditions of a place at a fine spatial resolution. It is useful in describing geography specific to a site, neighborhood, or city relative to the entire Portland region. We implemented Metro's Context

\footnotetext{
${ }^{1}$ Urban living infrastructure includes shopping and service destinations used in daily life. Some examples are banks, pharmacies, dry cleaners, grocery stores, and restaurants.
} 
Tool because our exploratory analysis showed that most of the built environment attributes at the PAZ level were highly correlated. The Context Tool bypasses multicollinearity issues in regression analysis because the built environment is represented as an index.

Table 4-2 outlines the input data sources for the Context Tool. Generally, a calculation was performed for most ${ }^{2}$ 264-foot-by-264-foot PAZs in the Portland region that measured how much of a certain attribute lay within an area designated by a circle with one quarter-mile radius around the PAZ's center. Once this calculation had been performed for the grid cells, they were reclassified into a one to five score based on the distribution of the specified attribute density in all cells. As such, Context Tool values were normalized to the Metro region: values are relative to the range of observed characteristics found in the region.

Table 4-2 Metro Context Tool Data Sources

\begin{tabular}{|c|c|c|c|c|}
\hline Context Tool layer & $\begin{array}{l}\text { Raster creation } \\
\text { method }\end{array}$ & $\begin{array}{l}\text { Search } \\
\text { radius }\end{array}$ & $\begin{array}{l}\text { Reclassification } \\
\text { (1 to 5; low to high) }\end{array}$ & Data source \\
\hline Bicycle access & Search radius & 1 mile* & Natural breaks & Bike There! map classification \\
\hline Block size & Search radius & $1 / 4$ mile & Natural breaks & $\begin{array}{l}\text { Dissolved Metro tax lots, } \\
\text { multipart to single-part features }\end{array}$ \\
\hline Access to parks & Path distance** & $\mathrm{n} / \mathrm{a}$ & Linear distance $* * *$ & Path distance from access points \\
\hline People per acre & Search radius & $1 / 4$ mile & Natural breaks & Population + employment \\
\hline Sidewalk density & Search radius & $1 / 4$ mile & Natural breaks & Metro Sidewalk Inventory \\
\hline Transit access & Search radius & $1 / 4$ mile & Natural breaks & TriMet transit stops \\
\hline $\begin{array}{l}\text { Urban Living } \\
\text { Infrastructure }\end{array}$ & Search radius & $1 / 4$ mile & Natural breaks & ESRI Business Analyst \\
\hline
\end{tabular}

* Because of the increased range of bicycles over pedestrian travel, a larger search radius was used to represent accessibility by bike.

** This layer was created based on raster path distance. Raster paths were derived from the Metro streets (minus freeways) and pedestrian paths/trails layers.

*** This layer was classified using quarter-mile increments: $5=0$ to $1 / 4$ mile; $4=1 / 4$ to $1 / 2$ mile; $3=1 / 2$ to $3 / 4$ mile; $2=3 / 4$ to 1 mile; 1 = greater than 1 mile.

Bicycle access: A one-mile radius around every grid cell was used to calculate the density of bicycle network links in that area. In this case, a one-mile radius represented the increased accessibility range of bicycles over pedestrian travel. The individual bicycle network links were weighted based on their classification in the Metro Bike There! map (see http://www.oregonmetro.gov/index.cfm/go/by.web/id=218). The classifications in the map are:

- Most suitable: off-street multiuse paths or trails, main bikeways, low-traffic streets;

- Moderately suitable: bike lanes, moderate-traffic streets; and

\footnotetext{
${ }^{2}$ At the time of analysis, Context Tool data were not available for entire Portland region. However, about $72.5 \%$ of trips in OHAS were within the boundaries of the Context Tool. The Context Tool did not cover rural parts of Washington and Clackamas counties in Oregon, as well as the entirety of Clark County, WA.
} 
- Less suitable: high-traffic streets with no bicycle facilities, caution areas.

Block size: Block size density is reported as a score that represents the distribution of block sizes around every PAZ within a quarter-mile radius. Block size data were based on Metro tax lots. The resulting scores were higher if blocks were small and lower if blocks were large.

Access to parks: Access to parks was measured along a raster path distance to park access points. The raster path was derived from the Metro street network and pedestrian paths/trails data. Freeways were excluded from the distance calculation. Park access points were defined by Metro and Alta Planning and Design. The index score was based on quarter-mile increments: a score of five was given to PAZs with 0.25 miles of a park access point; four for 0.25-0.5 miles; three for 0.5-0.75 miles; two for 0.75-one mile; and one for PAZs greater than one mile from a park access point.

People per acre: Population and employment density were calculated within a quarter-mile radius of every PAZ in the region. Population data originated from Metro household data created from census data. Employment data were gathered from InfoUSA and ESRI Business Analyst.

Sidewalk density: This measure was computed using the Metro Sidewalk Inventory within a quarter-mile radius of each PAZ. The Metro Sidewalk Inventory consisted of road segments in the region weighted by the percent of each individual road segment that had a sidewalk. Higher weights were given to road segments with continuous sidewalks on both sides of the street.

Transit access: The same quarter-mile radius procedure was used to measure the density of TriMet bus, light rail, and commuter rail stops. Transit stop points were weighted in the calculation based on the service frequency of the stop during the peak hour. For each cell, the tool found stops within a quarter-mile radius, summed the points (weighted by service headway), and then divided that by the area. For example, if there were three stops within that radius, each with 20-minute peak hour headways (three trips per hour), that would equate to approximately nine peak hour trips in that cell buffer per day (45 per week), or a total of 135 trips per week. That number (135 trips per week) would be divided by the area units for the quarter-mile buffer of that cell ( $\mathrm{pi}$ x radius squared $=3.14 \times(1,320$ feet $\mathrm{x} 1,320 \mathrm{feet}) /\left(43,560 \mathrm{feet}^{2} / \mathrm{acre}\right)=125.6$ acres), yielding (135/125.6=1.07) 1.07 weekly trips per acre.

Urban Living Infrastructure: Certain destination types were measured within a quarter-mile radius of each grid cell. Business location data from ESRI Business Analyst were queried for specific NAICS codes to determine the accessibility of PAZs to day-to-day living needs like grocery stores, cafes, restaurants, clothing and other retail stores, schools, dry cleaners, and entertainment venues.

\subsubsection{Pedestrian Index of the Environment}

The Metro Context Tool gives equal weight to each of its seven components. This works well as a general index to quantify the built environment across the Portland region. However, it is possible that certain Context Tool components have a stronger relationship with pedestrian trip mode choice than others. If this is true, than weighting each component equally overestimates the influence of factors that have weak relationships with walking and underestimates the influence 
of factors that have stronger relationships with walking. Therefore, we explored alternative weighting schemes for the Context Tool components. The weighting scheme that best expressed the relationship between the components and pedestrian mode choice is called the Pedestrian Index of the Environment (PIE). The following paragraphs describe how the PIE was developed.

A series of binomial logit regression models were estimated to derive weights for each Context Tool component. Each of these binomial logit regression models expressed the relationship between a single Context Tool component and the choice to walk or use another mode for trips reported in the OHAS database. The utility of respondents choosing to walk for each trip was expressed by:

$\varepsilon_{n}$

$$
U_{n}=\alpha+\beta x_{n}+
$$

where:

- $\alpha$ is a constant;

- $\quad \beta$ is a coefficient that quantifies the relationship between the Context Tool component value and the observed utility of choosing walking rather than some other mode;

- $x_{n}$ is a variable representing the Context Tool component value for each trip, the value of which is taken from the PAZ that contained each trip's production end; and

- $\varepsilon_{n}$ is an unobserved error term, assumed to be independently and identically distributed type 1 extreme value across respondent trips.

Respondents were assumed to choose walking when $U_{n}>0$ and to choose other modes when $U_{n}$ $\leq 0$.

The PIE was developed using the 90\% sample of OHAS trips in the Portland region. However, Context Tool index values were not available for some of the trips on the periphery of the region, ${ }^{3}$ so a total of 36,463 OHAS trips were used to develop the PIE. Of these trips, 3,560 $(9.8 \%)$ were made by walking and $32,903(90.2 \%)$ used another mode. However, the singlevariable binary logit models showed that the choice of walking was more likely when trips originated from locations with higher values for particular Context Tool components (Table 4-3). For example, people per acre had the strongest relationship with pedestrian trips (coefficient $=$ 0.812).

\footnotetext{
${ }^{3}$ Context Tool data, at the time of estimation, were not available for the entire Portland region. This is discussed further in Section 5.1.1.
} 
Table 4-3 Seven Binary Logit Models of Context Tool Components

\begin{tabular}{|c|c|c|c|}
\hline Context variable $\left(x_{n}\right)$ & Coefficient $(\beta)$ & p-value & $\begin{array}{c}\text { Model } \\
\text { pseudo-R }\end{array}$ \\
\hline Model 1 & & & 0.057 \\
\hline Bicycle access & 0.494 & 0.00 & \\
\hline Constant & -4.047 & 0.00 & \\
\hline Model 2 & & & 0.096 \\
\hline Block size & 0.543 & 0.00 & \\
\hline Constant & -3.729 & 0.00 & \\
\hline Model 3 & & & 0.016 \\
\hline Access to parks & 0.311 & 0.00 & \\
\hline Constant & -3.573 & 0.00 & \\
\hline Model 4 & & & 0.095 \\
\hline People per acre & 0.812 & 0.00 & \\
\hline Constant & -4.304 & 0.00 & \\
\hline Model 5 & & & 0.083 \\
\hline Sidewalk density & 0.500 & 0.00 & \\
\hline Constant & -3.900 & 0.00 & \\
\hline Model 6 & & & 0.083 \\
\hline Transit access & 0.621 & 0.00 & \\
\hline Constant & -3.386 & 0.00 & \\
\hline Model 7 & & & 0.073 \\
\hline ULI density & 0.549 & 0.00 & \\
\hline Constant & -3.204 & 0.00 & \\
\hline \multicolumn{4}{|c|}{ Data used for all models } \\
\hline Trips (n) & 36,463 & & \\
\hline Walk & 3,560 & & \\
\hline Not Walk & 32,903 & & \\
\hline
\end{tabular}

Access to parks had the weakest relationship with pedestrian trip mode choice (coefficient $=$ 0.311). Further, parks were considered to create potentially misleading results, since locations close to large, undeveloped parks such as Forest Park were given higher scores, leading to predicting more walking trips than warranted, given actual pedestrian activity levels. Due to these limitations, the access to parks component of the Context Tool was dropped from consideration.

The coefficients of the remaining six components of the Context Tool were used to calculate the weights in the PIE. The ratios among the six coefficients were maintained as they were scaled to their weighted index values. To make the PIE as intuitive as possible, the weights were set to generate a maximum possible weighted PIE value of 100 (and minimum weighted value of 20). The final weights used in the PIE are shown in Table 4-4. 
Table 4-4 Weights Assigned to Components of the PIE

\begin{tabular}{lccc}
\hline Component & $\begin{array}{c}\text { Possible } \\
\text { values }\end{array}$ & Weight & $\begin{array}{c}\text { Maximum } \\
\text { weighted } \\
\text { value }\end{array}$ \\
\hline Bicycle access & 1 to 5 & 2.808 & 14.04 \\
Block size & 1 to 5 & 3.086 & 15.43 \\
People per acre & 1 to 5 & 4.615 & 23.07 \\
Sidewalk density & 1 to 5 & 2.842 & 14.21 \\
Transit access & 1 to 5 & 3.529 & 17.65 \\
ULI density & 1 to 5 & 3.120 & 15.60 \\
\hline Total & & & 100.00 \\
\hline
\end{tabular}

Note that several other options were explored as weights were developed. Sets of single-variable binary logit models were estimated using trips made for specific purposes (one set for homebased work, one for home-based other, and one for non-home based). However, the coefficients in these three sets of models generally had similar ratios between models, so disaggregating the data by purpose did not add significant value to the weighting process.

PIE values were calculated for all grid cells in the Portland region. The highest PIE values were in Downtown Portland, followed by other major neighborhood centers (e.g., Northwest District, Hollywood, St. Johns) and suburban centers (e.g., Beaverton, Gresham, Hillsboro). The lowest PIE values were in isolated areas with distribution facilities and light industry, rural areas, and undeveloped areas. Figure 4-2 shows a regional map of PIE values and Figure 4-3 illustrates examples throughout the region of different PIE values to show the differences in urban form encompassed in the index.

The PIE was used as an explanatory variable in the pedestrian model. It was correlated with walking $(\rho=0.264)$ and was highly correlated with other measures of the built environment that were not included in the model, such as household density $(\rho=0.761)$, employment density $(\rho=0.631)$, and sidewalk density $(\rho=0.833)$. The PIE is a calibrated measure of pedestrianrelevant built environment characteristics that represents activity density, accessibility to activities, and facilities for walking. 


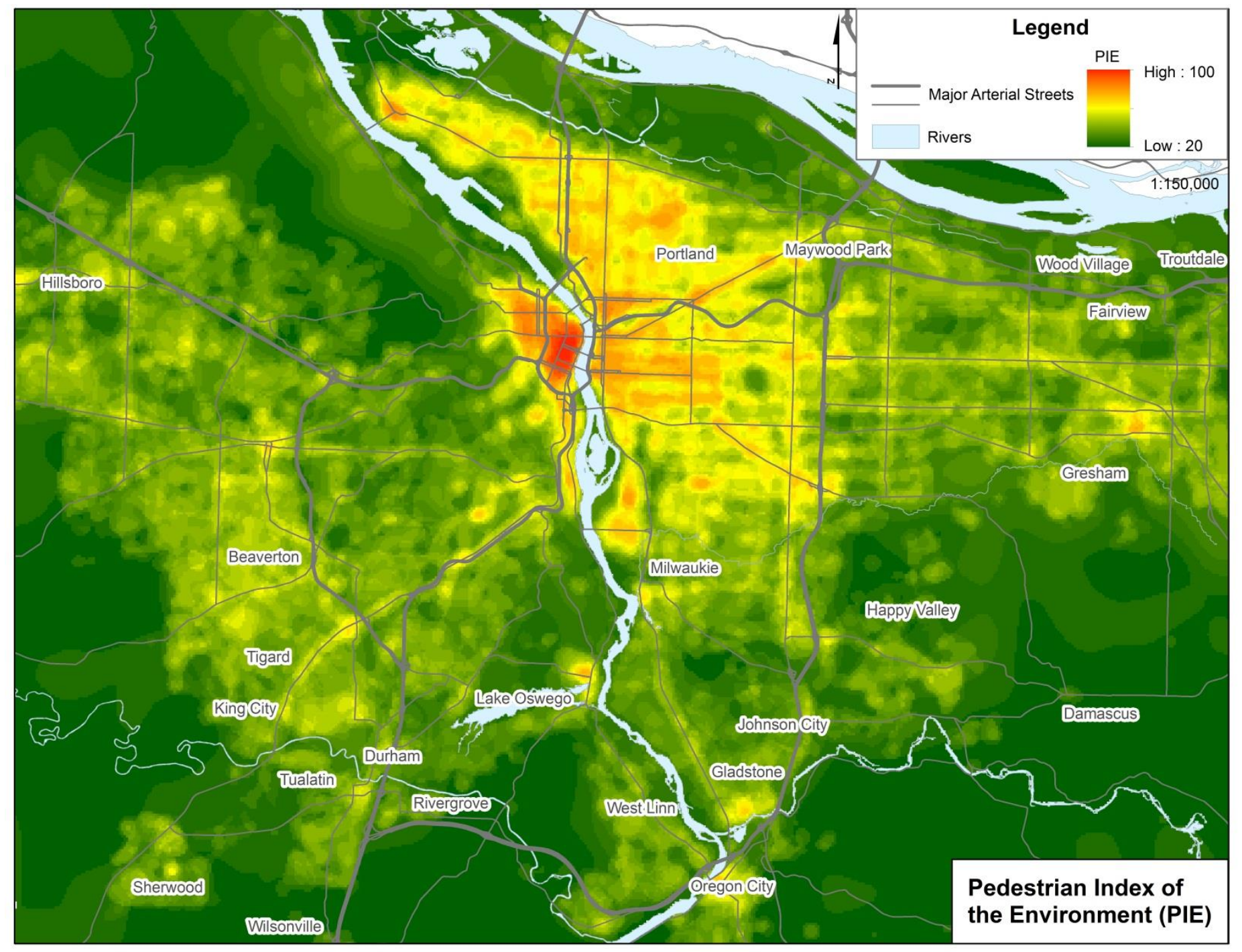

Figure 4-2 Regional Map of PIE Values 


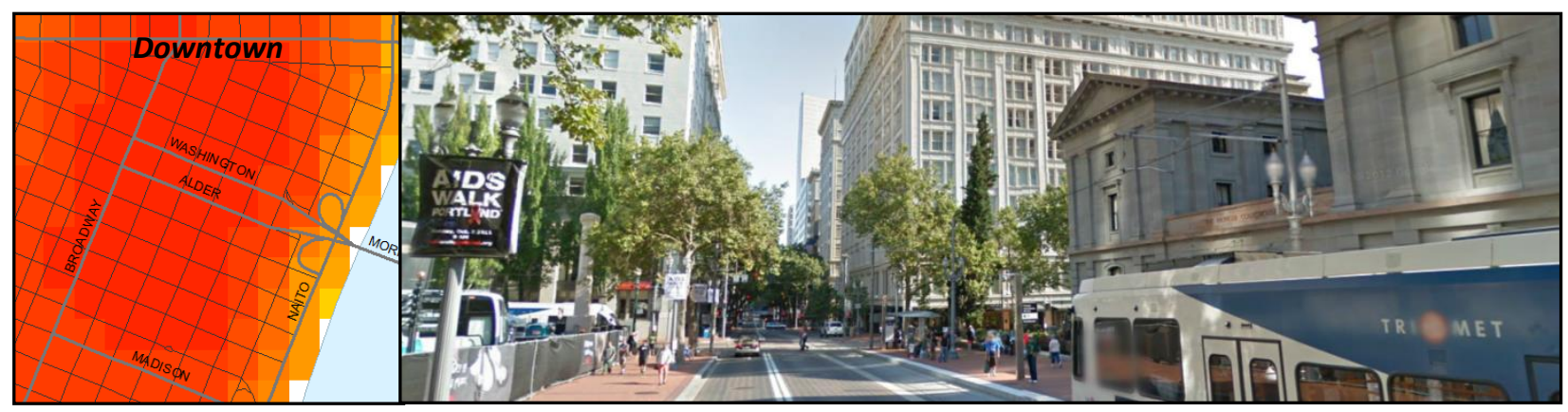

80 - Lloyd District, Northwest District, and other major Portland neighborhood centers (Hollywood, St. Johns)

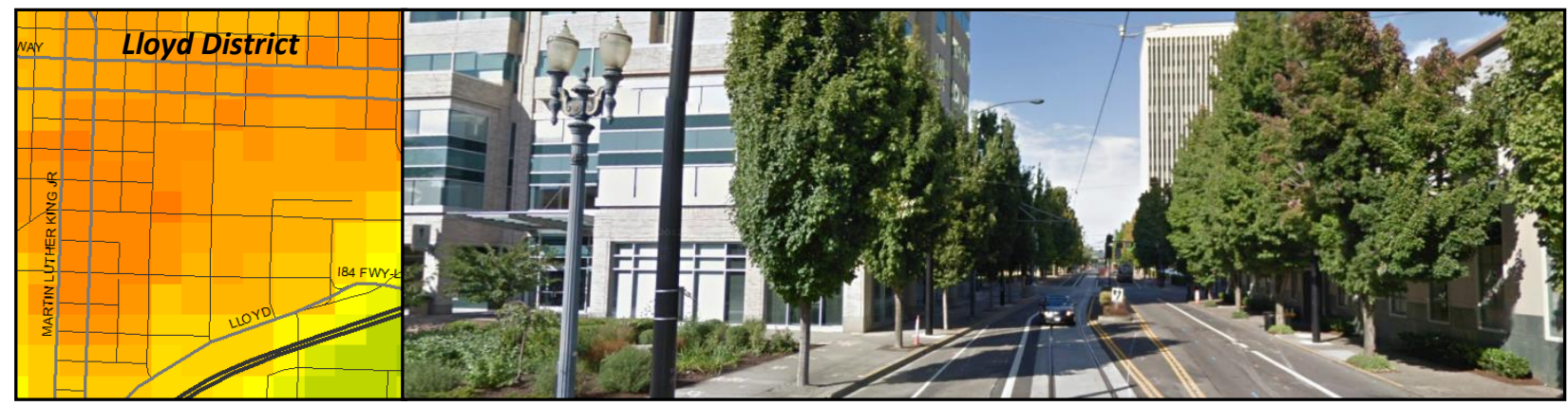

70 - Suburban downtowns (e.g., Beaverton, Gresham, Hillsboro, Lake Oswego, Oregon City)

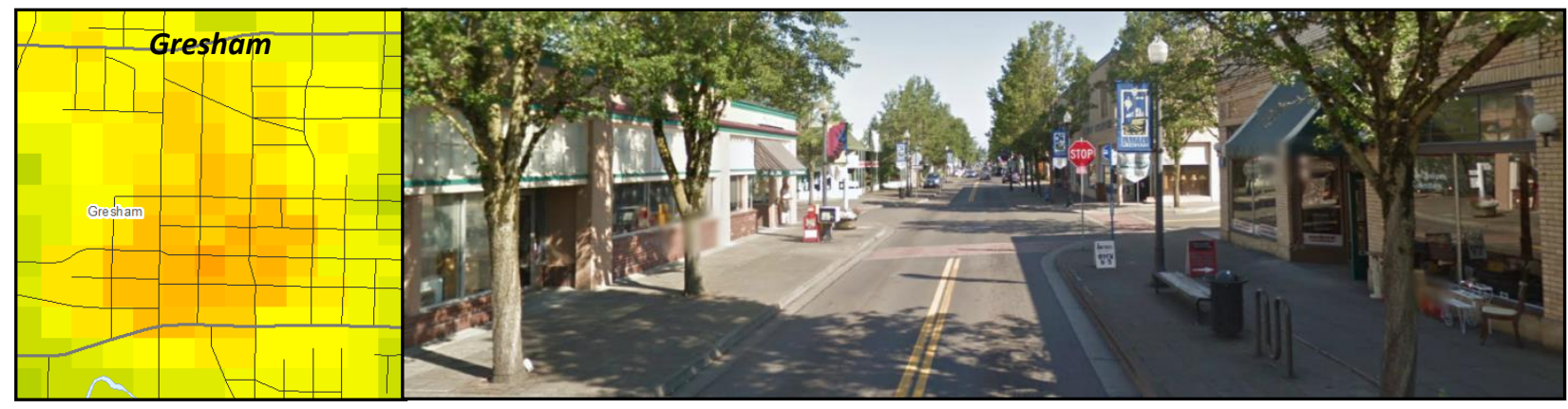

60 - Predominantly residential inner-city neighborhoods

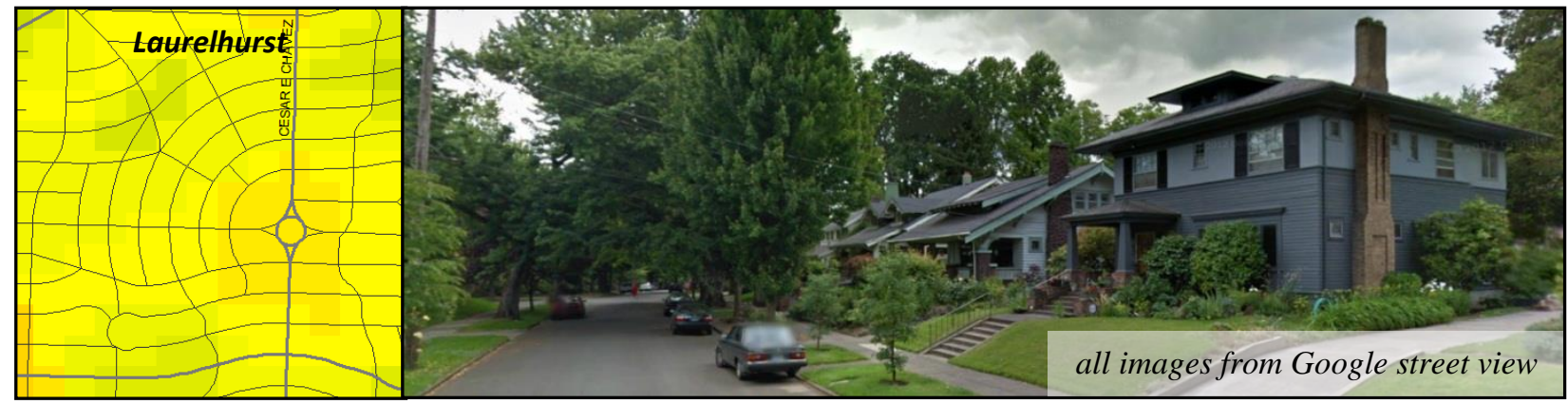

Figure 4-3 Examples of PIE Values in the Portland Region 


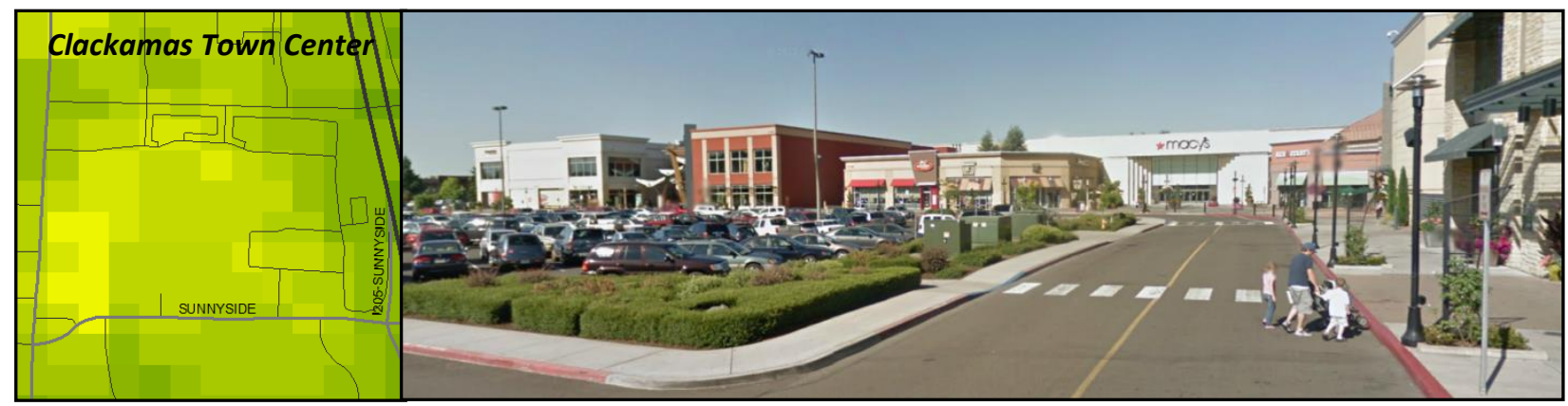

40 - Suburban neighborhoods and subdivisions

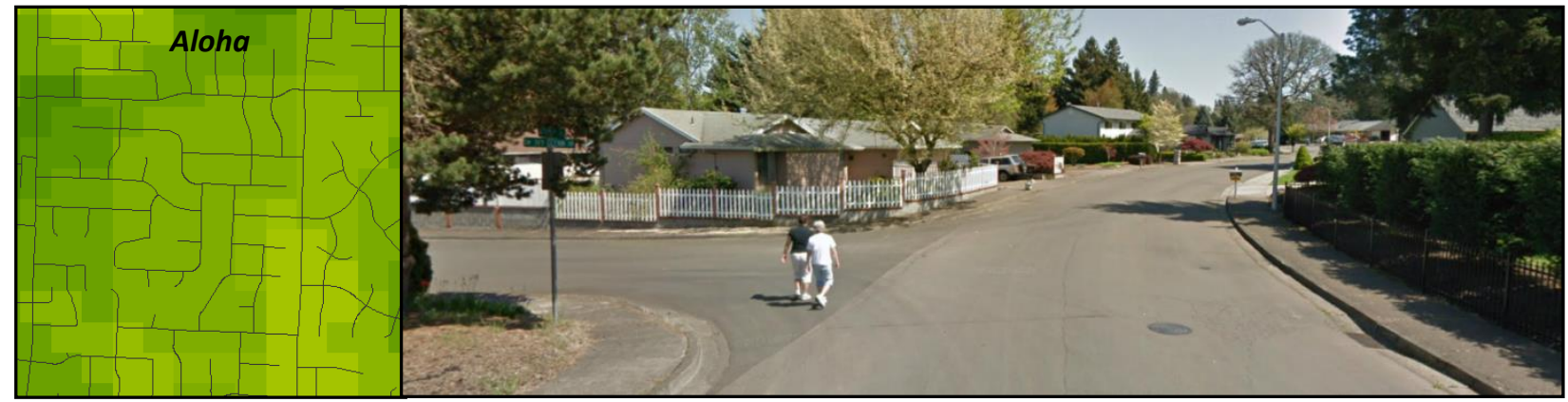

30 - Isolated areas with distribution facilities and light industry (e.g., Marine Drive, Northwest Industrial)

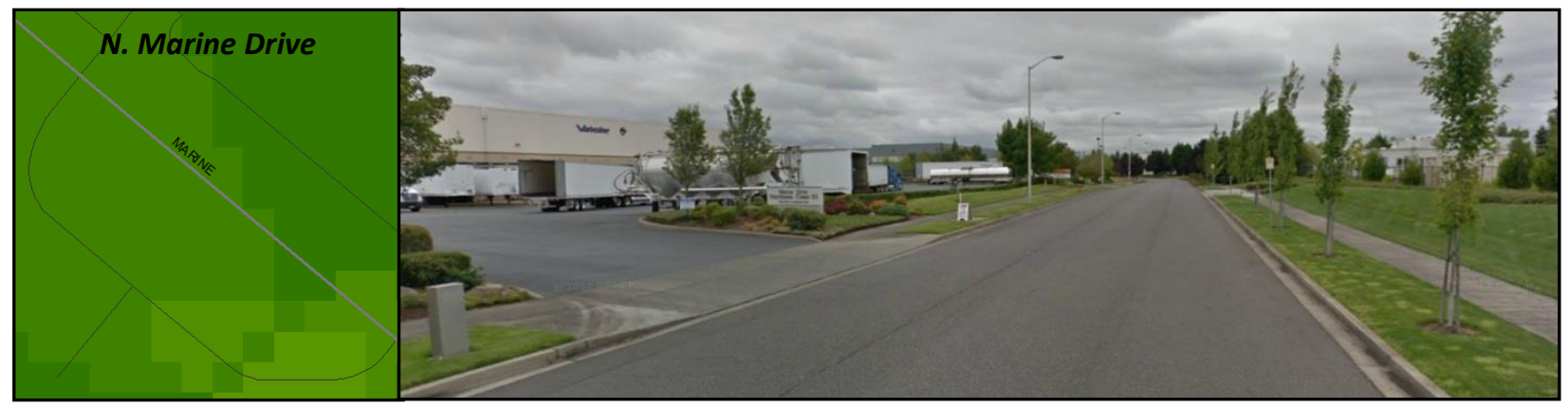

20 - Rural, undeveloped, and forested areas

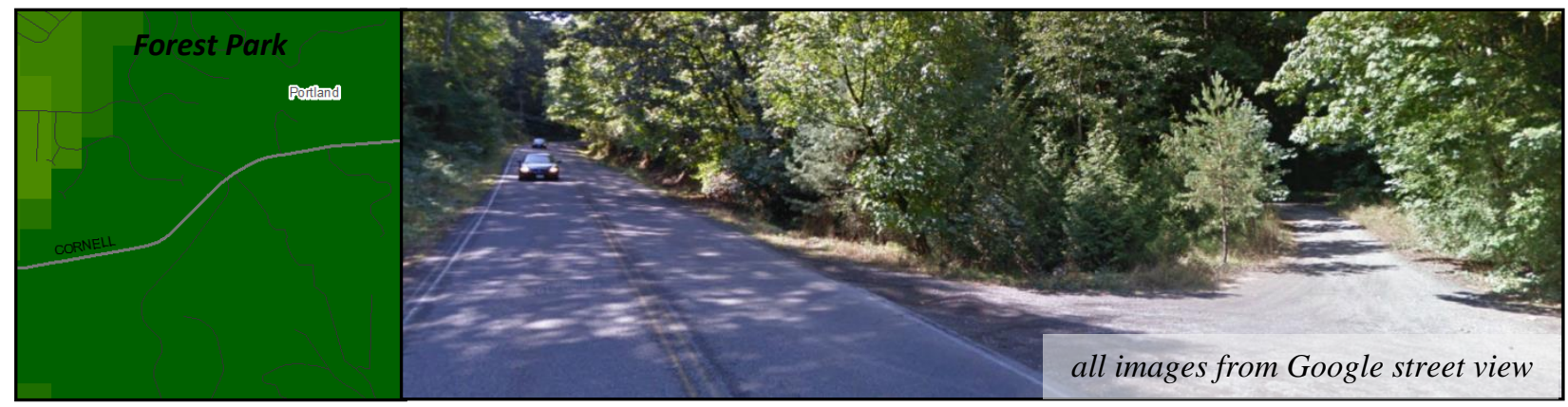

Figure 4-3 (continued) Examples of PIE Values in the Portland Region 


\section{WALK TRIP MODEL: ESTIMATION RESULTS AND VALIDATION}

This chapter describes the estimation and validation of the binomial logistic regression walk (pedestrian) trip end models. The models can be applied to distinguish walking from nonwalking trip productions. First we present the specification and estimation of the models followed by the validation of the models.

\subsection{BINARY LOGIT MODELS}

\subsubsection{Specification}

Models were specified for production trip ends. We used production trip ends only because Metro's model generally does not use the trip generation model to calculate trip attractions. Instead, trips are attached to an attraction zone using a logit-based destination choice model with size variables.

We estimated three separate models, one for each of three trip purpose categories: home-based work (HBW), home-based other (HBO), and non-home-based (NHB). This trip purpose distinction is similar to how Metro's model breaks up trip purposes for some model processes (destination choice and mode choice). We included dummy variables to account for more detailed trip purposes within the HBO and NHB models (e.g., "NHB non-work trip" is a dummy variable in the NHB model). Figure 5-1 illustrates how the three models account for all trip purposes; the dummy variables used in estimation are the trip purposes "within" HBO and NHB categorizations.

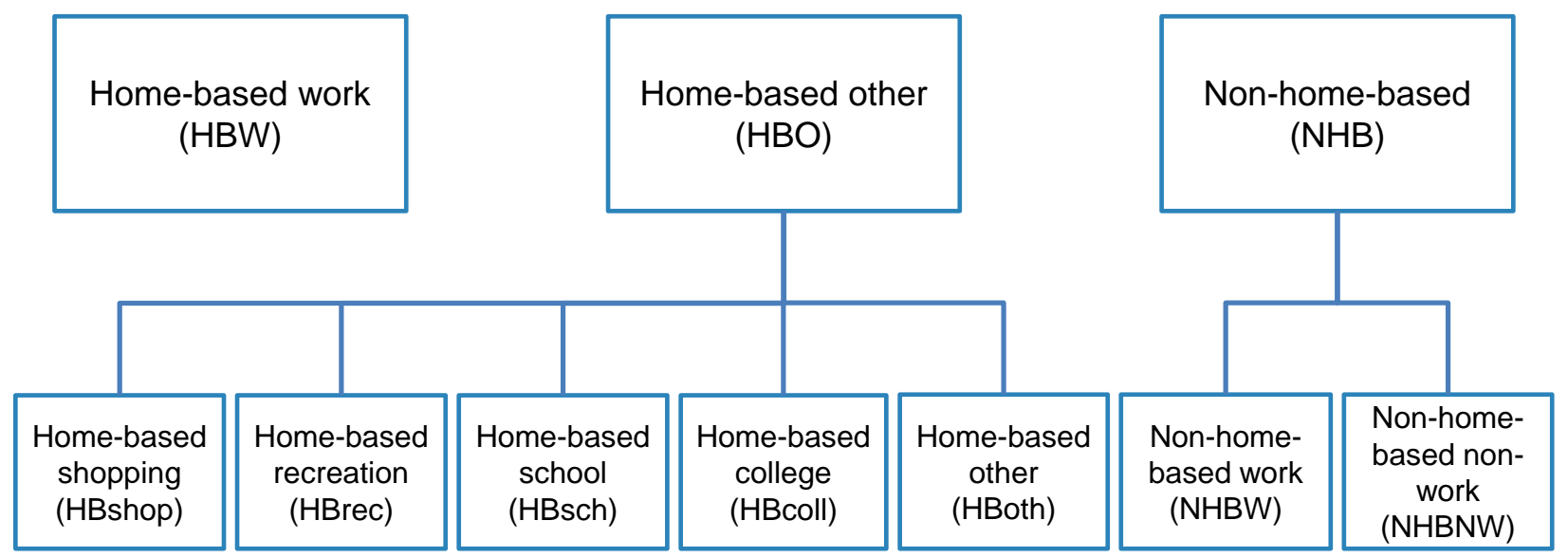

Figure 5-1 Trip Purposes Used in Model Estimation

We used $90 \%$ of all Portland-region OHAS production trip ends $(\mathrm{N}=50,271)$ to estimate the models and retained the other $10 \%$ of the data $(\mathrm{N}=5,607)$ to be used in model validation. The 
$90 \%$ and $10 \%$ samples were stratified within the HBW, HBO, and NHB purposes and within walk/non-walk trip ends. ${ }^{4}$

Traveler characteristics (demographic and socioeconomic) variables were limited to those in Metro's four-step model (Oregon Metro, 2008). Four categories for each of the following variables were used in the estimated models: age of household head, household size, number of workers, number of children, household income, and number of vehicles. Metro's travel model inputs are outputs from its economic and demographic model: households stratified by household size, income class, age of head of household (HIA). Pre-generation models then estimate the distribution of households with different numbers of workers, children, and automobiles. For our model estimation, these variables were constructed from OHAS data to match as closely as possible the categories used in Metro's travel model.

The built environment was represented in the binomial logit models by the PIE (see section 4.3.2) as well as the following transportation system variables: the length of freeway miles within an eighth-mile radius of PAZ centroids and the length of trails within a half-mile radius of PAZ centroids. For the HBW and HBO trip models, built environment data were calculated around the household location. In the NHB trip model, built environment data were calculated using the trip origin. Note that Context Tool data underlying the PIE were not available for the entire four-county region at the time of estimation, so we included a dummy variable for trip ends outside of the Context Tool boundary in the models. Figure 5-2 shows the boundaries of PIE coverage. The entire urban growth boundary of the Portland metropolitan area is within the PIE extents.

\footnotetext{
${ }^{4}$ In both the $90 \%$ and $10 \%$ samples, the proportion of HBW, HBO, and NHB trips as well as the proportion of walking trips in each trip purpose category remained approximately the same as in the full OHAS dataset.
} 


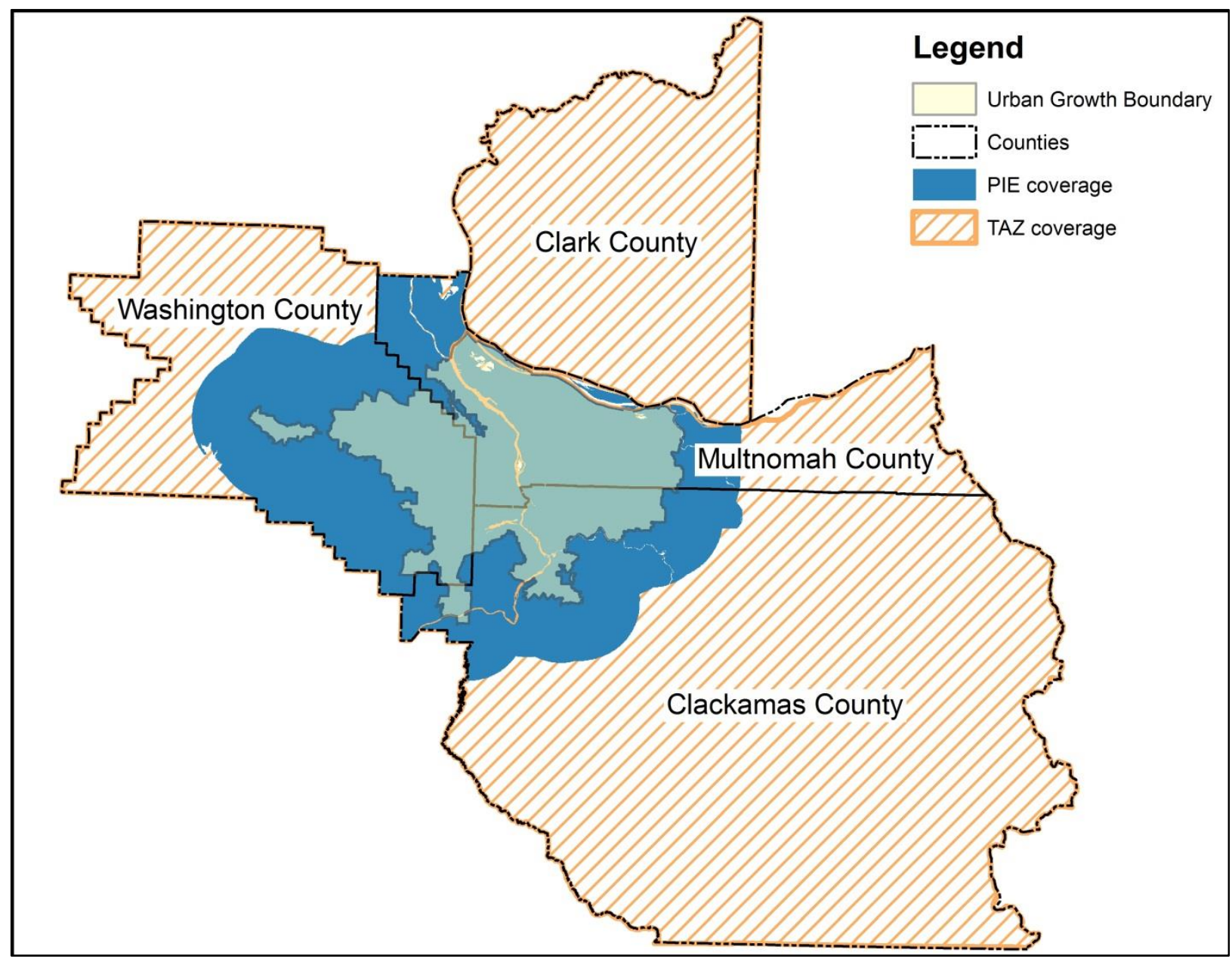

Figure 5-2 PIE Coverage

Several other transportation system variables - length of highways, arterials, minor streets, sidewalks, bicycle facilities, percentage of minor streets, sidewalks - were calculated at many buffer radius distances and tested during model exploration. These were not used in our final models because they were highly correlated with either the PIE or the two chosen transportation system measures. Note that transportation system variables were not available for Clark County, WA, so we included a dummy variable for production trip ends in Washington.

Table 5-1 lists the variables used in the binomial logit models and their abbreviations. 
Table 5-1 Variables Used in Model Estimation

\begin{tabular}{|c|c|c|c|}
\hline Variable & Definition & Mean & S. D. \\
\hline \multicolumn{4}{|c|}{ Traveler characteristics } \\
\hline Hhsize2 & Household size was 2 people (binary) & 0.31 & 0.46 \\
\hline Hhsize 3 & Household size was 3 people (binary) & 0.18 & 0.39 \\
\hline Hhsize4 & Household size was 4 or more people (binary) & 0.40 & 0.49 \\
\hline Income2 & Household income was $\$ 25,000$ to $\$ 34,999$ (binary) & 0.05 & 0.21 \\
\hline Income3 & Household income was $\$ 35,000$ to $\$ 74,999$ (binary) & 0.30 & 0.46 \\
\hline Income4 & Household income was $\$ 75,000$ or more (binary) & 0.52 & 0.50 \\
\hline IncomeX & Household income was not reported (binary) & 0.06 & 0.25 \\
\hline Agecat1 & Age of the head of the household was 0 to 25 (binary) & 0.01 & 0.10 \\
\hline Agecat3 & Age of the head of the household was 56 to 65 (binary) & 0.22 & 0.42 \\
\hline Agecat4 & Age of the head of the household was 66 or greater (binary) & 0.13 & 0.34 \\
\hline AgecatX & Age of the head of the household was not reported (binary) & 0.02 & 0.12 \\
\hline Workers1 & Number of workers in the household was 1 (binary) & 0.31 & 0.46 \\
\hline Workers 2 & Number of workers in the household was 2 (binary) & 0.51 & 0.50 \\
\hline Workers3 & Number of workers in the household was 3 or more (binary) & 0.10 & 0.30 \\
\hline Child1 & Number of children in the household was 1 (binary) & 0.15 & 0.36 \\
\hline Child2 & Number of children in the household was 2 (binary) & 0.20 & 0.40 \\
\hline Child3 & Number of children in the household was 3 or more (binary) & 0.10 & 0.30 \\
\hline Autos0 & Household members owned/leased 0 vehicles (binary) & 0.03 & 0.16 \\
\hline Autos2 & Household members owned/leased 2 vehicles (binary) & 0.46 & 0.50 \\
\hline Autos3 & Household members owned/leased 3 or more vehicles (binary) & 0.31 & 0.46 \\
\hline \multicolumn{4}{|c|}{ Transportation system variables } \\
\hline StFwy & Length (miles) of freeways within an eighth-mile of the trip end & 0.02 & 0.09 \\
\hline Trail & Length (miles) of trails within a quarter-mile of the trip end & 0.96 & 1.26 \\
\hline WA & Trip was located in Washington (binary) & 0.25 & 0.44 \\
\hline \multicolumn{4}{|c|}{ Built environment characteristics } \\
\hline PIE & Weighted sum of Context Tool data & 33.98 & 25.30 \\
\hline PIE Flag & Trip was located outside of PIE extents (binary) & 0.27 & 0.45 \\
\hline \multicolumn{4}{|c|}{ Trip purpose dummies } \\
\hline HBshop & Home-based shopping trip purpose (binary) & 0.09 & 0.29 \\
\hline HBrec & Home-based recreation trip purpose (binary) & 0.11 & 0.31 \\
\hline HBschool & Home-based school trip purpose (binary) & 0.09 & 0.29 \\
\hline NHBNW & Non-home-based non-work trip purpose (binary) & 0.18 & 0.39 \\
\hline
\end{tabular}

\subsubsection{Estimation and Results}

Models were estimated using SPSS version 19. The modeling procedure consisted of the following steps:

1. Adding all traveler characteristics variables (HIA, worker, child, auto);

2. Removing variables that were not significant;

3. Adding built environment variables; and

4. Removing other non-significant variables.

The final models are shown in Table 5-2. Traveler demographic and socioeconomic characteristics had significant effects in each model. Across all three models, the number of 
vehicles was a consistently significant predictor of walking. Zero-car households had a strong positive association with walking over one-car households, the base case. More vehicles in the household had an increasingly negative influence on walking, as indicated by the increasingly negative coefficient estimates of the variables for two- and three-or-more-vehicle households.

Age categories were also consistently significant in each model. In the HBW model, trips of households where the HIA was less than or equal to 25 years old saw higher odds of being walking trips than the 26 to 55 age base case. The HIA age category 56 to 65 was also associated with higher odds of walking. In the HBO model, the HIA age category 56 to 65 indicated lower odds of walking than other age categories. In the NHB model, older age categories (56 to 65 and over 65) were associated with lower odds of walking. The dummy variable to account for nonreporting of age was not significant in any model.

Interesting effects were observed for household size and number of children variables. In the HBW and HBO models, living in a household with more children increased one's odds of choosing to walk for a particular trip. HBW trips were more likely to be walk trips for two- and three-or-more-children households. The increasingly positive coefficients on the one-, two-, and three-or-more child household variables in the HBO model indicated that $\mathrm{HBO}$ trips were more likely to be performed on foot with more children in the household. These results suggest that parents living with children may have made more walk trips or that the children or others in these households were walking for these trip purposes.

Few income dummy variables had significant effects, possibly because income was moderately correlated with the number of autos and the number of workers. Members of households with incomes $\$ 25,000$ to $\$ 35,000$ had decreased odds of walking between home and work. However, the highest income category $(\geq \$ 75,000)$ had a positive significant association with the odds of walking in the NHB model. This result may be due to members of higher income households making NHB work trips in the city center or other dense, walkable places-for example, walking to lunch while on a break from work in the central business district. The dummy variable for non-reporting of income was not significant in any model.

The only transportation system variable that was significantly associated with walking trips was length of freeways within an eighth-mile of the home in the HBO model, which had a negative relationship. Many trip purpose dummy variables were significant in the models, suggesting that walking was more likely for certain trip purposes. In the HBO model, home-based shopping trips were less likely to have been made by walking than HBO trips (the base case), while home-based recreation and home-based school trips were more likely to have been made by walking. In the NHB model, non-home-based non-work trips were associated with a decreased likelihood of walking when compared to the base case, NHB work trips.

The PIE was a significant and positive factor in all models, indicating that our composite built environment measure was a good indicator of walking activity when controlling for all other variables. Interestingly, there were somewhat similar effects across all purposes: a one-point increase on the 20-100 scale was associated with $3.6 \%, 4.4 \%$, and $5.3 \%$ increases in the likelihood that a production trip end was a walking trip for HBW, HBO, and NHB purposes, respectively. Tests of alternative mathematical forms of the PIE (e.g., squared) did not significantly improve the model goodness-of-fit. 
Table 5-2 Model Results

\begin{tabular}{|c|c|c|c|c|c|c|c|c|c|}
\hline & \multicolumn{3}{|c|}{ HBW Model } & \multicolumn{3}{|c|}{ HBO Model } & \multicolumn{3}{|c|}{ NHB Model } \\
\hline Variable & B & $\mathrm{p}$ & OR & B & $\mathrm{p}$ & OR & B & $\mathrm{p}$ & OR \\
\hline \multicolumn{10}{|c|}{ Traveler characteristics } \\
\hline Hhsize2 & -- & -- & -- & 0.191 & 0.004 & 1.210 & -- & -- & -- \\
\hline Hhsize3 & 0.719 & 0.000 & 2.052 & -- & -- & -- & -- & -- & -- \\
\hline Hhsize4 & -- & -- & -- & -- & -- & -- & -- & -- & -- \\
\hline Income2 & -0.794 & 0.010 & 0.452 & -- & -- & -- & -- & -- & -- \\
\hline Income3 & -- & -- & -- & -- & -- & -- & -- & -- & -- \\
\hline Income4 & -- & -- & -- & -- & -- & -- & 0.270 & 0.000 & 1.311 \\
\hline IncomeX & -- & -- & -- & -- & -- & -- & -- & -- & -- \\
\hline Agecat1 & 0.957 & 0.011 & 2.605 & -- & -- & -- & -- & -- & -- \\
\hline Agecat3 & 0.343 & 0.024 & 1.409 & -0.242 & 0.000 & 0.785 & -0.238 & 0.002 & 0.788 \\
\hline Agecat4 & -- & -- & -- & -- & -- & -- & -0.330 & 0.002 & 0.719 \\
\hline AgecatX & -- & -- & -- & -- & -- & -- & -- & -- & -- \\
\hline Workers1 & -- & -- & -- & 0.208 & 0.003 & 1.231 & -- & -- & -- \\
\hline Workers2 & -- & -- & -- & 0.301 & 0.000 & 1.352 & -- & -- & -- \\
\hline Workers3 & -- & -- & -- & -- & -- & -- & -- & -- & -- \\
\hline Child1 & -- & -- & -- & 0.295 & 0.000 & 1.343 & -- & -- & -- \\
\hline Child2 & 0.752 & 0.000 & 2.122 & 0.455 & 0.000 & 1.576 & -- & -- & -- \\
\hline Child3 & 1.121 & 0.000 & 3.068 & 0.479 & 0.000 & 1.615 & -- & -- & -- \\
\hline Autos0 & 1.597 & 0.000 & 4.938 & 1.089 & 0.000 & 2.970 & 1.266 & 0.000 & 3.546 \\
\hline Autos2 & -0.834 & 0.000 & 0.434 & -0.463 & 0.000 & 0.629 & -0.597 & 0.000 & 0.551 \\
\hline Autos3 & -1.178 & 0.000 & 0.308 & -0.690 & 0.000 & 0.502 & -0.757 & 0.000 & 0.469 \\
\hline \multicolumn{10}{|c|}{ Transportation system variables } \\
\hline StFwy & -- & -- & -- & -1.093 & 0.003 & 0.335 & -- & -- & -- \\
\hline Trail & -- & -- & -- & -- & -- & -- & -- & -- & -- \\
\hline WA & -- & -- & -- & 0.792 & 0.006 & 2.208 & -- & -- & -- \\
\hline \multicolumn{10}{|c|}{ Built environment characteristics } \\
\hline PIE & 0.036 & 0.000 & 1.036 & 0.043 & 0.000 & 1.044 & 0.051 & 0.000 & 1.053 \\
\hline PIE Flag & 1.240 & 0.000 & 3.457 & 0.530 & 0.072 & 1.699 & 2.059 & 0.000 & 7.835 \\
\hline \multicolumn{10}{|c|}{ Trip purpose dummies } \\
\hline HBshop & -- & -- & -- & -0.145 & 0.034 & 0.865 & -- & -- & -- \\
\hline HBrec & -- & -- & -- & 0.288 & 0.000 & 1.333 & -- & -- & -- \\
\hline HBschool & -- & -- & -- & 0.444 & 0.000 & 1.558 & -- & -- & -- \\
\hline NHBNW & -- & -- & -- & -- & -- & -- & -0.208 & 0.002 & 0.812 \\
\hline Constant & -5.033 & 0.000 & 0.007 & -4.377 & 0.000 & 0.013 & -4.883 & 0.000 & 0.008 \\
\hline \multicolumn{10}{|c|}{ Overall model statistics } \\
\hline \multicolumn{3}{|c|}{-2 Log likelihood } & $2,124.57$ & & & $14,772.66$ & & & $7,147.62$ \\
\hline \multicolumn{2}{|c|}{ Nagelkerke R-square } & & 0.151 & & & 0.137 & & & 0.253 \\
\hline \multicolumn{2}{|c|}{ All trip ends } & & 9,949 & & & 29,448 & & & 17,137 \\
\hline \multicolumn{2}{|c|}{ Trip ends removed } & & 1,032 & & & 2,998 & & & 2,233 \\
\hline \multicolumn{2}{|c|}{ Trip ends used } & & 8,917 & & & 26,450 & & & 14,904 \\
\hline \multirow{2}{*}{\multicolumn{2}{|c|}{ Walk trip ends }} & & 275 & & & 2,490 & & & 1,329 \\
\hline & & & $3.08 \%$ & & & $9.41 \%$ & & & $8.92 \%$ \\
\hline
\end{tabular}




\subsection{VALIDATION}

Validation of the model was performed using the $10 \%$ of the OHAS trip ends withheld from model estimation, which contained 5,607 trip productions, 417 (7\%) of which were walk trips. The validation method consisted of the following process:

1. Applying the final $\mathrm{HBW}, \mathrm{HBO}$, and $\mathrm{NHB}$ model equations to trips in the validation sample and calculating the walk probability for each trip;

2. Averaging the probabilities to get the predicted walk mode share of trip ends (this method is called sample enumeration); and

3. Comparing the predicted and observed walk and non-walk mode shares.

Results are presented in Table 5-3. Our models generally recreated the observed walk mode shares in the $10 \%$ OHAS validation sample. The estimates were within $0.1 \%$ for $\mathrm{HBW}$ and $\mathrm{HBO}$ trip purposes, while the walk mode share was over-predicted by $1.9 \%$ for NHB trips.

Table 5-3 Validation Results

\begin{tabular}{lrcc}
\hline & \multicolumn{3}{c}{ Model } \\
\cline { 2 - 4 } & HBW & HBO & NHB \\
\hline Observed Walk Mode Share & $2.9 \%$ & $9.4 \%$ & $6.7 \%$ \\
Predicted Walk Mode Share & $3.0 \%$ & $9.5 \%$ & $8.6 \%$ \\
\hline
\end{tabular}




\section{WALK TRIP MODEL: APPLICATION IN METRO'S FOUR-STEP MODEL}

The PAZ walk mode split model discussed in Chapters 4 and 5 does not address the preliminary step of performing trip generation at the PAZs or the steps following the walk mode split model (see Figure 2-1 for further details). Once pedestrian trips are "split off" from the entirety of person trips generated, the non-walk trips are aggregated to TAZs and the normal four-step process continues without walk trips. These remaining walk trips might then be distributed and/or routed at the PAZ level using a stand-alone method. This chapter presents a description of the proposed PAZ trip generation model, procedures and adjustments needed to integrate it within Metro's existing TAZ-based travel modeling framework, forecasting and scalability concerns, and preliminary verification of this process.

\subsection{INPUT DATA}

To perform trip generation at a PAZ level, TAZ attributes must first be allocated down to PAZs. Inputs to Metro's existing TAZ pre-generation and purpose-segmented trip generation models include household demographic and socioeconomic attributes, TAZ employment totals, measures of accessibility to employment, and other information (Table 6-1).

A number of pre-generation models operate prior to the trip generation stage of Metro's travel model using some of these inputs. These pre-generation models have a multinomial logit model framework. First, households are assigned into categories of workers $(0,1,2,3+)$. Next, they are placed into auto ownership categories $(0,1,2,3+)$. Finally, the number of children per household $(0,1,2,3+)$ is determined. The number of workers is used in most of the trip generation models, while the number of children is used in the home-based school trip generation model. The number of vehicles per household is not used for trip generation but is a key input to the mode choice model. 
Table 6-1 Metro Trip Generation Input Data Needs

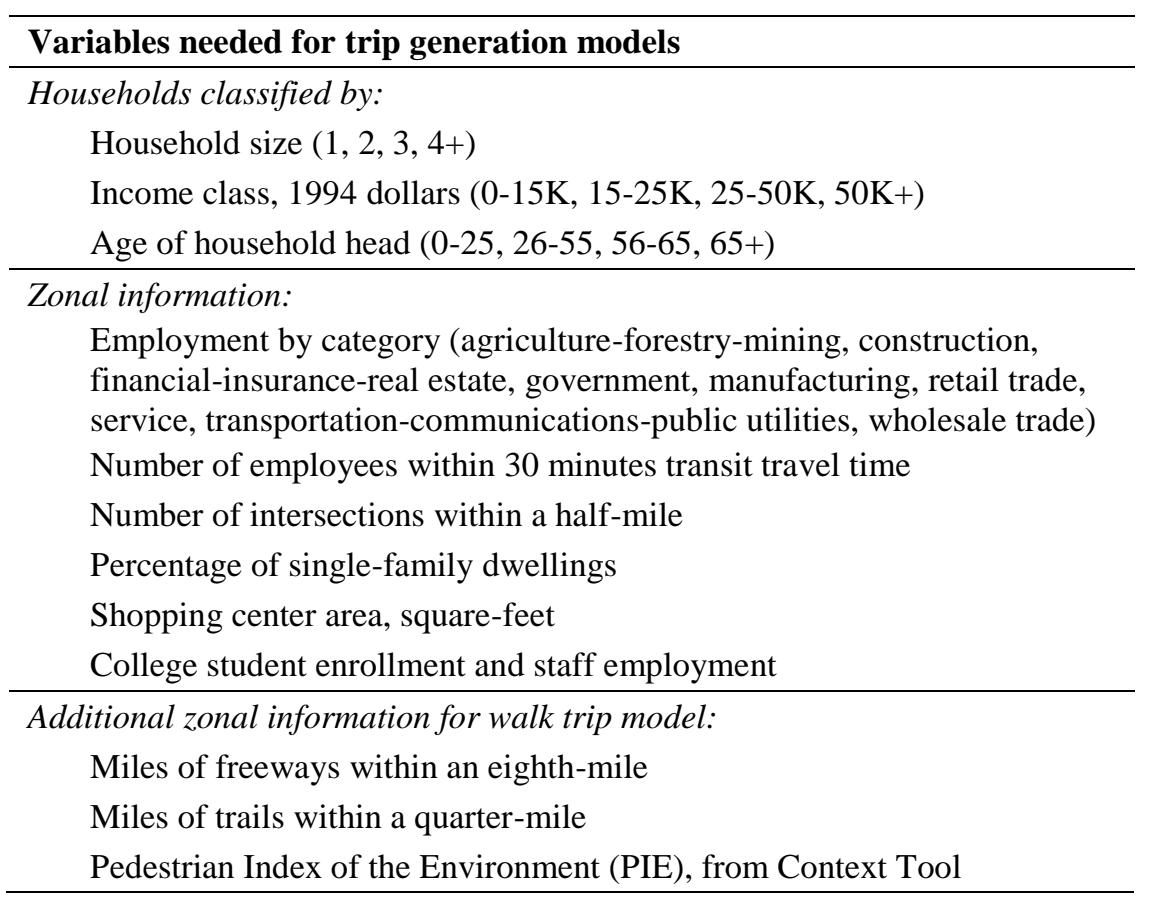

For the base model year (2010), trip generation input data could be created using a variety of methods. If TAZ data have been developed, synthetic PAZ data might be created by allocating TAZ-level data proportionally to all PAZs within a TAZ. Household and employment totals could be evenly allocated across all PAZs, with equal distributions of households and employment across categories. (For example, if $25 \%$ of the 1,000 households in a TAZ are in each age category, then $25 \%$ of the 20 households in a PAZ could be assumed to be in each age category.) Other PAZ inputs, including employment accessibility by transit or the single-family percentage, could be approximated by the TAZ value. Of course, such even allocation obscures the natural variation in household and employment density within zones. Trip generation estimates for shopping centers and colleges that occupy subareas within TAZs would also be skewed. If more spatially disaggregate base-year data are available, even the number of households or jobs within each PAZ, those could be used in place of TAZ allocations for any of the variables. Ideally, all input data would be able to be directly calculated for PAZs without having to make any TAZ-to-PAZ allocations.

For a future forecast or horizon year, creating trip generation input data may be more challenging. MetroScope, Metro's urban simulation framework for integrated land use and transportation modeling (within which the travel demand model is a key component), currently generates HIA and employment forecasts that are only as spatially disaggregate as the 2,162 TAZs in the regional travel model (Oregon Metro, 2009). A process, within or outside of MetroScope, would need to be created to forecast households and jobs for PAZs or allocate such forecasts from TAZs. This task is left to a future project.

A basic verification of a simple method to create synthetic base-year PAZ-level inputs was conducted based on partial allocations from TAZs. Metro provided the project team with 2010 
TAZ-level trip generation data inputs, as well as 2009 employment points (from the Quarterly Census of Employment and Wages) and 2010 household points (from the U.S. Census) for the entire four-county region. The team then aggregated point data to PAZs and allocated TAZ-level household HIA distributions to respective PAZ households. All other zonal information was evenly allocated over the PAZs within each TAZ or assigned the TAZ value. This method was able to capture variation in household and employment density across a TAZ but not variation in household characteristics. Total households and employment from point data closely matched (between $-0.5 \%$ and $+0.5 \%$ ) regional control totals, but TAZ-level totals varied widely, particularly for employment in Clark County, WA.

Some care must be taken with the creation of PAZ trip generation input data. For consistency with TAZ-level model runs, PAZ-level household and employment totals could be weighted to exactly match TAZ control totals in a proposed methodology. Also, when aggregating point data to PAZs, care should be exercised with land uses that may take up large areas of land but are grouped into one point. On the residential side, these may be mobile home parks, multifamily developments, or other properties with multiple housing units on one larger parcel. On the employment side, these may be hospitals, universities, headquarters with satellite offices, or large industrial or manufacturing operations. One solution might be to distribute such groups of households or jobs evenly over their parcels before aggregating to PAZs. This phenomenon is one limitation of the PAZ unit of analysis that occurs when PAZs are actually smaller than parcels.

\subsection{TRIP GENERATION}

To perform trip generation at PAZs, after allocating PAZ level attributes, Metro's existing trip generation model equations (Oregon Metro, 2008; 10-15) must be applied to them. Metro's trip generation model estimates average weekday person trips for eight trip purposes:

1. HBW - Home-based work;

2. HBshop - Home-based shopping;

3. HBrec-Home-based recreation;

4. HBoth - Home-based other (excludes school and college);

5. NHBW - Non-home-based work;

6. NHBNW - Non-home-based non-work;

7. HBcoll - Home-based college; and

8. HBsch-Home-based school.

The trip generation equations use cross-classification to calculate trip productions for most purposes, with exceptions. In general, trip attractions are not calculated; instead, trips are attached to an attraction zone using a multinomial logit destination choice model with size variables. Conceptually, most of Metro's trip generation equations and procedures, although designed for TAZ-level inputs, should also work for PAZs.

Basic verifications of the trip generation equations' compatibility with a PAZ-based process were conducted. Metro provided the project team with its trip generation scripts in R, which were used with minimal modification (limited to changes of reading and writing data), as well as TAZ-level trip productions from a year 2010 model run. First, the team verified that the 
equations could be correctly run by using Metro-provided TAZ-level inputs to reproduce TAZ trip production outputs. Results perfectly matched those trip productions provided by Metro.

\subsubsection{Scalability}

Next, the team tried to verify the scalability of the trip generation equations: that trip generations, when run for PAZs, could correctly produce results that aggregated back up to TAZ-level outputs. For this, the team used the synthetic PAZ inputs created in the previous section and applied the trip generation equations unchanged. For individual TAZs, trip generation results from PAZ aggregations varied widely from those provided by Metro, but the total region-wide trip productions by purpose deviated by only $-0.36 \%$ to $+0.06 \%$. These results were not surprising considering that the household and employment totals used to create the synthetic PAZ input data did not exactly match the TAZ input data provided. If PAZ-level household and employment totals were weighted to exactly match TAZ control totals, trip productions for PAZs would be expected to exactly aggregate to match TAZ-level model run outputs.

Figure 6-1 presents a map of the number of HBW trip productions for all PAZs in the region, while Figure 6-2 shows the same information for TAZs. These are estimates from Metro's trip generation models applied to the two different spatial scales. The figures show the greater spatial resolution in trip-making that can be attained with PAZs and how TAZs may obscure variations in trips produced, especially in the central city and along major suburban roadways. 
Trip Generation Outputs

PAZ Home-Based Work Productions

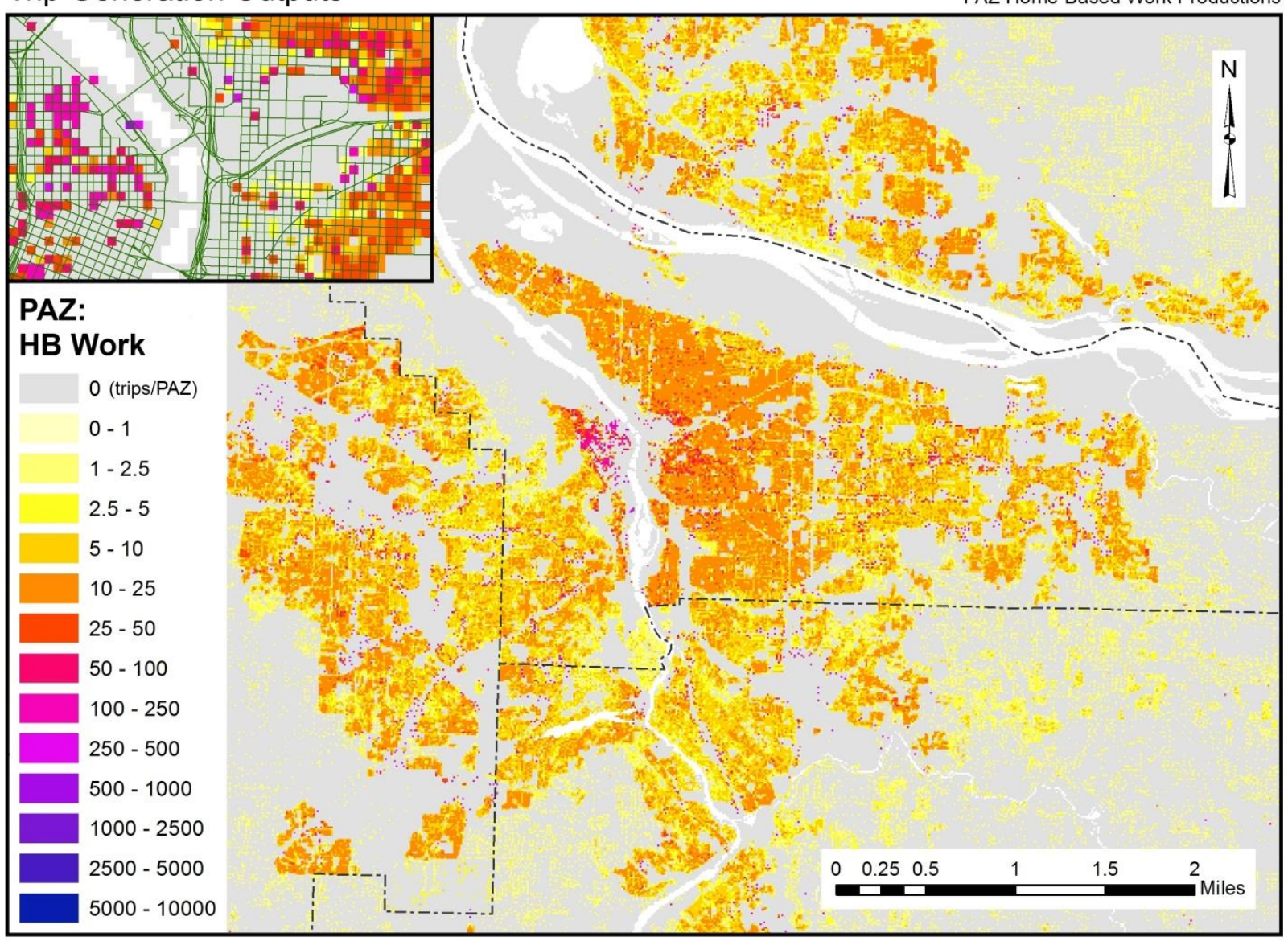

Figure 6-1 PAZ-level Home-Based Work Trip Productions 


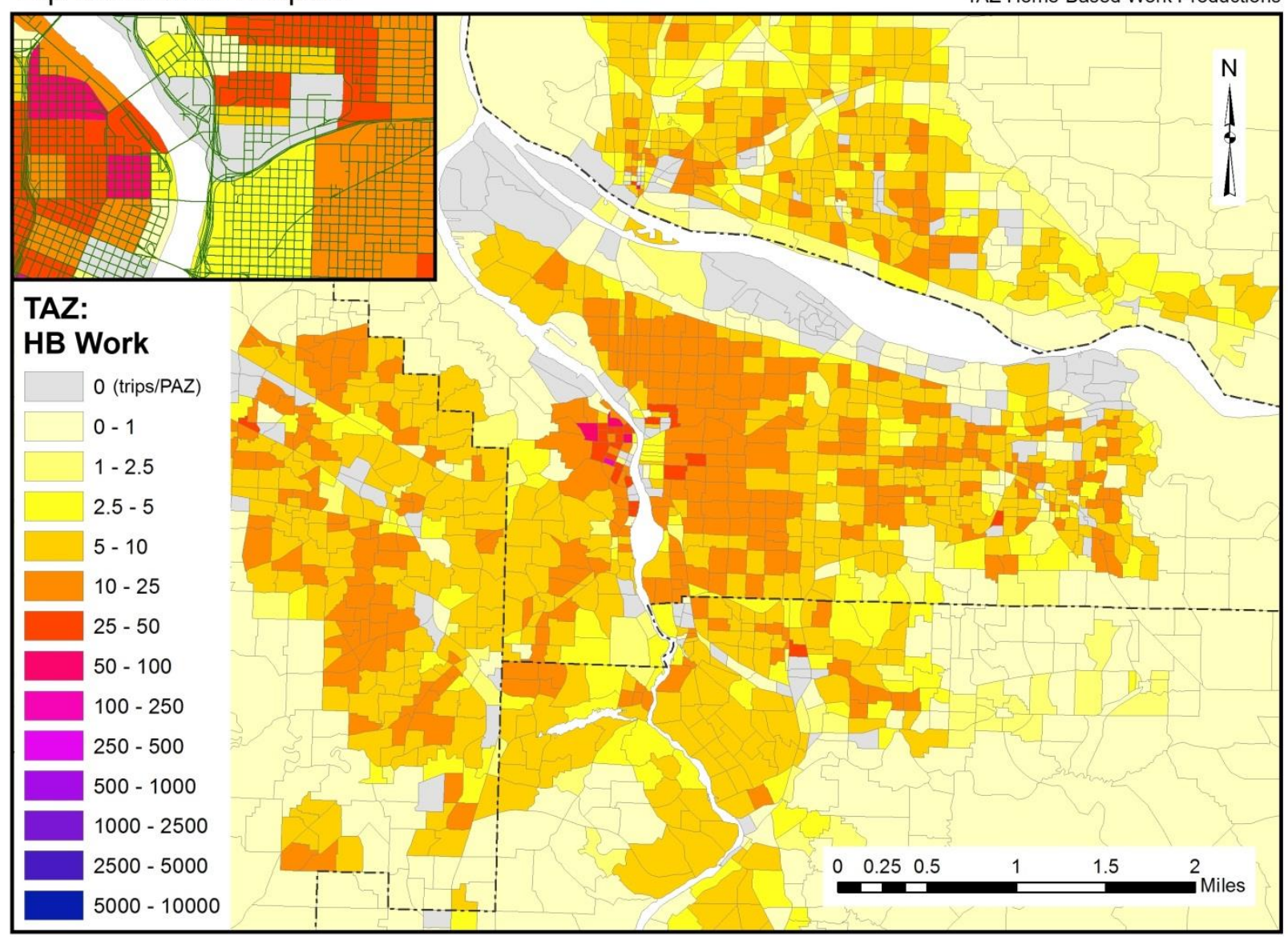

Figure 6-2 TAZ-level Home-Based Work Trip Productions

Conceptually, most of Metro's trip generation models (productions and preliminary attractions) should be scalable to the PAZ level. In other words, the input data and equations they use should scale without issue from TAZs to PAZs. One exception is the home-based school attractions model, which sets zonal attractions equal to zonal productions on the basis of assuming that students travel to neighborhood schools within the same zone. This modeling assumption would need to be adjusted somehow to implement the PAZ-level process; perhaps school attractions could instead be based on school employment or enrollment, similar to the equation for homebased college trip attractions. This task is left to a future project.

One final concern about the operation of trip generation at the grid cell or PAZ level is regarding computational processing power and time. Running the trip generation equations in $\mathrm{R}$ for the approximately 1.5 million PAZs in the model region overloaded the team's installation of R without making adjustments (using the bigmemory package) to how $\mathrm{R}$ objects were stored in memory; matrices upwards of $12 \mathrm{~GB}$ in size were trying to be stored. The process for PAZs also took considerably longer (a couple of hours) when compared to TAZ trip generation (a few minutes). A full implementation of trip generation at the PAZ level might need to adjust the calculation process, be run on computers with more memory, or even consider using different software. 


\subsection{WALK TRIP GENERATION}

After performing trip generation, the walk trip models developed in Section 5.1 can be applied to the trips generated at each PAZ in order to estimate the walk trip ends in a base or forecast year. This is a straightforward process utilizing a few additional variables, as shown in Table 6-1, and relatively simple equations, no more difficult to code than items in the current travel model. A future phase of this project will apply the walk trip models to verified PAZ-level trip generation outputs.

With the future implementation of Metro's Context Tool across the entire region, developing base-year data for use in the walk trip models should be a simple task. As always, developing horizon-year or policy-dependent forecasts of necessary inputs is more challenging; yet, this is where the flexibility of the PIE shines. Because it is mathematically based on the Context Tool, which is explicitly tied to objective measures of the built environment, the PIE could be forecast by developing projected or desired scenarios of households, business, transit service, bicycle facilities, etc. Alternatively, a procedure could be devised to develop future-year forecasts of the Context Tool itself instead of the underlying measures. Finally, the PIE can be used in a more general policy sense by forecasting collective investments and changes that result in certain point or percentage increases or decreases in the 20-to-100 pedestrian index for regional sectors. These tasks are left to a future project.

\subsection{AGGREGATION FROM PAZ TO TAZ}

Finally, once pedestrian trip ends have been split from trips by other modes, non-walk trip generation results must be aggregated from PAZs to TAZs for use in the other stages of the travel model: destination choice, mode choice, etc. This is a straightforward task that has been verified in the prior tests described above. One issue that might be of minor concern is the situation in which a PAZ is partially contained by two-or-more TAZs. As with input data, it is probably acceptable to assign PAZs to the TAZ in which their centroid falls. If this is not acceptable or produces bias for small TAZs, an alternative method could allocate shared PAZs based on the proportion of area in each TAZ.

Since walk trips will no longer be carried through the rest of the travel demand model framework, downstream model stages - particularly mode choice - will have to be re-estimated to account for these changes. This is not anticipated to add additional complexity or effort, because these models must already be re-estimated based on the updated household travel survey data from 2011. These tasks are left to a future project.

\subsection{CONTINUATION OF PAZ-LEVEL WALK TRIPS}

There are many opportunities for utilizing the PAZ-level walk trip productions estimated by the walk trip model. The walk trip model can be used as a pseudo stand-alone planning tool for estimating pedestrian activity that operates with limited travel model interaction. If consistency with travel model outputs is desired for assessments of walking outcomes, a parallel distribution (destination choice) and/or assignment (routing) process for walk trips could be developed and implemented at the PAZ-level. It might be interesting to perform a pseudo-assignment of walk trips through a network of PAZs instead of street segments. These add-on tools could be useful 
for a number of analyses, including pedestrian activity modeling, validation of pedestrian counts, active transportation plan evaluation, and health impact assessments, to name a few. These tasks are left to a future project. 


\section{DISCUSSION \& CONCLUSION}

\subsection{SUMMARY}

In this project, we have developed and presented a method to improve the representation of walking trips in traditional four-step trip-based regional travel demand forecasting models. We simply changed the spatial unit of analysis from TAZs to 264-foot-by-264-foot gridded PAZs and performed a binary logistic regression walk mode split model between the trip generation and trip distribution steps. The addition of a pedestrian index of the environment (PIE) factor in the walk trip model results in more sensitivity to influential aspects of the pedestrian-scale built environment. This fairly simple yet innovative method allows for detailed consideration of walking trips within the four-step model without adding significant additional complexity. The key takeaways from the study are the following:

\section{The method uses data that are available to Metro.}

We have developed and executed our method using the Metro Context Tool, the rasterized built environment dataset used in many planning and policy projects. We also used many of the same scripts and processes from the existing Metro four-step model with slight modifications. Metro needs not develop significant additional forecasting capabilities in order to use the method in base- or future-year model runs.

2. The units of analysis (PAZs) are at a finer-grained spatial scale than the existing TAZs, which is better for capturing and representing short walking trips.

A major weakness of four-step models highlighted in the literature is the mismatch between spatial analysis requirements for different travel modes. Simply, it is not always feasible to predict short walking trips when the unit of study is a TAZ designed for assessing vehicle trips. This project provides a solution to this problem for four-step models, which will remain widely used despite recent interest and work in activity-based models.

3. The weighted PIE improves upon the existing Context Tool for evaluating "walkability."

The PIE, developed as a weighted sum of Context Tool attributes of the built environment, is more strongly correlated to walking observations than the simple sum of all components. It is highly correlated with these and other known indicators of "walkability." Since it is structured as an index, the PIE also bypasses many of the multicollinearity issues inherent with regressions of multiple correlated built environment factors.

4. The parameters in the walk trip models are statistically significant and generally have expected relationships with the probability of walking.

The PIE is significantly and positively related to the odds of a trip being made by walking for all three trip generation purposes modeled. A one-point increase on the 20-100 PIE 
scale was associated with about a 4-5\% increase in the likelihood that a production trip end was a walking trip. This consistent result indicates that our composite measure of the local-scale and pedestrian-relevant built environment is a good indicator of walking activity and a good representation of the pedestrian environment.

5. Despite being integrated with travel demand modeling structures, the walk trip model can operate as a stand-alone pedestrian planning tool separate from the rest of the travel model.

The method was developed specifically to be integrated within Metro's existing travel model structure with limited modification. However, it has the added benefit of operating as a stand-alone pedestrian planning tool without having to spend the time and effort to run the rest of the travel model. With the possibilities of distributing or routing walk trips generated at a fine-grained level, this tool has the potential to be used for many planning purposes.

Although the pedestrian planning method presented in this report was developed to apply to Metro's travel model and the Portland region's context, it has value and applicability elsewhere. The use of PAZs and the estimation of a walk trip model could be applied to travel demand models used by other metropolitan planning organizations, especially those that have only a basic representation of walking. Despite the Context Tool being a Portland-specific database, similar data are becoming increasingly available in other regions from which to calculate a PIE. Indeed, the construction of a generally available PIE is one of the possible next steps listed in the following section.

\subsection{NEXT STEPS}

\subsubsection{Near-term Opportunities}

There are a number of logical next steps for the continuation of this work into a new phase of the project. A Phase II of this project may consider some or all of these opportunities.

- First, some further work is needed to fully integrate the method described herein into the operation of Metro's four-step travel demand model. The project team plans to work with Metro staff to provide model equations, R scripts, and other information as needed during the integration process.

- Second, the walk trip model could be refined. Context Tool data are now available for the entire region, so the PIE could be re-weighted and walk models could be re-estimated. Measures of regional accessibility for motorized modes might be added to the walk trip models in order to capture not just the pedestrian environment but some measures of the attractiveness of other modes.

- Third, consideration could be given to developing a process to forecast necessary model inputs for PAZs. This task would involve considerable coordination with Metro staff and perhaps require solicitation of input from Metro's local government partners. 


\subsubsection{Long-term Opportunities}

Other larger future tasks may be valuable to pursue as a follow-up to this project. This research project represents an important step forward for integrating pedestrian activity into regional travel models, and it has the potential to inform practice outside of the Portland region.

- First, future research might test the transferability of the methodological framework to other metropolitan regions. If necessary, the individual components and weighting scheme of the PIE could be modified for different regional contexts using commonly available measures of the built environment. In addition, the accuracy and ease-of-use of the method developed in this project could be compared with other new regional modeling approaches that attempt to quantify pedestrian travel.

- Second, extensions of the walk trip models and this stand-alone pedestrian planning tool may be promising. Opportunities in this area include developing a method, integrated with the travel model, to distribute and/or route walking trips generated for spatially disaggregate PAZs. These estimates could then be compared to intersection and segment pedestrian counts, providing a robust method of model validation. Such a tool would have a number of useful planning applications.

- Third, consideration might be given to how to better represent pedestrians in activitybased travel demand forecasting models. The trip-based pedestrian modeling methods described in this report likely have some application to activity-based models. Yet, the finer-grained spatial, temporal, and tour-based aspects of activity-based models add complexity to this issue, warranting additional research. 


\section{REFERENCES}

AMEC E\&I Inc., and Sprinkle Consulting Inc. 2011. "Pedestrian and Bicycle Data Collection: Final Report”. Prepared for Federal Highway Administration, Contract No. DTFH61-11F-00031. http://ahtd.info/yahoo_site_admin/assets/docs/Pedestrian_Bicycle_Data_Collection_FH WA_Dec_2011.14274024.

Badoe, D. A., and E. J. Miller. 2000. "Transportation-land-use Interaction: Empirical Findings in North America, and Their Implications for Modeling." Transportation Research Part D: Transport and Environment 5 (4) (July): 235-263. doi:10.1016/S1361-9209(99)00036-X.

Behnam, J., and B. G. Patel. 1977. "A Method for Estimating Pedestrian Volumes in a Central Business District." Transportation Research Record (629). http://trid.trb.org/view.aspx?id=72363.

Beyer, Berger, Metsger, Starr, Bentz, D Edwards, Hunt, Courtney, Johnson, and Morrisette. 2009. House Bill 2001: Oregon Jobs and Transportation Act. http://www.leg.state.or.us/09reg/measpdf/hb2000.dir/hb2001.en.pdf.

Boarnet, M. G., and R. Crane. 2001. "The Influence of Land Use on Travel Behavior: Specification and Estimation Strategies." Transportation Research Part A: Policy and Practice 35 (9) (November): 823-845. doi:10.1016/S0965-8564(00)00019-7.

Boarnet, M. G., A. Forsyth, K. Day, and J. M. Oakes. 2011. "The Street Level Built Environment and Physical Activity and Walking Results of a Predictive Validity Study for the Irvine Minnesota Inventory." Environment and Behavior 43 (6) (November 1): 735-775. doi:10.1177/0013916510379760.

Boarnet, M. G., and M. J. Greenwald. 1999. "Land Use, Urban Design, and Non-Work Travel: Reproducing for Portland, Oregon, Empirical Tests from Other Urban Areas”. UCI-ITSAS-WP-99-5. http://escholarship.org/uc/item/9zd6c7dh.

Boarnet, M. G., M. Greenwald, and T. E. McMillan. 2008. "Walking, Urban Design, and Health Toward a Cost-Benefit Analysis Framework." Journal of Planning Education and Research 27 (3) (March 1): 341-358. doi:10.1177/0739456X07311073.

Broach, J., J. P. Gliebe, and J. Dill. 2011. "Bicycle Route Choice Model Developed from Revealed-Preference GPS Data" presented at the Transportation Research Board 90th Annual Meeting, Washington, D.C. http://trid.trb.org/view.aspx?id=1093304.

Brownson, R. C., C. M. Hoehner, K. Day, A. Forsyth, and J. F. Sallis. 2009. "Measuring the Built Environment for Physical Activity." American Journal of Preventive Medicine 36 (4 Suppl) (April): S99-123.e12. doi:10.1016/j.amepre.2009.01.005.

Cambridge Systematics, Inc, and Barton Aschman Associates. 1994. "Short-term Travel Model Improvements”. Final Report DOT-T-95-05. Travel Model Improvement Program, Federal Highway Administration, U.S. Department of Transportation. http://ntl.bts.gov/DOCS/445.html.

Cambridge Systematics, Inc, and Parsons Brinckerhoff Quade and Douglas, Inc. 1996. "Making the Land Use Transportation Air Quality Connection: Analysis of Alternatives". Volume 5. 1000 Friends of Oregon. http://content.lib.utah.edu/utils/getfile/collection/FHWA/id/1404/filename/1405.pdf. 
Cambridge Systematics, Inc, Parsons Brinckerhoff Quade and Douglas, Inc, and S. H. Putman Associates, Inc. 1996. "Making the Land Use Transportation Air Quality Connection: Model Modifications". Volume 4, Part 2. 1000 Friends of Oregon. http://content.lib.utah.edu/utils/getfile/collection/FHWA/id/1404/filename/1405.pdf.

Cambridge Systematics, Inc, Vanasse Hangen Brustlin, Inc, Gallop Corporation, C Bhat, Shapiro Transportation Consulting, LLC, and Martin/Alexiou/Bryson, PLLC. 2012. "Travel Demand Forecasting: Parameters and Techniques". NCHRP Report 716. National Cooperative Highway Research Program, Transportation Research Board, National Academies of Science.

Cao, X., S L Handy, and P. L. Mokhtarian. 2005. "The Influences of the Built Environment and Residential Self-selection on Pedestrian Behavior: Evidence from Austin, TX."

Transportation 33 (1). http://escholarship.org/uc/item/4jn1w8qn.

Cao, X., P. L. Mokhtarian, and S. L. Handy. 2009. "Examining the Impacts of Residential SelfSelection on Travel Behaviour: A Focus on Empirical Findings." Transport Reviews 29 (3): 359-395.

Cervero, R, and K Kockelman. 1997. "Travel Demand and the 3Ds: Density Diversity and Design." Transportation Research Part D: Transport and Environment 2 (3): 199-219.

Cervero, R. 1996. "Mixed Land-uses and Commuting: Evidence from the American Housing Survey." Transportation Research Part A: Policy and Practice 30 (5) (September): 361377. doi:10.1016/0965-8564(95)00033-X.

Cervero, R., and M. Duncan. 2003. "Walking, Bicycling, and Urban Landscapes: Evidence From the San Francisco Bay Area." American Journal of Public Health 93 (9) (September): 1478.

Chen, C., H. Gong, and R. Paaswell. 2008. "Role of the Built Environment on Mode Choice Decisions: Additional Evidence on the Impact of Density." Transportation 35 (3) (May 1): 285-299. doi:10.1007/s11116-007-9153-5.

Clifton, K. J., and C. D. Muhs. 2012. "Capturing and Representing Multimodal Trips in Travel Surveys." Transportation Research Record: Journal of the Transportation Research Board 2285 (December 1): 74-83.

Courtney. 2010. Oregon Senate Bill 1059. http://www.leg.state.or.us/bills_laws/concepts/sen/SB1059.pdf.

Crane, R. 2000. "The Influence of Urban Form on Travel: An Interpretive Review." Journal of Planning Literature 15 (1) (August 1): 3-23. doi:10.1177/08854120022092890.

Desyllas, J., E. Duxbury, J. Ward, and A. Smith. 2003. "Pedestrian demand modelling of large cities: an applied example from London”. Working / discussion paper Paper 62. London: UCL Centre for Advanced Spatial Analysis. http://eprints.ucl.ac.uk/233/.

Donnelly, R., G. D. Erhardt, W. Moeckel, and W. A. Davidson. 2010. “Advanced Practices in Travel Forecasting: A Synthesis of Highway Practice". NCHRP Synthesis 406. National Cooperative Highway Research Program, Transportation Research Board, National Academies of Science.

Eash, R. 1997. “Incorporating Urban Design Variables in Metropolitan Planning Organizations' Travel Demand Models." In , 167-186. https://engineering.purdue.edu/ ce566/HO/eash.pdf. . 1999. "Destination and Mode Choice Models for Nonmotorized Travel." Transportation Research Record: Journal of the Transportation Research Board 1674 (January 1): 1-8. doi:10.3141/1674-01. 
Ewing, R, and R Cervero. 2010. "Travel and the Built Environment." Journal of the American Planning Association 76 (3): 265-294.

Ewing, R., and R. Cervero. 2001. "Travel and the Built Environment: A Synthesis." Transportation Research Record: Journal of the Transportation Research Board 1780 (January 1): 87-114.

Ewing, R., M. Greenwald, M. Zhang, J. Walters, M. Feldman, R. Cervero, L. Frank, and J. Thomas. 2011. "Traffic Generated by Mixed-Use Developments-Six-Region Study Using Consistent Built Environmental Measures." Journal of Urban Planning and Development 137 (3): 248-261. doi:10.1061/(ASCE)UP.1943-5444.0000068.

Forsyth, A. 2010. "NEAT-GIS Protocols Version 5.0.” Design for Health. http://designforhealth.net/.

Frank, L. D., and P. O. Engelke. 2001. "The Built Environment and Human Activity Patterns: Exploring the Impacts of Urban Form on Public Health." Journal of Planning Literature 16 (2): 202-218. . 2005. "Multiple Impacts of the Built Environment on Public Health: Walkable Places and the Exposure to Air Pollution." International Regional Science Review 28 (2) (April 1): 193-216. doi:10.1177/0160017604273853.

Greenwald, M. J., and M. G. Boarnet. 2001. "Built Environment as Determinant of Walking Behavior: Analyzing Nonwork Pedestrian Travel in Portland, Oregon." Transportation Research Record: Journal of the Transportation Research Board 1780 (January 1): 3341. doi:10.3141/1780-05.

Guo, J., C. Bhat, and R. Copperman. 2007. "Effect of the Built Environment on Motorized and Nonmotorized Trip Making: Substitutive, Complementary, or Synergistic?” Transportation Research Record: Journal of the Transportation Research Board 2010 (January 1): 1-11. doi:10.3141/2010-01.

Handy, S. L., M. G. Boarnet, R. Ewing, and R. E. Killingsworth. 2002. "How the Built Environment Affects Physical Activity: Views from Urban Planning.” American Journal of Preventive Medicine 23 (2, Supplement 1): 64-73.

Hood, J., E. Sall, and B. Charlton. 2011. "A GPS-based Bicycle Route Choice Model for San Francisco, California." Transportation Letters: The International Journal of Transportation Research 3 (1): 63-75. doi:10.3328/TL.2011.03.01.63-75.

Johnson Gardner. 2007. “An Assessment of the Marginal Impact of Urban Amenities on Residential Pricing”. Portland, Oregon. http://johnsongardner.com/files/Urban_Amenities_Final5.pdf.

Kim, K., and E. Y. Yamashita. 2011. "Urban Environmental Quality and Pedestrian Volumes." In Washington, D.C. http://trid.trb.org/view.aspx?id=1093228.

Kitamura, R., P. L Mokhtarian, and L. Laidet. 1997. "A micro-analysis of land use and travel in five neighborhoods in the San Francisco Bay Area." Transportation 24 (2): 125-158.

Kulkarni, A. A. 1996. "The Influence of Land Use and Network Structure on Travel Behavior". Master's Thesis, University of California Irvine.

Lee, C., and A. V. Moudon. 2004. "Physical Activity and Environment Research in the Health Field: Implications for Urban and Transportation Planning Practice and Research." Journal of Planning Literature 19 (2) (November 1): 147-181. doi:10.1177/0885412204267680.

Li, F., K. J. Fisher, R. C. Brownson, and M. Bosworth. 2005. "Multilevel Modelling of Built Environment Characteristics Related to Neighbourhood Walking Activity in Older 
Adults." Journal of Epidemiology and Community Health 59 (7) (July 1): 558-564. doi:10.1136/jech.2004.028399.

Lindsey, G. H., J. Borah, S. Hankey, K. Hoff, B. Utecht, and Z. Xu. 2011. "Forecasting Use of Nonmotorized Infrastructure: Models of Bicycle and Pedestrian Traffic in Minneapolis, Minnesota" presented at the Transportation Research Board 90th Annual Meeting, Washington, D.C. http://trid.trb.org/view.aspx?id=1092646.

Liu, F., J. Evans, and T. Rossi. 2012. "Recent Practices in Regional Modeling of Nonmotorized Travel." Transportation Research Record: Journal of the Transportation Research Board 2303 (December 1): 1-8. doi:10.3141/2303-01.

McGinn, A. P., K. R. Evenson, A. H. Herring, S. L. Huston, and D. A. Rodriguez. 2007. "Exploring Associations Between Physical Activity and Perceived and Objective Measures of the Built Environment." Journal of Urban Health 84 (2) (February 2): 162184. doi:10.1007/s11524-006-9136-4.

Metropolitan Travel Forecasting: Current Practice and Future Direction. 2007. TRB Special Report 288. Washington, D.C.: The National Academies Press.

Mohammadian, A., and Y. Zhang. 2007. "Investigating Transferability of National Household Travel Survey Data." Transportation Research Record: Journal of the Transportation Research Board 1993 (January 1): 67-79. doi:10.3141/1993-10.

Moudon, A. V., P. Hess, M. Snyder, and K. Stanilov. 1997. "Effects of Site Design on Pedestrian Travel in Mixed-Use, Medium-Density Environments." Transportation Research Record: Journal of the Transportation Research Board 1578 (January 1): 48-55. doi:10.3141/1578-07.

Nouzad, F. 2000. "Modeling of the Non-Motorized Travel Interregional Travel Model Development: Phase I - Task 3”. Technical Memorandum. Wasatch Front Regional Council.

Oregon Metro. 2008. "Metro Travel Forecasting 2008 Trip-Based Demand Model Methodology Report." http://library.oregonmetro.gov/files/model_documentation_ivan_march08.pdf. . 2009. "Metroscope 3.0 Generalized Design and Equation Specifications as Implemented at Portland Metro July 1, 2007”. Technical Memorandum. http://library.oregonmetro.gov/files//metroscope_3.pdf.

Oregon Modeling Steering Committee. 2011. 2009-2011 Oregon Travel and Activity Survey. http://www.oregon.gov/ODOT/TD/TP/pages/travelsurvey.aspx.

Parsons Brinckerhoff Quade and Douglas, Inc, Cambridge Systematics, Inc, and Calthorpe Associates. 1993. "Making the Land Use Transportation Air Quality Connection: The Pedestrian Environment". Volume 4A. 1000 Friends of Oregon. http://ntl.bts.gov/DOCS/tped.html.

Porter, C., J. Suhrbier, and W. Schwartz. 1999. "Forecasting Bicycle and Pedestrian Travel: State of the Practice and Research Needs." Transportation Research Record: Journal of the Transportation Research Board 1674 (January 1): 94-101. doi:10.3141/1674-13.

Purvis, C. 1997. "Review of the Literature: Home-Based Work Mode Choice Models". Technical Memorandum HBWMC \#1. Metropolitan Transportation Commission.

Replogle, M. 1997. "Integrating Pedestrian and Bicycle Factors into Regional Transportation Planning Models: Summary of the State-of-the-art and Suggested Steps Forward.” In , 75-94. http://media.tmiponline.org/clearinghouse/udes/replogle.pdf.

Rossi, T. F. 2000. “Modeling Non-Motorized Travel.” In Washington, D.C. 
Saelens, B. E., and S. L. Handy. 2008. "Built Environment Correlates of Walking: A Review." Medicine and Science in Sports and Exercise 40 (7): 550-566.

Schneider, R. J. 2013. "Theory of Routine Mode Choice Decisions: An Operational Framework to Increase Sustainable Transportation." Transport Policy 25: 128-137.

Schneider, R. J., L. S. Arnold, and D. R. Ragland. 2009. "Pilot Model for Estimating Pedestrian Intersection Crossing Volumes." Transportation Research Record: Journal of the Transportation Research Board 2140 (December 1): 13-26. doi:10.3141/2140-02.

Schneider, R. J., R. Pattern, J. Toole, and C. Raborn. 2005. "Pedestrian and Bicycle Data Collection in United States Communities: Quantifying Use, Surveying Users, and Documenting Facility Extent". Federal Highway Administration, U.S. Department of Transportation. http://katana.hsrc.unc.edu/cms/downloads/PBIC_Data_Collection_Case_Studies2005.pdf

Stein, B. 2011. "Regional Bicycle Demand Model: In Use Today in Portland" presented at the 13th TRB Transportation Planning Applications Conference, Reno, Nevada. http://trbappcon.org/2011conf/TRB2011presentations/Session9B/06_TRB_Applications_ Stein.ppt.

Steinberg, D. 2008. California Senate Bill 375: Sustainable Communities and Climate Protection Act. http://www.leginfo.ca.gov/pub/07-08/bill/sen/sb_03510400/sb_375_bill_20080930_chaptered.pdf.

Transportation Planning Capacity Building Program. 2013. "Metropolitan Planning Organization (MPO) Database". Office of Planning, Environment \& Realty, Federal Highway Administration, U.S. Department of Transportation. Accessed May 15. http://www.planning.dot.gov/mpo.asp.

Vanasse Hangen Brustlin, Inc. 2007. "Determination of the State of the Practice in Metropolitan Area Travel Forecasting: Findings of the Surveys of Metropolitan Planning Organizations". TRB Committee B0090.

Zhang, M. 2006. "Travel Choice with No Alternative Can Land Use Reduce Automobile Dependence?" Journal of Planning Education and Research 25 (3) (March 1): 311-326. doi:10.1177/0739456X05280544.

Zorn, L., E. A. Sall, and M. Bomberg. 2012. "Completing the Cycle: Incorporating Cycle Tracks into SF-CHAMP" presented at the 4th Annual Conference on Innovations in Travel Modeling, Tampa, Florida.

Zupan, J. M., and B. Pushkarev. 1971. "Pedestrian Travel Demand." Highway Research Record (377). http://trid.trb.org/view.aspx?id=116494. 


\section{APPENDIX A. THE RELATIONSHIP BETWEEN THE BUILT ENVIRONMENT AND PEDESTRIAN TRAVEL BEHAVIOR}

There are many factors that influence if, how frequently, and how far people walk. Distances between trip origins and destinations are consistently important factors. The economic status of a person or a household impacts the availability of a personal vehicle and their value of travel time (Greenwald and Boarnet 2001). Demographics and life situation (e.g., primary school student, working adult, elderly retiree, etc.) of individuals are related to the amounts, locations, and modes of travel undertaken. Also, some research suggests that people may walk more because they want to, and thus choose to live in places that facilitate walking (Kitamura, Mokhtarian and Laidet, 1997). The environment through which those potential walking trips are made is also critical: the built environment includes buildings, land uses, sidewalks, streets, and the networks that connect these components together. The pedestrian-level built environment is an important but still poorly understood (and poorly accounted for) influence on pedestrian travel behavior.

Two early studies by Pushkarev and Zupan (1971) and Benham and Patel (1977) were among the first to investigate pedestrian activity and relate it to the surrounding environment. Developed over the last two to three decades, a large body of literature has greatly improved the understanding of pedestrian travel behavior and the impact of the built environment. The objective of this literature review is to summarize the current state of knowledge, identify promising leads, and suggest innovative ways to measure the built environment that may be useful in improving the representation of pedestrian travel behavior in regional travel demand models.

\section{A.1 CLASSIFYING URBAN FORM AND BUILT ENVIRONMENT "INDEPENDENT" VARIABLES}

Several summaries of literature on the built environment's influence on travel behavior and pedestrian transportation in particular have been published that classify measures of the built environment into categories. A common theme in most studies is to make a slight deviation from the three "D"s: density, diversity, and design (Cervero and Kockelman, 1997). Density reflects the intensity and concentration of land uses; diversity measures how mixed or varied those land uses are; and design refers to all of the smaller scale measures of street and streetscape composition. A common additional variable, design, characterizes the network of streets and travel paths.

Ewing and Cervero (2001) review literature and classify variables as related to land use patterns (residential density, employment density, land use mix, micro-accessibility); transportation networks (street connectivity, directness of routing, block sizes, sidewalk connectivity); and urban design features (small-scale and aesthetic aspects). They agglomerate studies to calculate elasticities of travel for the categories local density, local diversity, local design, and regional accessibility. Similarly, Frank and Engelke (2001) split the built environment into three components: transportation systems, land development patterns, and micro-scale urban design. Transportation systems are used to connect activities, and street networks can be either grid or dendritic. They mention two "patterns" of land development: density (compactness) and mix 
(different activities close to each other). Their discussion of urban design focuses on measures of desirability or perceptions of safety.

Using slightly different language, Frank and Engelke (2005) later lay out three concepts about the relationships between the built environment and travel behavior: proximity, connectivity, and urban design. They define proximity as "how close different travel destinations are to one another in space" and say that it is operationalized in terms of density and mixture of uses. Connectivity is "the number and directness of transportation linkages between destinations" and is usually measured by intersection density. They introduce urban design as "those aspects of the built environment that influence how a person perceives a place." Badoe and Miller (2000) similarly classify urban form impacts into four categories: residential density, employment density, accessibility, and neighborhood design. Accessibility is defined as "how much of a given activity is located how close to the location in question" and described to be important in almost all studies. Two other influences they analyze are auto ownership and socioeconomics.

Some authors expand these short lists to include more elements. Crane (2000) uses the following categories of urban form measures: density, land use mixing, traffic calming, street and circulation pattern, land use balance (jobs/housing), and pedestrian features. Handy et al. (2002) group five dimensions of the built environment at the neighborhood scale: density and intensity, land use mix, street connectivity, street scale, and aesthetic qualities. Saelens and Handy (2008) later summarize this research as defining the built environment as: land use patterns, distribution of activities and buildings across space, transportation system, physical infrastructure and service, and urban design. Forsyth (2010) splits GIS-based measures of the built environment into categories of density, land use mix, street pattern, pedestrian infrastructure, and other. Although focusing more on physical activity than transportation, Brownson et al. (2009) similarly categorize variables into population density, land use mix (accessibility, intensity, and pattern), access to recreational facilities (accessibility and intensity), street pattern, and other. Ewing and Cervero (2010) use five "D" variables: density, diversity, design, destination accessibility, and distance to transit.

This project classifies independent variables that measure the built environment based on summaries of previous classifications, Handy et al. (2002) and Forsyth (2010) in particular, and contains an analysis of the variables. Variables are placed into the following categories: 1) intensity or density variables, which measure the concentration of residential and non-residential land uses in a certain area; 2) land use mix or diversity variables, which measure the relative balance of residential and non-residential land uses in a certain area; 3) network or connectivity variables, which measure the directness of path options; 4) other mobility and accessibility variables, which measure the nearby availability of transportation infrastructure or modes and non-motorized destinations; 5) street design variables, which measure design aspects of the streetscape and street-level built environment; 6) pedestrian environment factor and other compound variables, which group several different built environment measures into one variable; and 7) attitudinal and perceptional variables, which measure people's attitudes towards walking and the built environment. 


\section{A.2 CLASSIFYING TRAVEL BEHAVIOR AND TRAVEL OUTCOME "DEPENDENT" VARIABLES}

Just as the built environment can be described in different ways, so too can travel behavior and outcomes. However, because transportation outcomes have been an obvious focus of travel behavior literature for much longer than the built environment, they are more consistently described. Crane (2000) lists many possible travel-related measures: total miles traveled, number of trips, car ownership, travel mode, congestion, commute length, other commute measures, and differences by trip purpose. Handy et al.(2002) note that travel is generally described by characteristics of trips: frequency, destination, length, mode, and purpose. Ewing and Cervero (2001) also classify dependent travel variables into four types: trip frequencies (rates of trip making), trip lengths (distance or time), mode choice (or mode split), and cumulative measures (person miles traveled, vehicle miles traveled, or vehicle hours traveled). From a public health perspective, Lee and Moudon (2004) describe how dependent variables focus on characteristics of physical activity: engagement in, frequency of, duration of, and distance of walking.

Most of these classifications mirror the major outputs and structure of trip-based regional travel demand models. Trip generation considers the frequency of trip making; trip distribution selects destinations for those trips; mode choice picks a travel mode(s) for the trip; and trip distribution finds the actual path for the trip, from which trip length (both distance and time) can be determined. Cumulative measures can be calculated based on several of these model outputs. The focus of this project is on improving the knowledge of how the built environment influences the decision of whether or not to make a trip by walking, but the frequency of walking trips and their lengths are also secondarily important.

\section{A.3 DESCRIBING THE RELATIONSHIP BETWEEN BUILT ENVIRONMENT AND TRAVEL BEHAVIOR}

Many scholars have considered theories about the relationships between the built environment and travel behavior, particularly pedestrian travel behavior. Boarnet and Crane (2001) postulate that travel behavior can be explained through a microeconomic theory of utility maximization. In this formulation, the built environment affects travel behavior by changing the cost of travel through travel time and other factors; this is the common relationship expressed in travel demand models. In contrast, Badoe and Miller (2000) propose a new model for conceptualizing these relationships in which the street network, transit service, neighborhood design, socioeconomics, residential density, and employment density all influence accessibility, which in turn has the sole impact on travel and activity.

Ewing and Cervero (2001) examine the relative strengths of these possible relationships. They classify dependent travel variables into four types - trip frequencies, trip lengths, mode choice, and cumulative measures - and analyze the literature for relationships to the built environment and socioeconomic characteristics. The authors conclude that trip frequencies are primarily a function of socioeconomic characteristics and secondarily a function of the built environment, while trip lengths are primarily a function of the built environment and secondarily a function of socioeconomic characteristics. Mode choice seems to depend more on socioeconomics than the built environment, whereas cumulative measures seem to depend more on the built environment 
than on socioeconomics. In an follow-up meta-analysis, Ewing and Cervero (2010) attempt to quantify such relationships between travel and the built environment using weighted average elasticities.

These relationships have also been discussed in public health literature. Frank and Engelke (2001) describe a conceptual model of how the built environment influences public health indirectly through the encouragement (or discouragement) of physical activity patterns. In a later paper, the same authors (2005) expand this framework. They suggest that all human-made aspects of the built environment affect activity patterns, including travel and leisure patterns. These travel patterns generate health "precursors" such as vehicle emissions and physical activity, which in turn directly lead to public health outcomes. For the purposes of this study, the first relationship between the built environment and travel patterns is of primary concern, although it should be recognized that these results will be used for many other secondary purposes.

Some have questioned the strength of these proposed relationships between the built environment and (pedestrian) travel behavior. Several authors have noted that residential location choice may have a strong effect (if not a stronger effect than the built environment) on travel behavior (eg., Kitamura, Mokhtarian and Laidet, 1997; Kulkarni, 1996; Crane, 2000). For example, people may walk more in a dense, connected neighborhood because they want to walk more and so choose to live in a place that facilitates their desired travel behavior. However, summarized results of several studies show that characteristics of the built environment tend to significantly affect travel behavior after controlling for residential location choice (Cao, Mokhtarian and Handy, 2009).

Other authors take a wider view of pedestrian travel mode choice and place the built environment within a broader decision-making context. Schneider's "Theory of Routine Mode Choice Decisions" (2013) proposes the following sequence. First, a person must be aware of and consider a mode to be an acceptable option for routine travel. In the next three stages, they consider tradeoffs between the different acceptable modes based on, in order, basic safety and security, convenience and cost, and enjoyment. Finally, there is the reinforcing influence of habit, which completes the cycle. Socioeconomic factors influence how individuals respond during the first four stages. The built environment enters this framework through its influence on the tradeoffs between modes made in the middle three stages.

The way some authors conceptualize the relationships between aspects of the built environment and activity patterns or travel behavior are shown in the figures below. 


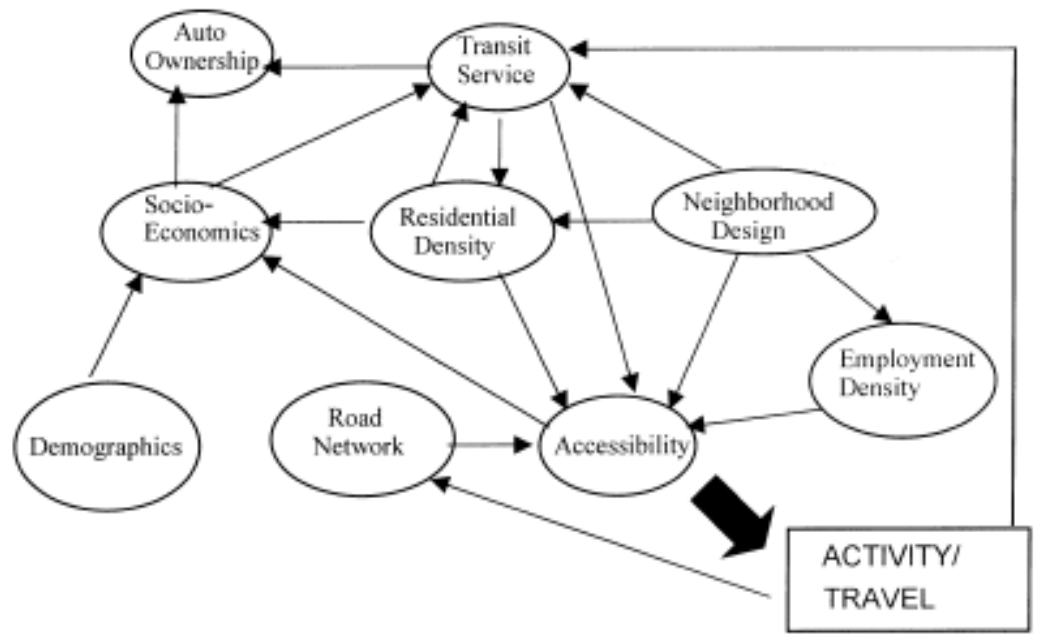

Fig. 1. Urban form impacts of activity and travel.

Badoe and Miller (2000)

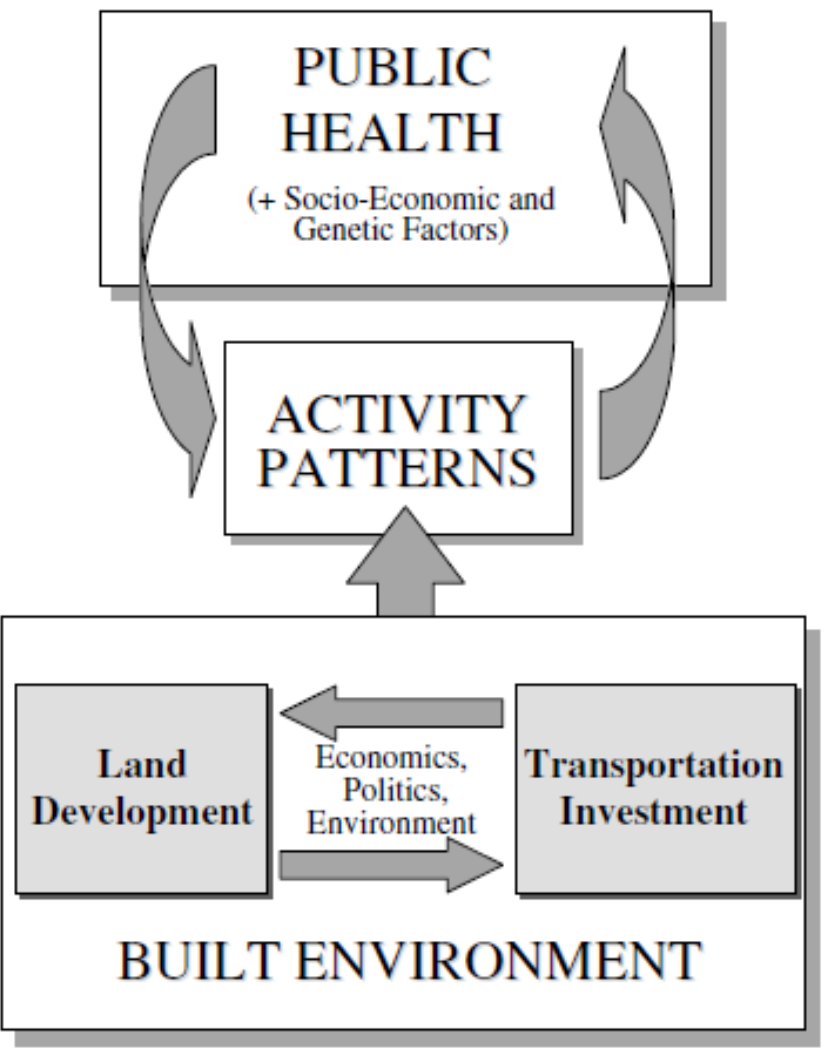

FIGURE 1. Linkages between Land Use, Transportation, and Public Health

Frank and Engelke (2001) 


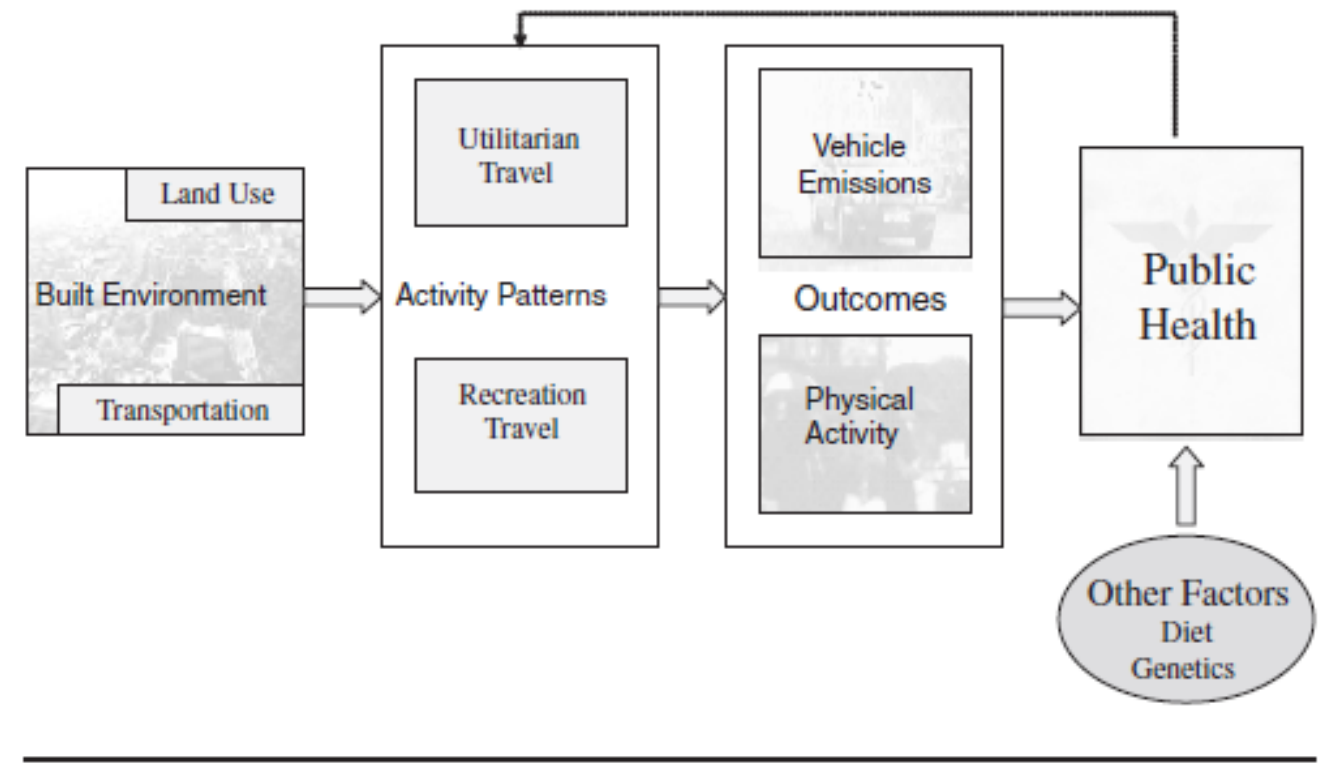

FIGURE 1. Conceptual Model

Frank and Engelke (2005)

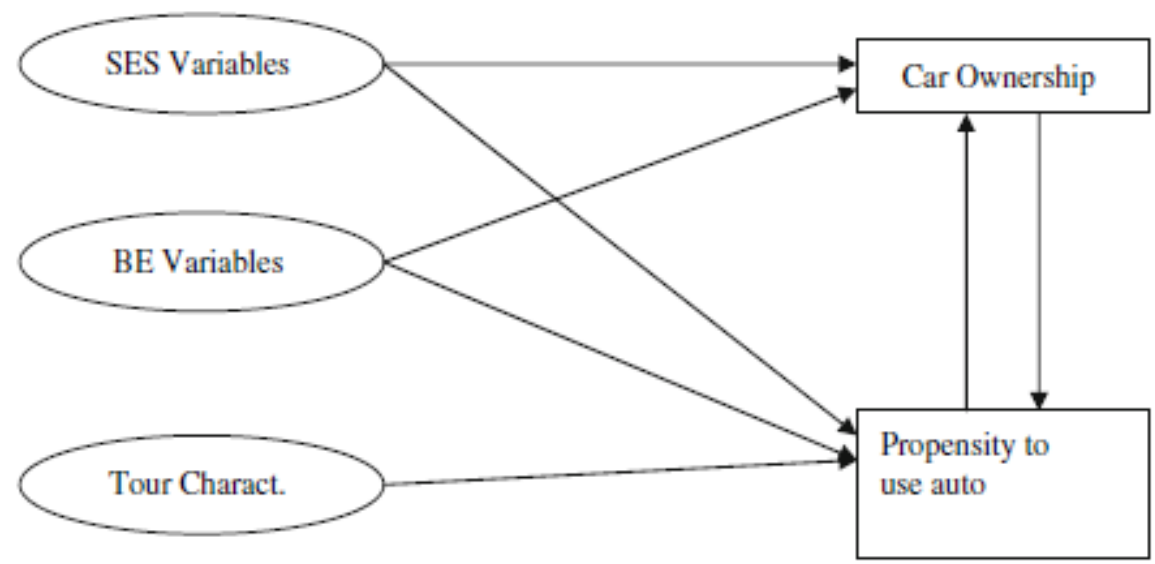

Fig. 2 Path analysis between endogenous variables (in rectangular shape) and exogenous variables (in oval shape)

Chen et al. (2008) 


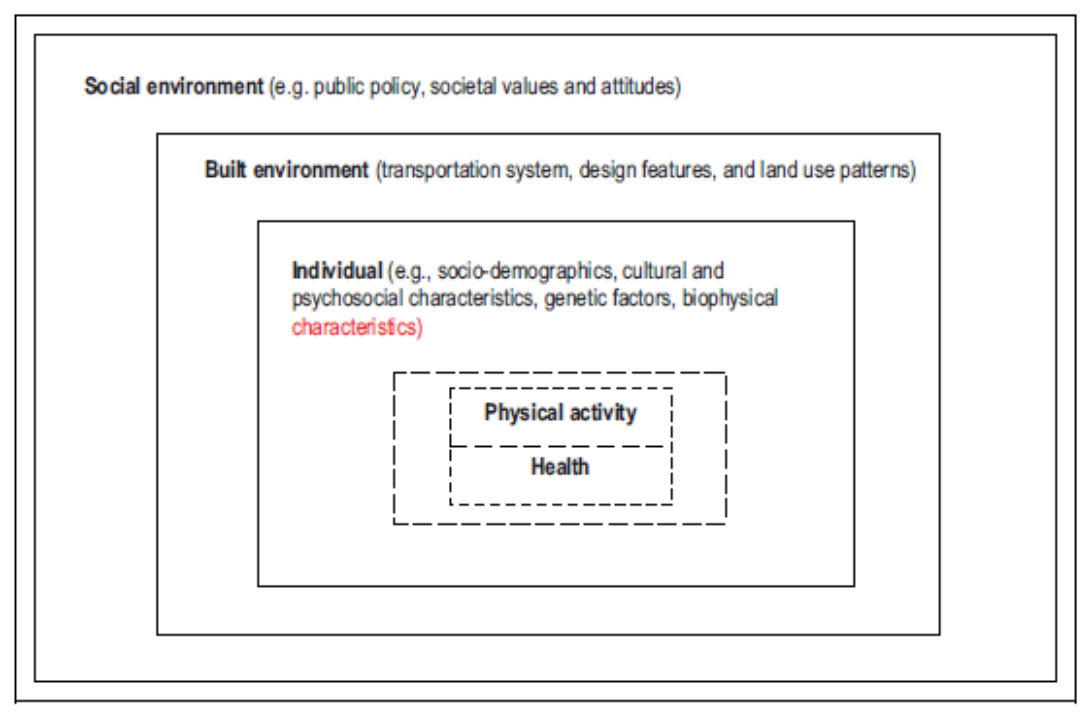

Figure I. Multiple levels of influence on physical activity and related health outcomes. (Adapted from Transportation Research Board, 2005.)

Cerin (2011)

Figure 7.1. A Theory of Routine Mode Choice Decisions

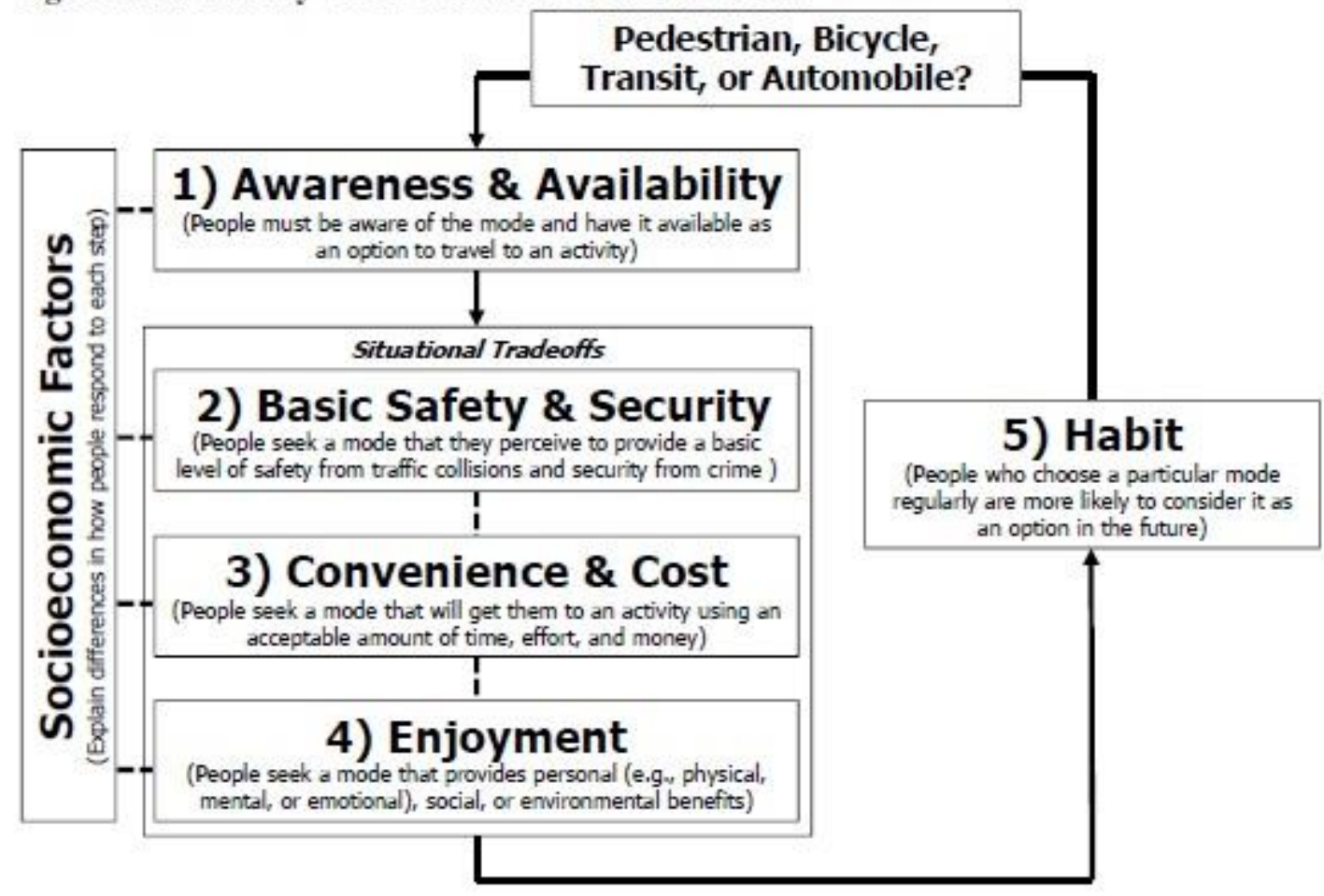

Schneider (2013) 


\section{A.4 THE INFLUENCE OF SCALE AND AGGREGATION}

The manner in which built environment variables are measured can make a large difference in the results of an analysis. Common items that can be counted (such as people, jobs, blocks, or intersections) are usually averaged over an area to calculate a surface density. This area can be a consistent standard unit of area, such as a square mile or within a one-mile radius of a point, or it can be a varying unit of area, such as a TAZ, census tract, or zip code. The choice of either a point buffer or zone area has different implications for predicting pedestrian travel behavior depending on what is being predicted. If the likelihood of making a walking trip, or the frequency, is being predicted for a household with a known location, the density variable can either be based on a buffer around the specific location or taken from the average for the geographic zone the household falls within. However, if the specific location is unknown, then the zonal average must be used. Furthermore, the point buffer density can itself be buffered to create a smoother surface.

\section{A.5 BUILT ENVIRONMENT VARIABLES THAT INFLUENCE PEDESTRIAN TRAVEL BEHAVIOR}

As previously mentioned, measures of the built environment are analyzed within seven categories: intensity or density variables; land use mix or diversity variables; network or connectivity variables; mobility and accessibility variables; street design variables; compound variables like the pedestrian environment factor; and attitudes and perceptions. The sections that follow describe each of these independent variables, how they are measured and calculated, what theoretically causal relationships they are trying to capture, their significance in different circumstances, and their usefulness for this and future studies.

\section{A.5.1 Intensity / Density Variables}

The most common way to represent the built environment is through a measure of intensity of development. This intensity is usually expressed as either residential density or employment density. Residential density is measured by the quantity of people, households, or dwelling units that are located within a certain unit of area. Employment density is measured by the quantity of jobs, businesses, or commercial/retail jobs or businesses that are located within a certain unit of area. Density variables have been calculated as an average surface density over a standard geographic unit such as within a 300-foot, eighth-, quarter-, half-, or one-mile radius from a specific point, or as an average density over a varying geographic unit such as a TAZ, Census block group, Census tract, neighborhood, or zip code. The specific point could be the location of a household or business, or the center of a unit such as a TAZ.

Local density — intensity of development or land use, either residential or employment — is expected to influence pedestrian travel behavior in several ways. Simply, higher densities should lead to higher cumulative measures of pedestrian travel, such as pedestrian volumes or miles of walking activity, because there are more people present in an area. More importantly, higher density areas are expected to see higher pedestrian trip frequencies and a higher rate of walking because destinations are closer together and thus trips are more viable by walking. Higher parking costs in areas of high density could also deter traveling by private vehicle. Finally, 
higher density areas are capable of sustaining more-frequent transit and may have better quality pedestrian environments, both of which should encourage walking.

A common dependent variable is walking trip frequency. Greenwald and Boarnet (2001) look at the number of non-work walking trips per person in Portland and find that population density (measured at the Census block group level) is significant with or without including trip cost variables, but only when a "grid-ness" variable is not included. Guo et al. (2007) investigate trip frequencies in the San Francisco Bay Area and find that population density (measured within a one-mile radius of home) is significant in predicting the number of non-motorized trips of both maintenance and discretionary purposes. On the other hand, the natural log of maintenance business density (measured within a quarter-mile radius of home) is significant only for discretionary non-motorized trips, and the natural log of discretionary business density (also measured within a quarter-mile radius of home) is significant only for both maintenance and discretionary non-motorized trips.

Another common dependent variable is mode choice. Cervero (1996) finds that the probability of commuting by non-motorized modes increases in the presence of high-density housing (mid- and high-rise multifamily buildings) within 300 feet of the household unit. Using San Francisco Bay Area data, Kitamura et al. (1997) find that high-density neighborhoods are significant in predicting the fraction of non-motorized trips. Looking at the same region, Cervero and Duncan (2003) find that that job density (measured within one mile of the origin) is not significant in predicting walking mode choice. However, when looking at the chance of walking for external trips to and from mixed-use developments, Ewing et al. (2011) find that employment density (measured outside but within one mile of the mixed-use development) is significant and positive in predicting walking mode choice for all trip purposes. In addition, they find that the combined density of population and employment within the mixed-use development is also significant and positive for the odds of walking for external home-based other and non-home-based trips. A meta-analysis by Ewing and Cervero (2010) found that employment density is less strongly related to walking than residential density.

Other studies have estimated pedestrian volumes. Lindsey et al. (2011) model pedestrian counts in Minneapolis and find that neighborhood population density is not significant in predicting pedestrian counts. Schneider et al. (2009), on the other hand, regress land use and transportation system variables, controlling for socioeconomics, and show that population density (measured within both tenth-mile and half-mile radii) and employment density (measured within a quartermile radius) are significant in predicting weekly pedestrian intersection crossings. The density of commercial properties (measured within both tenth-mile and quarter-mile radii) is also significant.

A few studies measure other aspects of walking activity. Li et al. (2005) find that both household and employment density are significant in predicting average self-reported walking activity levels in the neighborhood. Boarnet et al. (2008) use two-day walking distance as reported by individuals in Portland. They find that both population density (measured at the Census block group level) and retail employment density (measured at the TAZ level) but not total employment density (also measured at the TAZ level) are significant in predicting walking distance. Interestingly, these results are reversed when attempting to account for residential selfselection; only total employment density is significant. 
Small scale measures of density have also been tested and found to be insignificantly related to auto trip frequency. Boarnet and Crane (2001) look at the number of non-work auto trips for individuals in Orange County and Los Angeles, CA. They find that neither population density (measured at the Census block group level) nor retail or service employment density (both measured at the Census tract level) is significant in predicting auto trips. Boarnet and Greenwald (1999) perform a similar analysis using Portland data. They also find that neither population density (measured at the Census tract level) nor retail employment density (measured within a one-mile radius of home) are significant in predicting non-work auto trips per individual.

The literature contains mixed results for automobile trip frequency when density is measured at large scales. Boarnet and Greenwald (1999) find that population density has a positive association with automobile trip frequency when measured at the zip code level, when including only land use variables. They also find that retail employment density is only significant and negative when measured at the zip code level and when including land use, trip cost, and housing characteristics variables. Guo et al. (2007) find that population density (measured within a onemile radius of home) is a significant and negative predictor of the number of auto trips of both maintenance and discretionary purposes.

Using auto mode choice as the dependent variable has yielded similarly mixed results with density. Cervero (1996) finds that probability of commuting by automobile is reduced and the probability of commuting by transit is increased by the presence of mid- and high-rise multifamily buildings within 300 feet of the household unit. However, Kitimura et al. (1997) find that high-density neighborhoods are not significant in predicting the fraction of auto or transit trips. Chen et al. (2008) regress built environment and tour characteristics variables, controlling for socioeconomics and demographics, for the propensity to choose auto mode for home-based work tours in New York. They find that of population and employment densities (measured at the Census tract level of both home and work), only employment density at work is significant. It should be noted that non-motorized trips are removed from the data because Chen et al. think they are unlikely to compete with longer motorized trips. Finally, Zhang (2006) finds that population density at the origin and job density at the destination (both measured over a TAZ) are significant in predicting auto dependence in Boston.

One study creates a compound variable that includes many measures of density to investigate mode choice in the San Francisco Bay Area. Cervero and Kockelman (1997) construct an intensity factor, based on factors of retail store density, activity center density, retail intensity, walking accessibility to sales/service jobs, park intensity, and population density, measured at the neighborhood (Census tract) level. They find that this intensity factor is significant in predicting vehicle miles traveled (VMT) for non-work home-based trips (negative), non-single occupancy vehicle (SOV) mode choice for non-work home-based trips (positive), non-personal vehicle (PV) mode choice for non-work home-based trips (positive), and non-PV mode choice for personal business home-based trips.

The studies that include density or intensity-based measures of the built environment show that in general, they are significantly correlated with measures of pedestrian travel behavior. Higher residential or employment density is generally associated with higher non-motorized or walking trip frequency, the fraction of trips that use non-motorized or walking modes, and aggregate levels of walking volume or activity. However, it appears that the significance of the density 
measure may decrease as other measures of the built environment are added to the analysis. Furthermore, density has a much more mixed or insignificant record when correlated to motorized travel behavior. This suggests that localized density is a much more important influence on walking and non-motorized travel behavior than on vehicle trips.

Badoe and Miller (2000) comment on possible reasons why density may directly or indirectly affect pedestrian travel behavior. Their summary notes that the literature is consistent in finding that vehicle ownership is lower in higher-density neighborhoods, and that households with fewer cars use transit more and generate less VMT. This suggests that on aggregate, density impacts pedestrian travel more indirectly through vehicle ownership than directly.

The results of Greenwald and Boarnet (2001) begin to give direction about the scale at which density is important for pedestrian travel behavior. While they find that both population density and retail employment density are significant in predicting non-work walking trips per person when aggregated to the census block group level, both variables are not significant when measured for each zip code. Interestingly, Boarnet and Greenwald (1999) analyze the same data set (a 1994 Portland travel survey) instead for non-work car trips, and find that measures of population and retail employment density are significant only at the zip code level and not at the census block group level. These results suggest that density impacts travel behavior at different geographic scales for each mode; density is more important at the neighborhood level for walking trips, whereas density is more important at the regional level for driving trips.

One review provides guidance on the relative importance of residential and employment density. Badoe and Miller (2000) classify urban form impacts into four categories: residential density, employment density, accessibility, and neighborhood design. Some of the studies they reviewed find residential density to be the strongest indicator, while others discover a decreasing importance once other factors are included. Employment density shows consistently strong relationships. They suggest that the employment or activity center of a trip may be a much stronger driver of travel behavior than the residential side.

An empirical study by Greenwald and Boarnet (2001) also provides evidence to help determine the relative predictive powers of measures of the built environment. They individually regress four different land use variables, controlling for socioeconomics and demographics, for nonwork walking trips for individuals in Portland. They find that although all are significant individually, population density (measured at the Census block group level) is the strongest indicator, followed by retail employment density (measured within a one-mile radius of the home), pedestrian environment factor, and finally percentage of grid streets (measured within a quarter-mile buffer of the home).

\section{A.5.2 Land Use Mix / Diversity Variables}

Measurements of the diversity of land uses present in the built environment have also been captured to find relationships with pedestrian travel behavior. A wide range of measures have been developed, but most attempt to calculate the balance between residential and nonresidential uses over a unit of area. The assumption being that having a mix of land uses allows more needs (work, shopping, recreation, etc.) to be met within a closer area, reducing the need for multiple trips and increasing the chance of walking to meet those needs. 
Cervero (1996) was one of the first to investigate the influence of mixed land use on commuting mode choice. While the presence of commercial or non-residential buildings within 300 feet of the household unit significantly decreases the odds of commuting by automobile and increases the odds of commuting by transit and non-motorized modes, this influence is much greater for the walking/biking model. The author notes that the presence of mixed uses has a stronger effect on walking and biking than it does on commuting by auto or transit. Similarly, the presence of a grocery or drug store between 300 feet and one mile of the household unit significantly increases the odds of commuting by automobile and decreases the odds of commuting by transit and nonmotorized modes. The author hypothesizes that this is because the personal vehicle is better suited to reach destinations on the way to or from work that are nearby but just outside the immediate neighborhood.

Other studies have investigated the presence or percentage of mixed land uses along a street segment. Desyllas et al. (2003) create an urban pedestrian model for Central London and find that of land use variables, only the percentage of retail street frontage is significant in predicting sidewalk pedestrian flows. Boarnet et al. (2011), in the Irvine Minnesota Inventory, find that the presence of few vertical mixed-use buildings is significant and positive in predicting weekly miles of travel walking reported in diaries. Cervero and Kockelman (1997) find that the proportion of vertical mixed use buildings on one parcel in a neighborhood is significant in predicting personal vehicle VMT for non-work home-based trips.

Since measuring land use diversity is not straightforward, many studies have created their own factors or indices. Cervero and Duncan (2003) create a land use diversity factor, based on factors of land use entropy, employed residents-to-jobs balance index, and employed residents-toretail/service-jobs balance index. They find that this land use diversity factor is only significant in predicting the probability of a trip being made by walking when measured at the origin. The land use diversity measure of Guo et al. (2007) is a mix variable with a range where -1 means solely one land use and 1 means equal amounts of all three land uses. They find that this land use mix variable, measured within a quarter-mile buffer of home, is significant and negative only in predicting the number of discretionary auto trips. Ewing et al. (2011) find that their mixed-use index, with a range of 0 (only jobs or residents) to 1 (population is five times jobs), is significant in predicting the chance of walking for external trips to and from mixed-use developments for only home-based trips. A dissimilarity index developed by Cervero and Kockelman (1997), based on the number of changes in land use surrounding a grid cell, is found to be significant in predicting non-SOV mode choice for non-work home-based trips.

In addition to the dissimilarity index, Cervero and Kockelman (1997) create a measure of land use entropy that is used in several subsequent studies. This entropy equation is $\left(\sum_{k}\left(\sum_{j} p_{j k} \ln p_{j k}\right) / \ln (J)\right) / K$ where $J$ is the number of land use categories, $K$ is the number of developed hectares in a Census tract, and $p_{j k}$ is the proportion of land use category $j$ within a certain radius of the developed area surrounding hectare grid-cell $k$. This entropy measure is designed to range from a value of 0 (homogeneous, only one type of land use) to a value of 1 (heterogeneous, all land use types have equal area). However, unlike the dissimilarity index, Cervero and Kockelman (1997) find that their land use entropy measure is not significant in predicting mode choice. Similarly, Zhang (2006) finds that land use entropy is not significant in predicting auto dependence using logit models. Ewing et al. (2011) predict the chance of walking for external trips to and from mixed-use developments, and find once again that land use entropy 
is not significant. A meta-analysis by Ewing and Cervero (2010) suggests that jobs-housing balance has a stronger relationship to walking than land use entropy.

These studies suggest that land use mix is a significant influence on pedestrian travel behavior, but with limitations. For example, most of the studies suggest that mixed land use is only significant at the home end of trips and for non-work or discretionary trips only. This makes some sense, since a mix of nearby land uses may only be helpful if one wants to visit those different land uses, say for shopping. Zhang (2006) suggests that the effect of changing land use is to change the choice set of modes available to a traveler. These results also indicate that the mix measure itself is very important in determining significance. The consistently insignificant nature of the land use entropy measure developed by Cervero and Kockelman (1997) indicates that their definition of entropy is not a good explanatory measure.

\section{A.5.3 Network / Connectivity Variables}

Another way to capture information about the built environment that has grown in popularity is through some measure of the street or sidewalk network. Measures of the street network attempt to capture the ease, options, and directness of walking within a neighborhood. It is thought that areas that are more connected make it easier and faster, and therefore more likely, to make shorter walking trips. These variables are also relatively simple to calculate and can be objectively measured and transferred through the use of a GIS-based representation of the street network.

Three common measures of the street network include block density, intersection density, and grid-ness. Block density is measured by the number of blocks (land completely surrounded by streets) within a certain unit of area. Block density is usually calculated as an average density over a standard geographic unit such as a quarter-section, square mile, or within a radius from a specific point. An alternate way to measure block density is by measuring block size in units of area or circumference. Intersection density is measured by the number of a specific type(s) of intersections (typically all, only four-way, or three- and four-way) that are located within a certain unit of area. Similar to population density, intersection density has been averaged over a standard geographic unit such as within a half- or one-mile radius of a specific point or a varying geographic unit such as TAZ. Grid-ness is somewhat subjective and less easy to define, but is usually measured by the percentage of a certain unit of area that has a grid-like or rectilinear street network pattern. Again, grid-ness can be calculated as an average over a buffer from a specific point or averaged over a varying unit like TAZ, census block group, census tract, or zip code.

Few studies measure block density on its own; most combine this variable with others to create a pedestrian or connectivity factor. For examples, see the Pedestrian Environment Factor section below. However, one study, Guo et al. (2007), does use the number of blocks within a one-mile radius as a measure of the transportation network. The authors find that block density is significant in predicting the number of non-motorized trips of both maintenance and discretionary types, but not significant in predicting the number of auto trips. This result suggests that the structure of the street network has different effects on people walking and driving. 
Intersection density, which is in most cases is an approximately equivalent measure to block density, is more commonly used as an independent variable as opposed to being a component of an index. Interestingly, no study reviewed has used both variables in the same model estimation. Boarnet et al. (2008) show that the number of intersections in a TAZ is significant in predicting miles walked per day. They also report that this measure is more statistically significant than the percentage of four-way intersections within a half-mile radius. Intersection density within mixeduse developments is significantly related to the odds of using walking mode for external nonhome-based trips according to Ewing et al. (2011). In Li et al. (2005), the number of intersections per neighborhood is significantly associated with neighborhood average levels of walking activity. However, the number of intersections (measured within a half-mile radius of home) is only significantly associated with individual walking activity levels among those who feel that traffic is not a problem in their neighborhood.

Some studies test a slightly different measure: the percentage of four-way intersections within a given area. Boarnet and Crane (2001) cite results of Kulkarni (1996) as a strong motivation for testing this variable, which they average over a quarter-mile radius and find to be not significant for predicting non-work auto trips. Conversely, Cervero and Kockelman (1997) find that the percentage of four-way intersections within a census tract is significant in predicting non-work VMT and non-work non-SOV mode choice. Zhang (2006) uses the percentage of four-way intersections in a TAZ as the only measure of street connectivity and shows that it is significantly related to auto mode choice.

A closely related measure to four-way intersection density is grid-ness. Few studies have tested grid-ness by itself; this variable is more commonly used as one component of a pedestrian environment factor. Cervero and Kockelman (1997) find that the proportion of quadrilateral blocks within a census tract is significant and positive in predicting personal vehicle VMT for all trips and for non-work home-based trips. Boarnet and Greenwald (1999) measure grid-ness within a quarter-mile buffer and show that it is not significant in predicting non-work car trips at any geographic scale. Greenwald and Boarnet (2001) repeat the same analysis for non-work walk trips and show that grid-ness is only significant when used as the sole built environment variable, and that it is less strong than population density, retail employment density, or even the compound pedestrian environment factor. These results suggest that grid-ness is a poor explanatory measure of the pedestrian environment and should become less important as other better measures of the built environment are included.

The sidewalk network can also be measured. Sidewalk continuity is usually measured by the completeness of sidewalk facilities along a street segment, and can be calculated at the streetsegment level or aggregated across a TAZ, census block group, census tract, or zip code.

Sidewalk completeness is measured in Moudon et al. (1997) and Boarnet et al. (2011) and shown to be significant in predicting pedestrian volumes and walking miles per week, respectively. This measure is also used in pedestrian environment factors with mixed results.

A few other novel ways of calculating network and connectivity can be found in the literature. Route directness has been measured as the percentage of area within a half-mile radius that can be reached by a half-mile walk from a specific point. Moudon et al. (1997) show that route directness is significant in predicting pedestrian volumes between commercial and residential land uses in neighborhood centers. The visibility of a street grid has been measured as the 
quantity or area of the pedestrian realm that is visible within a direct line of sight from a specific point. Desyllas et al. (2003) show that street visibility is a strong predictor of pedestrian flow for street segments in central London.

This look into the testing of variables to represent the network or connectivity of the street system reveals important results about the representation of the built environment. Measures that try to capture how "grid-like" a street network is, either through the percentage of four-way intersections or the percentage of area that is rectilinear, show mixed results and are significant only when used as the sole street network variable. This indicates that grid-ness is likely correlated with a stronger measure of the street network. Block and intersection density, which are two related ways to represent the density of streets or path options, are more consistently significant, but may be applicable only to walking trips and not trips of other modes.

Experimentation with other measures of the street or sidewalk network may yield fruitful results. For example, a promising but underutilized measure is route directness. Instead of using intersection or block density to represent how well connected an area is, Moudon et al. (1997) actually calculate connectivity directly through their route directness measure. One possible option for calculating route directness for use in a travel demand model is to average this value, measured at each intersection, over all of the intersections in a TAZ.

\section{A.5.4 Mobility and Accessibility Variables}

Measures of mobility document the nearby availability of infrastructure or routes of different transportation modes. For example, the presence of shared-use paths or bicycle lanes/routes has been measured. The most common mobility measure is that of transit access. This can be represented as the simple presence of a transit route along a street segment, the distance (or number of turns) from the nearest transit stop or rapid transit station, or the number of transit stops or rapid transit stations within a tenth- or half-mile radius. The presence of non-motorized infrastructure should encourage more trip-making by non-motorized modes. The availability of transit service may decrease vehicular trip-making or auto ownership and thus increase walking trips (not just to access transit), or be correlated with denser land uses and more destinations.

The nearby availability of non-motorized infrastructure such as off-street paths and bikeways is rarely measured and shows mixed results when done so. Kitamura et al. (1997) regress measures of five San Francisco Bay Area neighborhoods for mode choice and trip frequency by mode, and find that the presence of sidewalks and/or bike paths is only significant in predicting the number of non-motorized trips. Guo et al. (2007) investigate the impact of land use, density, and network measures of the built environment on trip frequencies, also in the San Francisco Bay Area. They find that the density of bikeways (measured within a one-mile radius of home) has a significant and positive impact on the number of both maintenance and discretionary non-motorized trips, but not on the number of auto trips. Interestingly, the density of highways (also measured within a one-mile radius of home) is only significant and negative for the number of discretionary auto trips and not non-motorized trips. Using a different region, Boarnet et al. (2011) come to the opposite conclusion and find that the presence of greenbelts and other paths along a street segment is significant and unexpectedly negative in predicting weekly miles of leisure walking reported in diaries. 
These results suggest that the nearby availability of non-motorized infrastructure probably has little impact on vehicular trip frequency. Although non-motorized trip frequency is likely positively influenced by the nearby availability of non-motorized infrastructure, this influence may be stronger on discretionary/leisure/recreational trips than on mandatory/work trips. To summarize, creating off-street multi-use paths or on-street bicycle infrastructure may increase the frequency of non-motorized trips, particularly for recreation or leisure, but is unlikely to decrease driving trips.

Mobility as measured by transit accessibility is more commonly tested and shows stronger and more consistent correlative results. The San Francisco Bay Area is a popular region for studies of this kind. Regressing neighborhood measures for mode choice and trip frequency by mode, Kitimura et al. (1997) find that access to BART is only significant in predicting the number of non-motorized trips. Not surprisingly, they also find that the distance to the nearest rail station is significant and negative in predicting both the number and fraction of transit trips. Looking at local transit, they find that the distance to the nearest bus stop is only significant in predicting the fractions of auto trips (positive) and non-motorized trips (negative). Investigating the impact of land use, density, and network measures of the built environment on trip frequencies, Guo et al. (2007) find that the presence of transit is only significant and positive in predicting the number of discretionary non-motorized trips. Taking a slightly different look, Schneider et al. (2009) regress land use and transportation system variables, controlling for socioeconomics, and show that the density of regional rail stations (measured within both tenth-mile and quarter-mile radii) and the density of bus stops (measured within a tenth-mile radius) are significant in predicting weekly pedestrian intersection crossings.

The nearby availability of transit also been analyzed in other regions with similar results. Desyllas et al. (2003) create an urban pedestrian model for Central London and find that accessibility to a Tube station, based approximately on the number of turns, is significant in predicting sidewalk pedestrian flows. Boarnet et al. (2008) regress land use variables, controlling for socioeconomics and demographics, for two-day walking distance as reported by individuals in Portland. They find that the distance from the nearest light rail station is significant and positive in predicting walking distance per day. Chen et al. (2008) regress built environment and tour characteristics variables, controlling for socioeconomics and demographics, for the propensity to choose auto mode for home-based work tours in New York. They find that the distance from the nearest transit stop to home and to work are both significant. They also find that of job accessibilities to both home and work via auto and transit (calculated as the weighted sum of jobs in and distances to all Census tracts), only job accessibility at work by transit is significant.

The results of these studies indicate that the nearby availability of transit is correlated to increased amounts of active (non-motorized) transportation through both trip frequencies and mode choice. However, it appears that different types of transit service (regional rail, light rail, local bus) may have varying levels of effect. The results of Schneider et al. (2009) suggest that regional rail has a larger or wider effect on walking than local bus-based transit. One major limitation of these studies is that they do not consider the frequency of transit service, only its presence. 
Measures of accessibility mirror those of mobility except they document the nearby availability of non-transportation-related destinations. The presence of or distance to parks and other recreation facilities has been measured. The presence of strip malls, drive-through retail businesses, and coffee shops along a street, the distance to the central business district or other commercial destinations, and the number of grocery or drug stores within a certain radius have also been measured. The closeness of land uses and other destinations should influence walking at least through decreased trip costs.

Accessibility to areas of recreation such as parks and open spaces has been found to influence travel behavior in expected ways. Li et al. (2005) find that the area of green and open space for recreation is significant in predicting both neighborhood average and individual self-reported walking activity levels when measured over the entire neighborhood and within a one-half mile radius of home, respectively. Kitimura et al. (1997) find that, for five San Francisco Bay Area neighborhoods, the distance to the nearest park is significant in predicting the fraction of auto trips (positive), the number and fraction of transit trips (negative), and the fraction of nonmotorized trips (negative). Similarly, Boarnet et al. (2011) find that the presence of attractive playing or sports fields is significant and positive in predicting weekly miles of travel walking reported in diaries.

The Irvine Minnesota Inventory, reported by Boarnet et al. (2011), captures accessibility to some types of land uses and shows that the presence of coffee shops and strip malls or rows of shops are both significant and positive in predicting weekly miles of total and leisure walking reported in diaries. Unexpectedly, the presence of drive-thru retail is also significant and positive in predicting weekly miles of travel walking reported in diaries. Finally, Boarnet et al. (2008) regress land use variables, controlling for socioeconomics and demographics, for two-day walking distance as reported by individuals in Portland. Not surprisingly, they find that the distance from City Hall is significant and negative in predicting walking distance per day.

These studies indicate that accessibility to specific types of pedestrian-attracted land uses, parks and recreational open space in particular, has a positive effect on the frequency, share, and/or quantity of walking. However, it seems like these effects may only be applicable for some types of land uses, which may depend on how they are defined or their urban context.

\section{A.5.5 Street and Other Urban Design Variables}

Variables that describe the design or other characteristics of the built environment of the urban fabric or individual streets come in all types. The wide range of measures and proposed significant variables indicates that the street-level built environment's influence on pedestrian travel behavior is not well understood. Indeed, many of the variables used could be considered to be qualitative or amenity/nuisance type variables. Sidewalks are one of the most common things studied. Another consideration is the quality or ease of crossing the street at intersections as measured by the type of traffic control, the presence of curb cuts, or the type of pedestrian crossing markings. Aspects of the roadway such as number of lanes, speed limit, and traffic volume have also been measured. Other street design variables investigated include the presence of abandoned buildings or lots, visible electric wiring, having a high number of driveways, and the presence of dumpsters. 
Most studies that have considered the impact of the presence, size, or condition of sidewalks on walking travel behavior have found significant and positive relationships. Cervero and Kockelman (1997) find that average sidewalk width is significant and positive in predicting nonpersonal-vehicle mode choice for non-work home-based trips in the San Francisco Bay Area. Desyllas et al. (2003) create an urban pedestrian model for Central London and find that sidewalk width is significant in predicting sidewalk pedestrian flows. Boarnet et al. (2011), in the Irvine Minnesota Inventory, find that both the presence of a sidewalk in good condition and the presence of a buffer between the sidewalk and street are significant and positive in predicting weekly miles of total and travel walking reported in diaries.

Fewer studies have examined aspects of pedestrian crossings of streets or metrics of streets themselves. The Irvine Minnesota Inventory does consider street crossings and reports findings consistent with expectations. Boarnet et al. (2011) find that the presence of curb cuts at all crossings and the presence of stop signs are both significant and positive in predicting weekly miles of total and travel walking reported in diaries. Not surprisingly, the absence of any curb cuts at crossings is significant and negative in predicting weekly miles of total and travel walking. Also, the presence of a mid-block crossing (and it being marked with white lines, zebra lines, or other) is significant (and positive) in predicting weekly miles of travel walking reported in diaries.

Two studies have investigated specific aspects of the roadway being crossed or the adjacent street, with mixed results. Boarnet et al. (2011) find that both two lanes and four lanes of traffic on the street are significant (and negative and positive, respectively) in predicting weekly miles of total and travel walking reported in diaries. A posted speed limit of 25 miles per hour is significant and positive in predicting weekly miles of total walking. McGinn et al. (2007) find that low traffic volume, based on a summary score of interpolated average annual daily traffic values and measured within a one-mile and eighth-mile radius, is significant and negative in predicting daily walking duration, and significant and positive in predicting non-motorized transportation activity in minutes per week, respectively. They also report that low crash rates, based on a summary score of pedestrian and bicycle crashes and measured within one-mile and half-mile radii, is significant and negative in predicting daily walking duration.

Some studies investigate parking's effects on travel behavior, also with inconclusive results. Cervero and Kockelman (1997) find that the proportion of non-residential parcels with front- or side-lot on-site parking is significant in predicting non-SOV mode choice for non-work homebased trips (negative) and non-PV mode choice for non-work home-based trips (positive) in the San Francisco Bay Area. Also looking at same region, Kitimura et al. (1997) find that the presence of available parking spaces is significant and positive in predicting the fraction of auto trips but significant and unexpectedly negative in predicting the number of auto trips. Boarnet et al. (2011) find that garage doors that are not very visible and the number of driveways are both significant and negative in predicting weekly miles of total and travel walking reported in diaries.

The large scale of the Irvine Minnesota Inventory (Boarnet et al., 2011) allows for the testing of many other streetscape micro-level urban form details, with mixed results. Visible overhead electrical wiring is significant and positive in predicting weekly miles of leisure walking. The presence of an attractive open view is significant and positive in predicting weekly miles of 
travel walking. Interestingly, the presence of abandoned buildings or lots is significant and unexpectedly positive in predicting weekly miles of total walking. Also, the presence of unattractively maintained buildings is significant and unexpectedly positive in predicting weekly miles of total and travel walking. The presence of dumpsters is significant and positive in predicting weekly miles of total and leisure walking reported in diaries. Also, the presence of menacing dogs is significant and negative in predicting weekly miles of travel walking reported in diaries. The wide array of possible street design variables and the mixed and unexpected results from the Irvine Minnesota Inventory suggests that these factors are not consistently significant and/or their influence is poorly understood.

Most street and urban design variables are applied at the level of an individual street segment or sidewalk segment and used to calculate a quantity of walking (either as total miles traveled per day or week or a volume of persons per hour). Only rarely are street design variables aggregated to a larger unit of area such as the TAZ or Census block group. However, Cervero and Kockelman (1997) construct a walking quality factor, based on factors of sidewalk provisions, street-light provisions, block length, planted strips, lighting distance, and flat terrain, measured at the neighborhood (Census tract) level in the San Francisco Bay Area. They find that this walking quality factor is significant in predicting non-SOV mode choice for non-work home-based trips (positive); non-PV mode choice for non-work home-based trips (positive); non-PV mode choice for personal business home-based trips; and non-PV mode choice for work home-based trips.

While the presence of sidewalks seems to be consistently significant and positive in predicting walking, this review echoes that of Badoe and Miller (2000), who find that micro-level neighborhood design impacts on travel behavior are mixed. The wide range of measures and differences in significant variables indicates that the street-level built environment's influence on pedestrian travel behavior is not well understood and likely less strong than larger-scale measures of the built environment. Also, even if strong relationships were found between the street-level built environment and pedestrian travel behavior, the large requirements for data collection and processing would likely yield diminishing returns of explanatory power.

\section{A.5.6 Pedestrian Environment Factor}

The correlation of many of the above aspects of the built environment to travel behavior, especially walking, is mixed and sometimes insignificant. It can be hypothesized that this is the result of many smaller relationships, such as those of street crossings and sidewalk continuity or other street design factors, being insignificant on their own; however, when taken together, they may prove significant in explaining some amount of pedestrian travel behavior. Thus, some compound pedestrian environment variables have been developed and tested in various studies.

One aspect of the LUTRAQ (Making the Land Use, Transportation, Air Quality Connection) project in Portland during the 1990s attempted to improve the accuracy of travel demand models by incorporating such a factor. This "Pedestrian Environment Factor" (PEF) is an equally weighted compound factor of four parameters, each rated somewhat subjectively on a three-point scale. Ease of street crossings is a measure of the width, signalization, and traffic volume of key intersections. Sidewalk continuity is a measure of the extensiveness of sidewalks on principle arterials, transit streets, and neighborhood collectors. Street system connectivity is a measure of the extent of grid patterns and distances between intersections. Topography is measured based on 
steepness of sloping terrain. The LUTRAQ report states that the PEF, measured for each TAZ, significantly improved the auto ownership, destination choice, and mode choice components of Portland's model (Parsons Brinckerhoff Quade and Douglas, Inc., Cambridge Systematics, Inc, and Calthorpe Associates, 1993).

Many studies since the LUTRAQ project have attempted to correlate the PEF with pedestrian travel behavior, with limited success. Boarnet and Greenwald (1999) regress land use variables, controlling for socioeconomics, demographics, and trip costs, for trip frequencies as reported by individuals in Portland. They find that the PEF, measured for the home location at both the Census tract and zip code levels, is not significant in predicting the number of non-work auto trips. Looking at the same data, Greenwald and Boarnet (2001) conclude that the PEF, measured for the home location at the Census block group level, is also not significant in predicting the number of non-work walking trips. In fact, they find that the PEF score is only significant when it is the sole land use variable. Also using Portland data, Boarnet et al. (2008) find that the PEF of a neighborhood is not significant in predicting walking distance per day.

Two studies create different compound factors using mostly connectivity or network-based variables. Cervero and Duncan (2003) construct a pedestrian-/bike-friendly design factor, based on factors of block size, proportion of three-way intersections, proportion of four-way intersections, proportion of five-way intersections, and proportion of dead ends, all measured within one mile. They show that the ped/bike friendly design factor is not significant in predicting the probability of walk mode choice for either the origin or the destination. On the other hand, McGinn et al. (2007) find that high street connectivity, based on a summary score of the number of street segments, ratio of street segments to intersections, average length of street segments, density of 3+-way intersections, and Census block density, and measured within an eighth-mile radius, is significant (and negative) in predicting daily walking duration.

Taking a different tactic, Kim and Yamashia (2011) regress five compound measures of the street-level built environment (cleanliness, landscaping, environment, amenities, and nuisance) for pedestrian volumes in Waikiki. Some of these measures are subjective and others are objective. Cleanliness includes litter, detritus, stains, graffiti, and postings; landscaping includes plant health and sidewalk adjacent coverage; environments include sidewalk widths, sidewalk continuity, pavement materials, pavement conditions, lighting, signage, and street furniture; amenities includes curb ramps, shade, protection from elements, and seating; and nuisance includes noise levels, odors, panhandling, sex solicitation, homelessness, etc. They find that although each measure is significant when included alone, only the landscaping and environment scores are significant when all five measures are included.

This mixed record of compound factors of the pedestrian-level built environment, and the insignificance of the PEF in particular, indicates that these types of compound variables should be treated with caution. The PEF and other compound measures obscure the underlying aspects of the built environment, making causal relationships harder to judge. Without clear documentation, the formulation of a compound index measure can be missed, giving practitioners and researchers a lack of understanding on how to set policies that change built environment features to achieve some increase in the PEF or some other compound variable. In addition, the creation of compound factors can involve a level of subjectivity in both the selection of variables and their weight. We show in this project that developing a compound 
index variable for the pedestrian-scale built environment is a useful way to account for high correlations between individual urban form variables that result in a useful way to assess walk mode choice. However, we pay careful attention to its formulation to show that it is objective and practical.

\section{A.5.7 Attitudes and Perceptions}

Attitudes and perceptions about the built environment also have the potential to influence pedestrian travel behavior, yet few studies have attempted to determine and quantify these relationships. Part of the problem is that these factors likely depend to a great degree on characteristics of the individual traveler and less so on the actual built environment around them. For example, a household that is inclined to seek walking opportunities may decide to locate in an area they consider walkable and thus walk more.

Some studies find that perceptions of the built environment are significant in predicting walking travel behavior. Li et al. (2005) find that considering one's neighborhood to be safe to walk in is significantly related to higher levels of individual self-reported walking activity. Boarnet et al. (2011), in the Irvine Minnesota Inventory, find that a neutral rating for the (design and maintenance) attractiveness of a street segment is significant and positive in predicting weekly miles of leisure walking reported in diaries, but that a positive rating for the attractiveness of a street segment is significant and unexpectedly negative in predicting weekly miles of leisure walking reported in diaries. On the other hand, Kitamura et al. (1997) find that perception-based measures of the quality of a neighborhood (such as pleasant for walking and cycling, enough transit service and parking, and no traffic congestion problems) are insignificant in general.

To consider the relative impacts of perceptions on travel behavior, Cao et al. (2005) ask Austin, TX, residents about their perceptions of aspects of their neighborhood built environment (safety, shade, traffic, and people), and regress for strolling frequency, controlling for residential location choice. They find that both perceptions of shade and safety are significant in predicting strolling frequency, sometimes more importantly than self-selection. When investigating walking to the store frequency, however, they find that self-selection factors are the strongest, although some perceptions of traffic and comfort are also significant. Results show that residential self-selection can be a strong factor in determining the prevalence of walking.

These attitudinal variables are difficult to define and measure. McGinn et al. (2007) noted little agreement between perceived and objective measures of the built environment. Furthermore, affecting peoples' perceptions of the built environment in order to impact travel behavior is currently a less common policy issue than directly changing the built environment to affect travel behavior changes. This is an important area of research, but one that will be set aside for the remainder of this paper.

\section{A.6 CRITICISMS}

\section{A.6.1 Criticisms in the Literature}

One limitation of investigating the relationship between the built environment and pedestrian travel behavior is the difficulty of consistently defining and measuring built environment 
variables. Frank and Engelke (2001) claim that two reasons for inconsistent results relating urban form to travel behavior are the different ways of measuring and aggregating independent variables and the lack of non-motorized data and longitudinal studies. Handy et al. (2002) also note that data on the built environment and walking travel are limited. While Saelens and Handy (2008) conclude that aesthetic qualities of the walking environment are associated with more walking, they also note that measures of these aesthetic qualities are especially variable across studies. Although suggesting that multivariate statistical studies are more methodologically sound than descriptive studies, Crane (2000) describes the difficulties of selecting urban form variables, controlling for other independent influences, and regressing. Badoe and Miller (2000) suggest that the mixed significance of residential density on travel behavior is because it ignores the important consideration of connectivity or accessibility to destinations. They also note that neighborhood design variables are also mixed in impact, in great part due to the fact that people do not travel solely within their own neighborhood.

The lack of consistent measures of the built environment and consistent conclusions about relationships indicates that a larger problem is at play: there is little consensus on the theoretical relationships between the built environment and pedestrian travel behavior. Frank and Engelke (2001) note this lack of consensus on the theoretical relationships between urban form and travel behavior in general. Boarnet and Crane (2001) propose that travel behavior can be explained by filling an economically derived demand for travel. However, Handy et al. (2002) note that walking behavior is less likely to be explained solely by a derived-demand perspective of travel behavior, and suggests that the quality of the walking experience may be as important as the utility of travel. Crane (2000) notes that "the literature on the transportation impacts of urban form has rarely employed a strong conceptual framework when investigating these issues, making both supportive and contrary empirical results difficult to compare or interpret." Very recently, however, Schneider's Theory of Routine Mode Choice Decisions (2013) has established a conceptual framework upon which relationships beyond a derived demand perspective between walking and the environment may be tested. This travel theory is based on socioeconomic characteristics, awareness and availability, safety and security, convenience and cost, enjoyment, and habit. The theory is supported through qualitative interviews but it has not yet been extensively tested by others.

Further complicating the understanding of pedestrian environment relationships is the cocorrelation between built environment variables that have been correlated with walking. Crane (2000) notes that shortcomings of studies that examine the influence of urban form on travel behavior include the need to disentangle the effects of the land use and the built environment from socioeconomic and demographic effects that may be correlated. Frank and Engelke (2001) also note that the covariance of urban design variables is one reason for inconsistent results relating urban form to travel behavior. Finally, Saelens and Handy (2008) speculate on the relationships between correlates of walking. While their review of reviews finds that accessibility (based on distance to destinations), mixed land use, and density are all associated with more walking, they say that all three are related to the proximity of destinations. They also speculate that land use and density may affect walking (only or mostly) through their influence on aesthetic qualities of the walking environment.

The final major criticism of the way in which linkages between the built environment and pedestrian travel behavior are studied is the limited ability to demonstrate causal rather than 
simply correlative relationships. Crane (2000) criticizes various types of studies that examine the influence of urban form on travel behavior, noting that descriptive studies in particular use results of travel behavior but do not attempt to explain that behavior. Handy et al. (2002) notes that the "causal mechanism that might link the built environment to travel behavior has been given limited attention by researchers." They suggest that different causal mechanisms may apply in different situations, and speculate that the built environment may impact travel behavior indirectly through longer-term attitudinal changes. Handy et al. conclude by stating that "Not only has the existence of a causal relationship not yet been established, the nature of potential causal relationships is poorly understood."

\section{A.6.2 Criticisms from the Research Team}

This literature review has revealed similar limitations in the study of the built environment's influence on pedestrian travel behavior. Data that describe pedestrian travel behavior are very limited because pedestrians are not the focus of most data collection efforts and such data are more costly to collect. In addition, the pedestrian data that are collected and the method of collection vary between regions and studies, making comparisons difficult. Finally, a common source of pedestrian travel data, regional household travel surveys, is known to systematically undercount shorter pedestrian trips both because respondents are more likely to forget about or not consider short walking trips as reportable trips and because of poor survey structure.

Data describing the built environment have similar characteristics that constrain their use. Most regions do not have detailed information on aspects of the built environment beyond those of land use densities and street networks, and collecting more detailed data is an expensive and time-consuming proposition. Again, the lack of standard data sets between regions makes it tough to compare impacts of the built environment.

The inconsistent use and measurement of the built environment is another limitation to the understanding of its influence on pedestrian travel behavior, due in part to variations in available data. The many different ways in which the street network and land use diversity, for example, are measured make it very difficult to come to conclusions about possible relationships. Also, the scale at which densities are measured or aggregated is not consistent across studies and has been shown to yield different results. Furthermore, most studies assume built environment variables are linearly related to measures of pedestrian travel behavior, despite the lack of evidence to say whether these relationships are linear or of another form (such as threshold-based). Finally, characteristics of the built environment itself generate problems. In particular, many measures of the built environment (such as residential density, intersection density, and sidewalk completeness) are often correlated among themselves. This covariation of built environment correlates of pedestrian travel behavior makes it difficult to isolate influences and relationships.

Studies may use different variables to represent the built environment not only because there is limited data available for each study, but also because there is an inconsistent and poorly understood theoretical basis for relationships between the built environment and pedestrian travel behavior. Some authors claim that the built environment only influences travel behavior by adjusting measures of the utility of travel, such as travel distance, time, and cost. Others suggest that the built environment does influence pedestrian travel behavior by also affecting the quality of trip-making. Still other authors claim that most of the impact of the built environment on 
pedestrian travel behavior that is observed can be explained by self-selection of residential location: those who want to walk move to built environments where they can do so more easily.

These criticisms and limitations suggest ways in which researchers of the built environment's impacts on pedestrian travel behavior can improve the knowledge. Possibly most importantly, this field needs a comprehensive research objective to test different behavioral theses and help direct research in the most beneficial direction. While many research projects are generated and conducted based on local or regional needs, a national or international framework for such research is valuable. Also, authors should specifically state the theoretical bases for their selection of independent variables and pay close attention to how those variables are calculated. Although different data is available in different regions, some standards over the measurement and calculation of these variables may be useful. Variable formulations that have proven consistently insignificant, such as grid-ness and land use entropy, should be discarded. Also, the development of compound factors like the PEF should occur with particular attention to the underlying attributes.

\section{A.7 RECOMMENDATIONS}

This literature review suggests ways to approach the process of analyzing pedestrian travel data with respect to the built environment to improve regional travel demand models' representation of pedestrian travel behavior. For example, the analysis should control for demographic, socioeconomic, and vehicle-ownership characteristics before considering the built environment. When the built environment is considered, the analysis should move beyond linear regression to determine correlative significance and instead begin to describe the relationships in more detail. Is there a threshold beyond which the relationship changes? Does the magnitude of the relationship change across the spectrum of possible built environments? How does the relationship change when the built environment is measured at a small spatial scale versus over a larger geographic area?

The literature review also provides guidance in terms of built-environment variables on which to focus. Density at the local level, especially residential density, should be considered for walking mode choice, and perhaps for pedestrian trip frequency. On the other hand, larger-scale density is more appropriate for auto trip frequency. Employment density should also be considered, especially for work or shopping trips. Different measures of mixed land use should be investigated, since land use diversity seems to influence pedestrian travel behavior, especially for home-based and non-work trips. However, the land use entropy variable is unlikely to be useful.

Intersection density will probably be the strongest yet simplest measure of the street network, although it applies mostly to pedestrian and not automobile trips. Yet, it may not be an obvious driver of travel behavior. There might be more direct routes for pedestrians when there are more intersections, but intersection density may be a proxy for other, more important variables such as short distances between activity locations and limited or expensive parking. Intersection density also provides limited policy-sensitivity because the quantity of intersections is generally stable over time. Experimentation with other measures of the street or sidewalk network, such as direct measures of connectivity and route directness (Moudon et al. 1997), may be useful. Including the presence of nearby non-motorized infrastructure (such as bike lanes or paths) is probably not helpful, especially not for mode choice. Similarly, transit accessibility is more valuable when 
looking at walking-to-transit tours rather than just walk-only trips. If the analysis model needs more explanatory power, only then should the addition of smaller-scale design aspects like parks and open space, sidewalk condition, and street crossings be considered. The use of compound variables to measure the built environment, such as the PEF, should occur with caution.

Compound variables or indices allow for many correlated variables to be accounted for at the same time, but the real value of the results is the underlying measures that correspond to particular values of the index. We present in this project a compound variable that represents the built environment to analyze walk mode choice, but we pay careful attention to the formulation of the index and highlight the details of its composition in order for practitioners and researchers to understand it and to use it appropriately. 
A-26 


\section{APPENDIX B. REPRESENTING PEDESTRIAN TRAVEL IN REGIONAL TRAVEL DEMAND FORECASTING MODELS}

Metropolitan planning organization (MPO) forecasting processes are under pressure to address policy concerns including air quality, public health, climate change, energy and environmental sustainability, and equity. To support such evaluations, many policymakers demand tools that better represent the interconnected relationships of activities, travel, and land use. MPOs move in this direction by expanding the representation of pedestrian or non-motorized modes in their regional travel demand forecasting models.

Pedestrian modeling improvements can make forecasting tools more sensitive to predicting the mode shift effects of economic changes and policy interventions, such as higher energy prices and smart-growth strategies. Travel models can then be used in the evaluation of long-range regional plans dealing with both transportation investments and land use development scenarios, informing planning decisions at regional and municipal levels. At the same time, a more detailed representation of walking travel behavior assists local planning studies for non-motorized modes, such as predicting the usage of new non-motorized facilities or the mode shares at transit-, bicycle-, and pedestrian-oriented developments.

Although the first regional travel models to include non-motorized modes appeared over 20 years ago (Cambridge Systematics Inc. and Barton Aschman Associates, 1994; Purvis, 1997), current regional pedestrian modeling practices vary considerably. The challenges non-motorized modelers face include limited quantities and ranges of non-motorized travel behavior data, insufficient modeling resources and expertise, and even lack of decision-maker interest. Many smaller and some larger MPOs still exclude non-motorized travel from their models.

At the same time, other MPOs are pushing ahead with advances. Improved computing capabilities in data processing allow for disaggregate analyses of travel behavior at a scale more compatible with walking. Data on walking use and the pedestrian environment are increasingly available, allowing for the development of more detailed models. These advances make modeling pedestrian travel more useful and relevant to a growing field of interested planners, engineers, policymakers, decision-makers, stakeholders, advocates, and the general public.

This review documents the state-of-the-practice in representing walking in MPO regional travel demand forecasting models. It updates previous studies on the subject (Cambridge Systematics, Inc and Barton Aschman Associates, 1994; Purvis, 1997; Replogle, 1997; Eash, 1997 and 1999; Porter, Suhrbier and Schwartz, 1999; Nouzad, 2000; Rossi, 2000; Metropolitan Travel Forecasting: Current Practice and Future Direction, 2007; Vanasse Hangen Brustlin Inc., 2007; Liu, Evans and Rossi, 2012) and is an in-depth companion resource to other recent (Cambridge Systematics Inc. et al., 2012) and ongoing efforts, such as NCHRP Project 08-78. The following sections present the results of a comprehensive review of MPO model documentation; describe and discuss modeling frameworks, model structures and variables; and assess barriers and innovations in representing non-motorized and/or walk travel in regional models. 


\section{B.1 HISTORY}

Explicit inclusion of non-motorized modes in regional travel demand forecasting models began in the late 1980s and early 1990s. Previously, and in many cases still today, MPO models only included personal-vehicle and transit trip-making; non-motorized trips were excluded. The travel surveys upon which the models were based underreported or did not consider non-motorized travel (Eash, 1999; Cambridge Systematics Inc. and Parsons Brinckerhoff Quade and Douglas Inc., 1996); many surveys in the 1980s only asked for non-motorized home-based work trips (Rossi, 2000; Clifton and Muhs, 2012). A secondary factor was a general lack of interest in nonmotorized travel at regional and national levels. This began to change with the Clean Air Act Amendments of 1990 (CAAA) and the Intermodal Surface Transportation Efficiency Act of 1991 (ISTEA).

The first documented regional travel demand model to include non-motorized travel was developed in 1988 at the Metropolitan Service District (now Metro) of Portland, OR, (Purvis, 1997). In preparation for a light rail expansion project, a 1985 travel survey was used to estimate a binary-logit motorized/non-motorized mode split model for home-based trips, based on trip distance and the relative number of cars and workers per household. Other trip purposes used a static non-motorized mode share (Cambridge Systematics Inc. and Barton Aschman Associates, 1994; Rossi, 2000; Cambridge Systematics Inc., Parsons Brinckerhoff Quade and Douglas Inc., and S. H. Putman Associates Inc., 1996). In comparison, an Institute for Transportation Engineers study found that as of 1992, none of 10 major MPOs included non-motorized modes in their travel demand models (Purvis, 1997).

Partially in response to ISTEA and CAAA, through the 1990s many large MPOs began incorporating non-motorized or walk and bicycle travel modes into their models. Sacramento, CA, followed Portland in 1993 with the first documented use of separate walk and bicycle modes within a mode choice model. By 1997, MPOs in the Baltimore, Chicago, Hampton Roads, Los Angeles, Philadelphia, and San Francisco Bay Area regions either had or were in the late stages of incorporating non-motorized modes into their models.

At the same time as non-motorized modes were being added to regional travel models, measures of the pedestrian-level built environment were being developed for use in these revised models. The first documented application of non-motorized-specific built environment measures occurred in 1988 at the Maryland-National Capital Park and Planning Commission. The pedestrian and bicycle friendliness index - a combination of land-use mix, building setback, bus shelters, bicycle infrastructure, and extent of sidewalks - was used in the walk- and bicycleaccess-to-transit mode choice utility equations for home-based work trips. However, the model did not consider single-mode non-motorized trips (Cambridge Systematics Inc. and Barton Aschman Associates, 1994; Replogle, 1997).

A second influential project - Making the Land Use Transportation Air Quality Connection (LUTRAQ) - occurred during the early-to-mid-1990s at Portland's Metro. The PEF it developed was an index of the ease of street crossings, sidewalk continuity, grid street pattern, and terrain to be applied in the pre-mode choice non-motorized split model (Cambridge Systematics Inc., Parsons Brinckerhoff Quade and Douglas Inc., and S. H. Putman Associates Inc., 1996; Parsons Brinckerhoff Quade and Douglas Inc., Cambridge Systematics Inc., and Calthorpe Associates, 
1993). The PEF or modifications thereof has since been applied in many models around the country, including in the Chicago, Hampton Roads, Miami, Philadelphia, Portland, Sacramento, and Salt Lake City regions. Interestingly, Portland's regional model had discarded the PEF by 2000 in favor of the less subjectively defined variables of local intersection density and land use mix (Nouzad, 2000). Several other MPOs have similarly transitioned from indices to direct measures of the pedestrian environment.

Through the mid-2000s, more regions continued to add non-motorized modes to their travel demand forecasting models. A TRB-sponsored study found in 2005 that more than half of large MPOs $(54 \%, \mathrm{~N}=35)$ reported including non-motorized trips in their models (Metropolitan Travel Forecasting: Current Practice and Future Direction, 2007; Vanasse Hangen Brustlin Inc., 2007). A more recent review reported that between half $(41-45 \%, \mathrm{~N}=29)$ and two-thirds $(68 \%, \mathrm{~N}=28)$ of large MPOs have non-motorized travel in their trip-based models, with about half $(53 \%)$ of those that do including non-motorized trips in the mode choice model (Liu, Evans and Rossi, 2012). This paper, the most comprehensive review of the practice of representing pedestrian and/or non-motorized modes in MPO travel demand forecasting models, provides an update of the practice as of mid-2012. Currently, about $63 \%$ of the largest 48 MPOs model nonmotorized travel.

\section{B.2 REVIEW METHODOLOGY}

To review the state-of-the-practice of representing walk and/or non-motorized modes in MPO travel demand forecasting models, the 48 largest MPOs serving greater than 1 million people (in the 2010 U.S. Census) were selected as the study population (Transportation Planning Capacity Building Program, 2013). Table B-1 lists these large MPOs.

Model information was obtained and reviewed through a variety of sources, including documentation reports from MPO websites and direct correspondence with modeling staff members. In addition, the authors conducted a brief survey of MPO staff members regarding their models' representation of pedestrians, challenges, and future modeling changes; 29 responses were received, a $60 \%$ response rate. Results from the analysis of MPO model documentation are presented in the following section; results from the survey of MPO modelers are presented in later sections. Only aspects of full non-motorized or walk trips were investigated; walking as an access/egress mode in multimodal trips was not considered.

\section{B.3 MODELING FRAMEWORKS, MODEL STRUCTURES, AND VARIABLES}

There are several ways in which MPOs represent walk or non-motorized modes in regional travel demand forecasting models. In four-step trip-based models, non-motorized trips can be generated on their own, separated from motorized trips before or after distribution, distinguished from trips of other modes during mode choice, or further segmented into walk and bicycle trips. Calculated non-motorized or walk trips are then output and not used in future modeling stages. Figure 8-1 graphically represents these different pedestrian modeling frameworks. Table B-2 describes the framework classifications and their use among large MPOs. Although these distinctions are based on trip-based model sequences, similar frameworks are used to represent non-motorized or 
walk travel in tour- and activity-based models (ABMs). At their heart, ABMs use the same model structures as trip-based models; therefore, they can be described analogously.

There are also many model structures used to forecast pedestrian or non-motorized travel; most modeling frameworks utilize a single type of model structure. The most common structures are discrete choice models, where the tradeoffs between two or more travel modes are explicitly defined through utility equations: linear combinations of explanatory variables. Discrete choice model structures include binary logit, multinomial logit, and nested logit. Other model structures include percentages, cross-classification, and multiple regression.

Just as MPO models use different modeling frameworks and model structures, so is there a range of variables by which walk or non-motorized trips are forecast. These variables can be categorized by what they measure: socioeconomic and demographic characteristics of the traveler, level-of-service characteristics of the trip itself, and characteristics of the environment from, to, or through which the trip occurs. Built environment variables are further categorized according to the "three D's" method: density, diversity, and design (Cervero and Kockelman, 1997). The variables used often depend on the modeling framework employed. Full documentation was obtained and reviewed for 26 of the 31 models studied that represent walk and/or non-motorized travel. Table B-2 lists, categorizes, and assesses the frequency of variables by modeling framework.

\section{B.3.1 Detailed Descriptions of Frameworks, Structures, and Variables}

\section{Option 0: Non-Motorized Travel Not Included}

Eighteen large MPOs do not include non-motorized modes in their travel demand models. These organizations cannot forecast non-motorized trips using their regional models and thus must develop separate demand forecasting tools if they wish to evaluate walking and cycling policies and projects. 
(0) Generation $\rightarrow$ Distribution $\rightarrow$ Mode Choice $\rightarrow$ Assignment

(1)
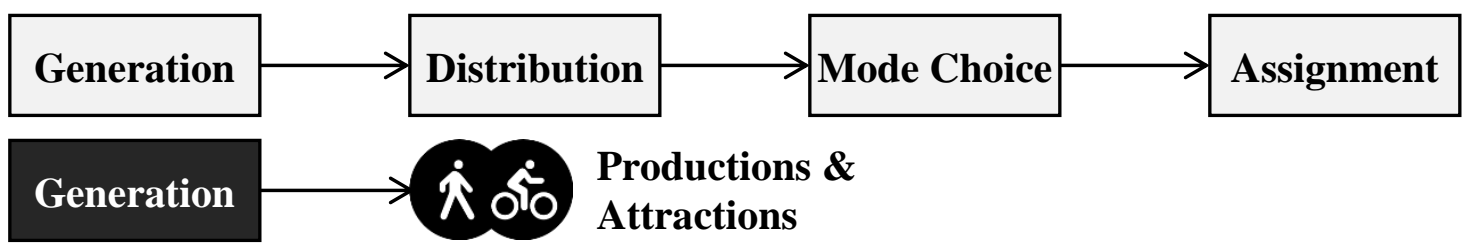

(2) Generation $\rightarrow$ Split $\rightarrow$ Distribution $\rightarrow$ Mode Choice $\rightarrow$ Assignment $\dot{\lambda}$ ơ Productions \& Attractions

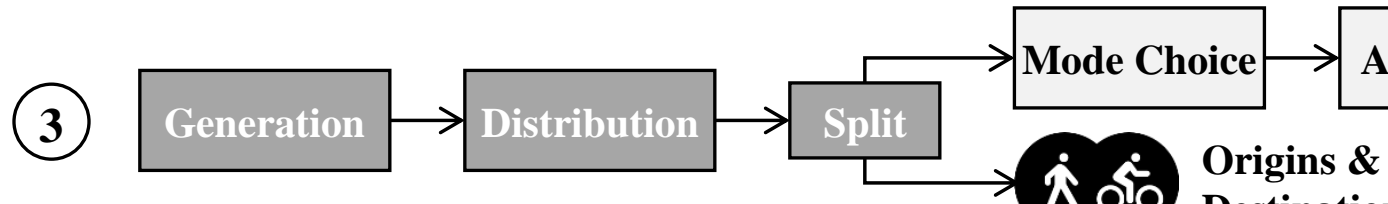
Assignment Destinations
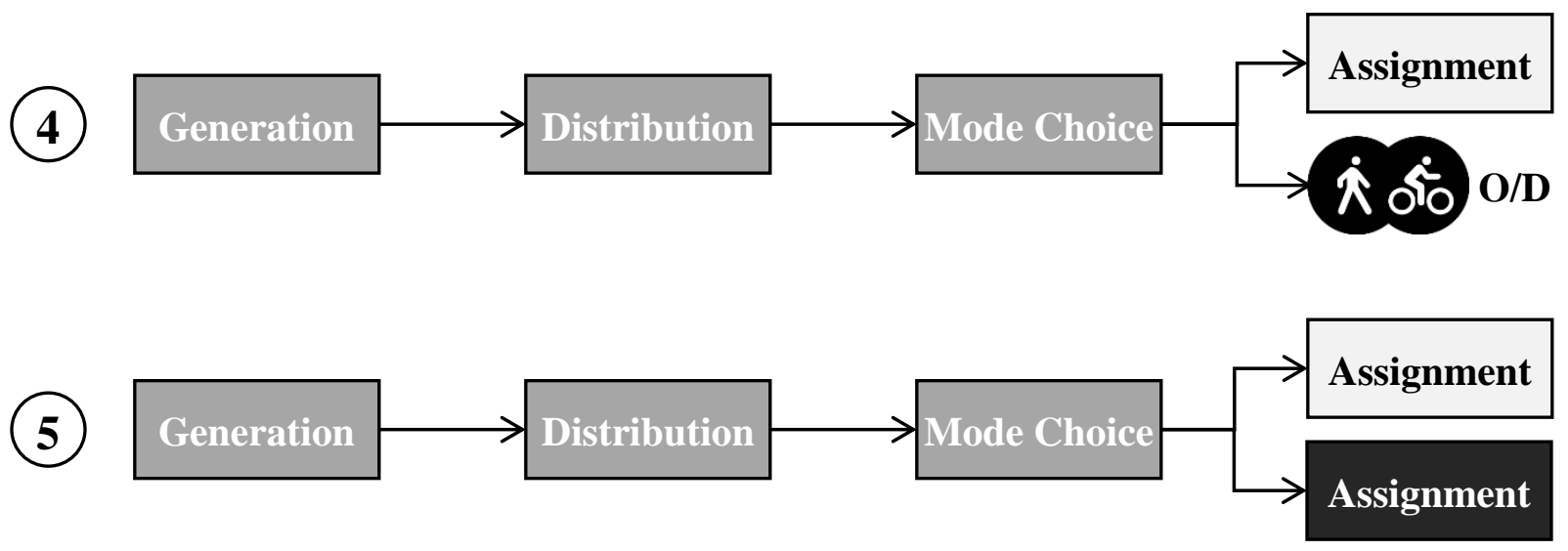

Legend

\begin{tabular}{|c|c|c|c|}
\hline Motorized & All Modes & $\begin{array}{c}\text { Non- } \\
\text { Motorized }\end{array}$ & Model Stage, Modes \\
\hline
\end{tabular}

Figure 8-1 Pedestrian Modeling Frameworks 
Table B-1 Large MPOs and their Pedestrian Modeling Frameworks

\begin{tabular}{|c|c|c|c|c|c|c|c|c|c|}
\hline \multirow[b]{2}{*}{ City, State } & \multirow[b]{2}{*}{ Metropolitan Planning Organization } & \multicolumn{8}{|c|}{ Modeling Framework } \\
\hline & & $0^{a}$ & $1^{b}$ & $2^{c}$ & $3^{d}$ & $4 \mathrm{~A}^{e}$ & $4 \mathrm{~B}^{f}$ & $4 C^{g}$ & $5^{h}$ \\
\hline Atlanta, GA & Atlanta Regional Commission (ARC) & - & - & $\mathrm{X}$ & - & - & - & - & - \\
\hline Austin, TX & Capital Area MPO (CAMPO) & - & - & - & - & - & - & $\mathrm{X}$ & - \\
\hline Baltimore, MD & $\begin{array}{l}\text { Baltimore Regional Transportation Board } \\
\text { (BRTB) }\end{array}$ & - & - & $\mathrm{X}$ & - & - & - & - & 一 \\
\hline Boston, MA & Boston Region MPO & - & - & - & - & $X$ & - & - & - \\
\hline Buffalo, NY & $\begin{array}{l}\text { Greater Buffalo-Niagara Regional } \\
\text { Transportation Council (GBNRTC) }\end{array}$ & - & - & - & - & $\mathrm{X}$ & - & - & - \\
\hline Charlotte, NC & Mecklenburg-Union MPO (MUMPO) & - & - & - & - & - & - & $\mathrm{X}$ & - \\
\hline Chicago, IL & $\begin{array}{l}\text { Chicago Metropolitan Agency for } \\
\text { Planning (CMAP) }\end{array}$ & - & - & $\mathrm{X}$ & - & - & - & - & 一 \\
\hline Cincinnati, $\mathrm{OH}$ & $\begin{array}{l}\text { Ohio-Kentucky-Indiana Regional COG } \\
\text { (OKI) }\end{array}$ & $\mathrm{X}$ & - & - & - & - & - & - & - \\
\hline Cleveland, $\mathrm{OH}$ & $\begin{array}{l}\text { Northeast Ohio Areawide Coordinating } \\
\text { Agency (NOACA) }\end{array}$ & - & - & - & - & - & - & $\mathrm{X}$ & - \\
\hline Columbus, $\mathrm{OH}$ & Mid-Ohio RPC (MORPC) & - & - & - & - & $\mathrm{X}^{i}$ & - & - & - \\
\hline Dallas, TX & North Central Texas COG (NCTCOG) & $\mathrm{X}$ & - & - & - & - & - & - & - \\
\hline Denver, CO & Denver Regional COG (DRCOG) & - & - & - & - & - & - & $\mathrm{X}^{i}$ & - \\
\hline Detroit, MI & Southeast Michigan COG (SEMCOG) & $\mathrm{X}$ & - & - & - & - & - & - & - \\
\hline $\begin{array}{l}\text { Fort Lauderdale, } \\
\text { FL }\end{array}$ & Broward MPO & - & - & - & $\mathrm{X}$ & - & - & - & - \\
\hline Houston, TX & $\begin{array}{l}\text { Houston-Galveston Area Council } \\
\text { (H-GAC) }\end{array}$ & $X$ & - & - & - & - & - & - & - \\
\hline Indianapolis, IN & Indianapolis, IN & $\mathrm{X}$ & - & - & - & - & - & - & - \\
\hline Jacksonville, FL & $\begin{array}{l}\text { North Florida Transportation Planning } \\
\text { Organization (TPO) }\end{array}$ & $\mathrm{X}$ & - & - & - & - & - & - & 一 \\
\hline Kansas City, MO & Mid-America Regional Council (MARC) & $\mathrm{X}$ & - & - & - & - & - & - & - \\
\hline Las Vegas, NV & $\begin{array}{l}\text { Regional Transportation Commission of } \\
\text { Southern Nevada (RTC) }\end{array}$ & $\mathrm{X}$ & - & - & - & - & - & - & - \\
\hline Los Angeles, CA & Southern California AOG (SCAG) & - & - & - & - & - & - & $\mathrm{X}$ & - \\
\hline Louisville, KY & $\begin{array}{l}\text { Kentuckiana Regional Planning and } \\
\text { Development Agency (KIPDA) }\end{array}$ & $\mathrm{X}$ & - & - & - & - & - & - & - \\
\hline Memphis, TN & Memphis Urban Area MPO & - & - & - & - & $\mathrm{X}$ & - & - & - \\
\hline Mian & Miami-Dade MPO & - & - & - & $\mathrm{X}$ & - & - & - & - \\
\hline Milwaukee, WI & Southeastern Wisconsin RPC (SEWRPC) & - & $\mathrm{X}$ & - & - & - & - & - & - \\
\hline Minneapolis, MN & Metropolitan Council & - & - & - & - & - & - & $\mathrm{X}$ & - \\
\hline Nashville, TN & Nashville Area MPO & $\mathrm{X}$ & - & - & - & - & - & - & - \\
\hline New Orleans, LA & $\mathrm{RPC}(\mathrm{RPC})$ & $X$ & 一 & - & - & - & - & - & - \\
\hline New York, NY & $\begin{array}{l}\text { New York Metropolitan Transportation } \\
\text { Council (NYMTC) }\end{array}$ & 一 & - & 一 & $\mathrm{X}^{i}$ & - & - & - & - \\
\hline Newark, NJ & $\begin{array}{l}\text { North Jersey Transportation Planning } \\
\text { Authority (NJTPA) }\end{array}$ & - & - & $\mathrm{X}$ & - & - & - & - & - \\
\hline $\begin{array}{l}\text { Oklahoma City, } \\
\text { OK }\end{array}$ & $\begin{array}{l}\text { Association of Central Oklahoma } \\
\text { Governments (ACOG) }\end{array}$ & $X$ & - & - & - & - & - & - & - \\
\hline Orlando, FL & MetroPlan Orlando & $\mathrm{X}$ & - & - & - & - & - & - & - \\
\hline Philadelphia, PA & Delaware Valley RPC (DVRPC) & - & $\mathrm{X}$ & - & - & - & - & - & - \\
\hline Phoenix, AZ & Maricopa AOG (MAG) & $\mathrm{X}$ & - & - & - & - & - & - & - \\
\hline Pittsburgh, PA & $\begin{array}{l}\text { Southwestern Pennsylvania Commission } \\
\text { (SPC) }\end{array}$ & $X$ & - & - & - & - & - & - & - \\
\hline Portland, OR & Metro & - & - & - & - & - & $\mathrm{X}$ & - & - \\
\hline Providence, RI & Rhode Island State Planning Council & $\mathrm{X}$ & - & - & - & - & - & - & - \\
\hline
\end{tabular}




\begin{tabular}{|c|c|c|c|c|c|c|c|c|c|}
\hline \multirow[b]{2}{*}{ City, State } & \multirow[b]{2}{*}{ Metropolitan Planning Organization } & \multicolumn{8}{|c|}{ Modeling Framework } \\
\hline & & $0^{a}$ & $1^{b}$ & $2^{c}$ & $3^{d}$ & $4 \mathrm{~A}^{e}$ & $4 \mathrm{~B}^{f}$ & $4 C^{g}$ & $5^{h}$ \\
\hline Raleigh, NC & $\begin{array}{l}\text { North Carolina Capital Area MPO } \\
\text { (CAMPO) }\end{array}$ & - & - & - & $\mathrm{X}$ & - & - & - & - \\
\hline Sacramento, CA & Sacramento Area COG (SACOG) & - & - & - & - & - & $\mathrm{X}^{i}$ & - & - \\
\hline $\begin{array}{l}\text { Salt Lake City, } \\
\text { UT }\end{array}$ & $\begin{array}{l}\text { Wasatch Front Regional Council } \\
\text { (WFRC) }\end{array}$ & - & - & - & - & - & - & $\mathrm{X}$ & - \\
\hline San Antonio, TX & $\begin{array}{l}\text { San Antonio-Bexar County MPO } \\
\text { (SA-BC MPO) }\end{array}$ & - & - & - & - & - & $\mathrm{X}$ & - & - \\
\hline San Diego, CA & San Diego AOG (SANDAG) & - & - & - & - & - & - & $\mathrm{X}$ & - \\
\hline $\begin{array}{l}\text { San Francisco Bay } \\
\text { Area, CA }\end{array}$ & $\begin{array}{l}\text { Metropolitan Transportation Commission } \\
\text { (MTC) }\end{array}$ & - & - & - & - & - & - & $\mathrm{X}^{i}$ & - \\
\hline Seattle, WA & Puget Sound Regional Council (PSRC) & - & - & - & - & - & $\mathrm{X}$ & - & - \\
\hline St. Louis, MO & East-West Gateway COG (EWG) & - & - & - & - & - & - & $\mathrm{X}$ & - \\
\hline Tampa, FL & Hillsborough County MPO & $\mathrm{X}$ & - & - & - & - & - & - & - \\
\hline $\begin{array}{l}\text { Virginia Beach, } \\
\text { VA }\end{array}$ & $\begin{array}{l}\text { Hampton Roads Transportation Planning } \\
\text { Organization (HRTPO) }\end{array}$ & $\mathrm{X}$ & - & - & - & - & - & - & - \\
\hline Washington, DC & $\begin{array}{l}\text { National Capital Region Transportation } \\
\text { Planning Board (TPB) }\end{array}$ & - & - & $\mathrm{X}$ & - & - & - & - & - \\
\hline $\begin{array}{l}\text { West Palm Beach, } \\
\text { FL }\end{array}$ & Palm Beach MPO & - & - & - & $\mathrm{X}$ & - & - & - & 一 \\
\hline- & Total Number of Large MPOs & 18 & 2 & 5 & 5 & 4 & 4 & 10 & 0 \\
\hline - & Percentage of all Large MPOs (N=48) & 38 & 4 & 10 & 10 & 8 & 8 & 21 & 0 \\
\hline - & Percentage of MPOs with $1-5(\mathrm{~N}=30)$ & - & 7 & 17 & 17 & 13 & 13 & 33 & 0 \\
\hline
\end{tabular}

$\mathrm{X}$ The MPO uses this modeling framework.

- Not applicable.

a $\quad$ 0: Does not model non-motorized travel.

$b \quad$ 1: A cross-classification model to perform separate non-motorized and motorized trip generation processes.

$c \quad 2$ : A percentage, linear regression, or binary logit model to split non-motorized and motorized trips after trip generation and before trip distribution.

d 3: A binary logit model to split non-motorized and motorized trips after trip distribution and before mode choice.

$e \quad$ 4A: A multinomial or nested logit mode choice model with only non-motorized mode.

$f \quad 4$ B: A multinomial logit mode choice model with walk and bicycle modes but not within a non-motorized nest.

$g \quad$ 4C: A nested logit mode choice model that considers walk and bicycle modes within a non-motorized nest.

$h \quad$ 5: A routing process to assign walk and bicycle trips to the network.

$i \quad$ A tour- or activity-based model.

Acronyms:

AOG: Association of Governments

COG: Council of Governments

MPO: Metropolitan Planning Organization

RPC: Regional Planning Commission 
Table B-2 Variables and their Frequency of Use, by Modeling Framework

\begin{tabular}{|c|c|c|c|c|c|c|c|c|c|c|}
\hline \multirow{3}{*}{$\begin{array}{l}\text { Category } \\
\text { Variable }\end{array}$} & \multicolumn{10}{|c|}{ Modeling Framework } \\
\hline & \multicolumn{2}{|c|}{1} & \multicolumn{2}{|c|}{2} & \multicolumn{2}{|l|}{3} & \multicolumn{2}{|c|}{$4 \mathrm{~A} / \mathrm{B} / \mathrm{C}$} & \multicolumn{2}{|l|}{5} \\
\hline & \# & $(\%)$ & $\#$ & $(\%)$ & \# & $(\%)$ & $\#$ & $(\%)$ & \# & $(\%)$ \\
\hline Socioeconomic and & 2 & $(100)$ & 3 & (75) & 2 & (67) & 16 & (94) & - & - \\
\hline Demographic Variables & & & & & & & & & & \\
\hline $\begin{array}{l}\text { Population, Households, and } \\
\text { Employment }\end{array}$ & 2 & $(100)$ & - & - & - & - & - & - & - & - \\
\hline Household Income & - & - & 1 & (25) & 2 & (67) & 5 & (29) & - & - \\
\hline Household Size & 1 & $(50)$ & - & - & 1 & (33) & 3 & (18) & - & - \\
\hline Vehicle Ownership & 2 & $(100)$ & - & - & - & - & 6 & (35) & - & - \\
\hline Vehicle Sufficiency & - & - & 2 & (50) & 2 & (67) & 9 & (53) & - & - \\
\hline Traveler Demographics & - & - & - & - & 1 & (33) & 4 & (24) & - & - \\
\hline Density Variables & 2 & $(100)$ & 4 & $(100)$ & 3 & (100) & 13 & (76) & - & - \\
\hline Residential Density & - & - & 2 & $(50)$ & 1 & (33) & 7 & (41) & - & - \\
\hline Employment Density & - & - & 2 & (50) & 1 & (33) & 8 & (47) & - & - \\
\hline Area Type & 2 & $(100)$ & 4 & $(100)$ & 3 & $(100)$ & 8 & (47) & - & - \\
\hline Diversity Variables & - & - & - & - & 1 & (33) & 4 & (24) & - & - \\
\hline Land Use Mix & - & - & - & - & 1 & (33) & 4 & (24) & - & - \\
\hline Design Variables & - & - & 2 & $(50)$ & 2 & (67) & 6 & (35) & - & - \\
\hline Block Size & - & - & - & - & 1 & (33) & - & - & - & - \\
\hline Block Density & - & - & 1 & (25) & - & - & - & - & - & - \\
\hline Intersection Density & - & - & 1 & (25) & - & - & 4 & (24) & - & - \\
\hline Non-motorized Path Density & - & - & - & - & 1 & (33) & - & - & - & - \\
\hline Network Connectivity & - & - & 1 & (25) & - & - & - & - & - & - \\
\hline Network Restrictivity & - & - & 1 & (25) & - & - & - & - & - & - \\
\hline Pedestrian Index & - & - & - & - & 1 & (33) & 2 & (12) & - & - \\
\hline Level-of-Service Variables & - & - & - & - & 2 & (67) & 17 & (100) & - & - \\
\hline Trip Distance & - & - & - & - & 2 & (67) & 3 & (18) & - & - \\
\hline Travel Time & - & - & - & - & - & - & 14 & (82) & - & - \\
\hline Travel Time Difference & - & - & - & - & 1 & (33) & - & - & - & - \\
\hline Accessibility Variables & - & - & 1 & (25) & 1 & (33) & - & - & - & - \\
\hline Tour-Based Variables & - & - & - & - & 1 & $(33)$ & 6 & (35) & - & - \\
\hline \# of Documented Models & 2 & $(100)$ & 4 & (80) & $3^{a}$ & $(100)$ & $17^{b}$ & (81) & $0^{c}$ & - \\
\hline
\end{tabular}

\section{Option 1: Separate Trip Generation Process}

One option involves estimating separate trip production and attraction rates for motorized and non-motorized trips, and then only taking the motorized trips through the remaining stages of the travel demand model. Milwaukee and Philadelphia use this modeling framework, but Philadelphia is planning to transition to a different option. This framework is a relatively simple way for an Option 0 MPO to add non-motorized trips without having to re-estimate the remainder of its model. Several MPOs have replaced this framework with more sophisticated approaches because it provides little information about non-motorized travel behavior, has limited policy sensitivity, and cannot represent modal tradeoffs. 
Both models using Option 1 apply the cross-classification structure, although there is no reason why a different trip generation model structure could not be applied instead. Milwaukee calculates non-motorized trip productions but not attractions, while Philadelphia calculates both. The variables used for non-motorized trip generation are common to cross-classification structures: demographic, socioeconomic, and density-based area type variables. Milwaukee's non-motorized trip rates per household are segmented by household size, vehicle availability, and area type for all purposes. Philadelphia's non-motorized trip rate structures differ based on purpose, but all are also segmented by area type.

\section{Option 2: Post-Trip Generation, Pre-Trip Distribution Mode Split}

The second option separates non-motorized from motorized trips immediately following generation but prior to distribution. A variety of model structures are used by the five MPOs in this category, including binary logit, multiple regression, and simple estimated mode shares. A few MPOs have moved from percentages or regression to binary logit structures because such discrete choice structures can include more policy-sensitive variables. Nevertheless, because Option 2 occurs before trips are distributed, important level-of-service variables cannot be included. On the other hand, this framework presents a good option for those MPOs that may be unable or unwilling to tackle the calculation of non-motorized network skims.

The model structures and variables used in Option 2 range from the basic to the complex. Nonmotorized mode shares are used for less dense zones in Washington and for many trip purposes in Baltimore. The binary logit home-based productions model of Baltimore includes area type and vehicle sufficiency: relating the numbers of vehicles and workers. For denser zones, Washington's regression model uses floating population, employment, and street block densities, measured within one mile of the TAZ.

Option 2 binary logit models are not limited to basic built environment measures. Newark's trip production mode share models use street network design variables, including intersection density, network connectivity (\# intersections / total street distance), and network restrictivity (\% roadway network where pedestrians are prohibited). One of the most unique variables, and one that circumvents this stage's lack of level-of-service variables and knowledge of destinations, is the accessibility measure used in Atlanta's binary logit models:

$$
\text { Accessibility }_{\text {Zone } i}=\sum_{j} \frac{\text { Activity }_{\text {Zone } j}}{\text { Distance }_{i, j}{ }^{2}}
$$

where "activity" could be population, employment, or their sum. Home-based work and shopping trips use employment; home-based school trips use population; and home-based other and non-home-based trips use combined accessibility.

\section{Option 3: Post-Trip Distribution, Pre-Mode Choice Split}

The third option calculates non-motorized mode shares after trip distribution; the primary benefit over Option 2 is the use of level-of-service variables. Option 3 is appropriate for MPOs that have insufficient walk and bicycle records and wish to avoid the complication of estimating a full mode choice model. All five MPOs in this category, including New York's tour-based model, 
apply a binary logit model structure. The three Florida MPOs use one combined model, the Southeast Florida Regional Planning Model (SERPM).

These models utilize level-of-service variables in different ways. SERPM uses highway network distance for all trip purposes. Raleigh's highly specified model uses non-motorized distance for some purposes and a travel time difference measure - non-motorized time minus a weighted average of auto and transit times - for others. Squared distance and travel time terms are also included to attenuate the chance of extremely long non-motorized trips. Instead of distance or time, New York's model has a non-motorized density of attractions variable. It is basically a non-motorized destination choice log-sum:

$$
\text { NMDensity }_{\text {Zone } i}=\ln \sum_{j} \frac{\text { Attractions }_{\text {Zone } j}}{\Psi\left(\text { Distance }_{i, j}\right)}
$$

where $\Psi$ is a impedance function, accounting for all zones $j$ within three miles.

This framework is also conducive to applying unique built environment measures. SERPM is one of the few models to still include a pedestrian index. The "non-motorized friendliness index" is the sum of assessing sidewalk availability (\% streets with sidewalks), ease of street crossings (\% streets that are easy to cross by pedestrians), and area type on a 0 to 3 scale. Raleigh's model takes a different approach with unique design variables, including block size (average block perimeter length) and non-motorized path density (distance of paths / zonal area). A land use mix diversity variable, calculated as

$$
L U M=\frac{2 *(\text { People }+ \text { Jobs })-\mid \text { People }- \text { Jobs } \mid}{\text { Zonal Area }}
$$

is also used for some purposes, in addition to the typical socioeconomic and density measures.

\section{Option 4: Mode Choice Model}

This framework grouping formally includes non-motorized travel modes as options in the mode choice model; structures include multinomial or nested logit discrete choice models. Option 4A keeps walk and bicycle trips lumped into a non-motorized mode, a good option if few bicycle trips are found in the travel survey. Option 4B explicitly includes both walk and bicycle modes, placing them in equal competition in the upper nest of the logit model. Option 4C places walk and bicycle modes within a non-motorized nest for stronger intra-non-motorized mode substitution effects.

Most ABMs fall within this framework. Although ABMs have a sequential process in which trip mode choice is dependent on tour mode choice, they use the same discrete choice model structures as trip-based models. Explanatory variables are also similar, with the addition of person type and tour interaction variables made possible by synthetic populations and tour-based travel representations. In ABMs, trip mode choice models are similar in structure and specification to tour mode choice models, with the addition of hierarchical rules and tour mode variables. Usually, only walk trips are allowed on walk tours, but walk trips may be taken on tours of almost any mode. 
In general, the mode choice non-motorized or walk utility equations are simpler than the binary logit equations of Options 2 and 3. A level-of-service variable is included for all trip purposes; although travel time is by far the most common, Memphis and Portland use distance for all purposes and Minneapolis uses generalized cost for some purposes. An advanced practice is to use different travel time coefficients for longer walk trips to reduce their likelihood. The Cleveland, San Francisco Bay Area, and Salt Lake City models attenuate walk trips longer than one or 1.5 miles, while Atlanta, Minneapolis, and San Diego distinguish between short, medium, and long walk trips.

Relatively few different built environment measures are used in Option 4. Area type dummies are used sparingly, primarily to account for special places like downtowns or university districts/towns. A unique density and diversity mix variable used in Portland and San Diego is:

$$
M i x=\ln \left(\frac{\text { Intersections } *(\text { Retail Employment }) * \text { Households }}{\text { Intersections }+(\text { Retail Employment })+\text { Households }}\right)
$$

where the employment and household variables are normalized to local intersection units by multiplying by the regional averages ( $\frac{\text { mean(Employment) }}{\text { mean(Intersections) }}$ or $\frac{\text { mean(Households) }}{\text { mean(Intersections) }}$ ), and all secondary variables are measured within a half-mile of the production zone. Sacramento's and Denver's ABMs include a similar mixed-use density variable, defined as

$$
M U D=\frac{0.001 *(\text { Retail }+ \text { Service Employment }) * \text { Households }}{(\text { Retail }+ \text { Service Employment })+\text { Households }}
$$

with employment and households measured within a half-mile of the parcel.

Nearly every ABM in this framework uses person and tour variables. Person type dummies include life stage (child, university student, worker, etc.), age, and gender. Tour variables include the number of tour stops and an intrazonal dummy. More complex travel behaviors are accommodated in trip-based models from Cleveland and St. Louis through the use of trip type dummies (intrazonal, direct, complex, and strategic work trips). Standard socioeconomic and demographic variables round out the model specification.

\section{Option 5: Non-motorized Trip Assignment}

Although Portland's model and an ABM for the city/county of San Francisco now assign bicycle trips to the network (Stein, 2011; Zorn, Sall and Bomberg, 2012), no MPO currently assigns walk trips to the network. This is a logical next step for regional travel demand forecasting models, be they trip- or activity-based. Non-motorized network assignment is discussed in a later section.

\section{B.3.2 Other Considerations}

The prevalence of travel time variables necessitates the application of an assumed average travel speed to network distance skims. Most models use an assumed walk speed of $3 \mathrm{mph}$, but some instead use $2.5 \mathrm{mph}$; bicycle speeds vary from 7 to $12 \mathrm{mph}$. When only non-motorized trips are 
represented, non-motorized speed becomes difficult to define; based on their use of a nonmotorized speed in the range of walking speeds, it appears that several MPOs - Boston, Columbus, Memphis, and New York - presume all non-motorized trips to be walk trips.

Another common modeling practice is to prohibit walk and bicycle modes from being available to trips longer than a given distance. Common walk trip limits are 3 to 5 miles; bicycle maximums vary from 6 to 20 miles. Raleigh is one MPO that limits non-motorized trips to 15 miles in length. Note that these limits are different from the walk access-to-transit distance limits, which are in the range of one-quarter to one mile. An alternate way of accounting for the rarity of long distance walk trips in a modeling framework is to include an appropriate distancedecreasing impedance function in walk utility equations.

\section{B.3.3 Discussion}

The most advanced representations of walking in travel demand forecasting models are Options 4B and 4C. Both frameworks produce origin-destination walk trip tables for each trip purpose. Neither option is necessarily more behaviorally sound; the decision is often based on whether the model estimation process produces theoretically valid nesting coefficients $(<1.0)$. Additionally, these options are by no means the only ways to model walk and bicycle mode choices. Future mode choice models, especially in regions with high shares of bicycle commuters and/or bikeshare programs, might experiment with alternative nesting structures, especially those that put transit and bicycle modes in direct competition.

Tied closely with model frameworks are practices of model specification. It remains unclear which models are better: 1) those with highly specified equations - like Minneapolis, Newark, or Raleigh - utilizing many variables that differ across purposes; or 2) those with simple equations - like Buffalo, Portland, and Salt Lake City - using the same few key variables throughout. Complex models can utilize a number of different built environment measures that apply to specific modes and purposes and may provide better statistical fits. Conversely, simple models require less data collection, are quicker to estimate and calibrate, and focus on variables of importance. Travel behavior literature suggests that socioeconomics and trip level-of-service are stronger influences on mode choice than the built environment (Cervero and Kockelman, 1997; Ewing and Cervero, 2010). Over-specification may lead to more deviations in forecasts or challenges during re-calibration. Under-specification may place more weight on alternativespecific constants, indicating greater unobserved preferences/biases for specific modes.

Mode choice utility equations tend to be simpler than their binary logit counterparts, which may be an artifact of the processes that govern their specification and estimation. Many model changes were premised on the use of revised regional models for air quality conformity or major capital transit projects, such as a Federal Transit Administration New Starts application. Critical New Starts concerns over the calculation of user benefits required the consistency of time and cost coefficients and discouraged complex mode choice model specifications.

The treatment of built environment variables is an important aspect of modeling for pedestrians. Most MPOs have transitioned away from subjectively defined pedestrian environment indices like the PEF towards more objective design measures like intersection density. Significant disadvantages of indices include imprecise measurements, reproducibility concerns, lack of 
standardization between regions, and limited policy sensitivity for forecasts due to their stepwise nature. Nevertheless, indices provide some benefits, including representing variables that are impossible to objectively measure or require time-consuming data collection, and grouping explanatory but highly correlated built environment and street-design variables. Newer access or mix variables, such as the one developed for Portland, may provide a middle ground forward for further inclusion of pedestrian environment measures.

While not examined in this paper, walking as a transit access mode has a longer history in travel demand models. Splitting zones into various walk-to-transit sheds, assigning maximum distances/times to centroid connectors, and segmenting walk, wait, and transfer times in utility equations is established practice; nevertheless, improvements are possible. More effective survey design approaches can reduce the underreporting of multimodal trips (Clifton and Muhs, 2012). Additionally, more behavioral data on walking distances to different transit modes and frequencies can improve practices of representing walking as an access/egress mode.

Finally, some MPOs are adopting more innovative pedestrian modeling practices, including new measures of the pedestrian environment, more disaggregate spatial analysis units, and nonmotorized network assignment. Simultaneously, other MPOs face data, resource, and institutional limitations to improving representations of walk travel in their models. These challenges and opportunities are discussed in the following sections.

\section{B.4 BARRIERS TO REPRESENTING NON-MOTORIZED AND/OR WALK TRAVEL}

To uncover why a third of large MPOs do not include non-motorized travel and another third do not distinguish between walk and bicycle travel in their models, a survey asked lead modelers to select from a list of possible reasons. Figure 8-2 shows the frequencies of responses $(\mathrm{N}=19)$.

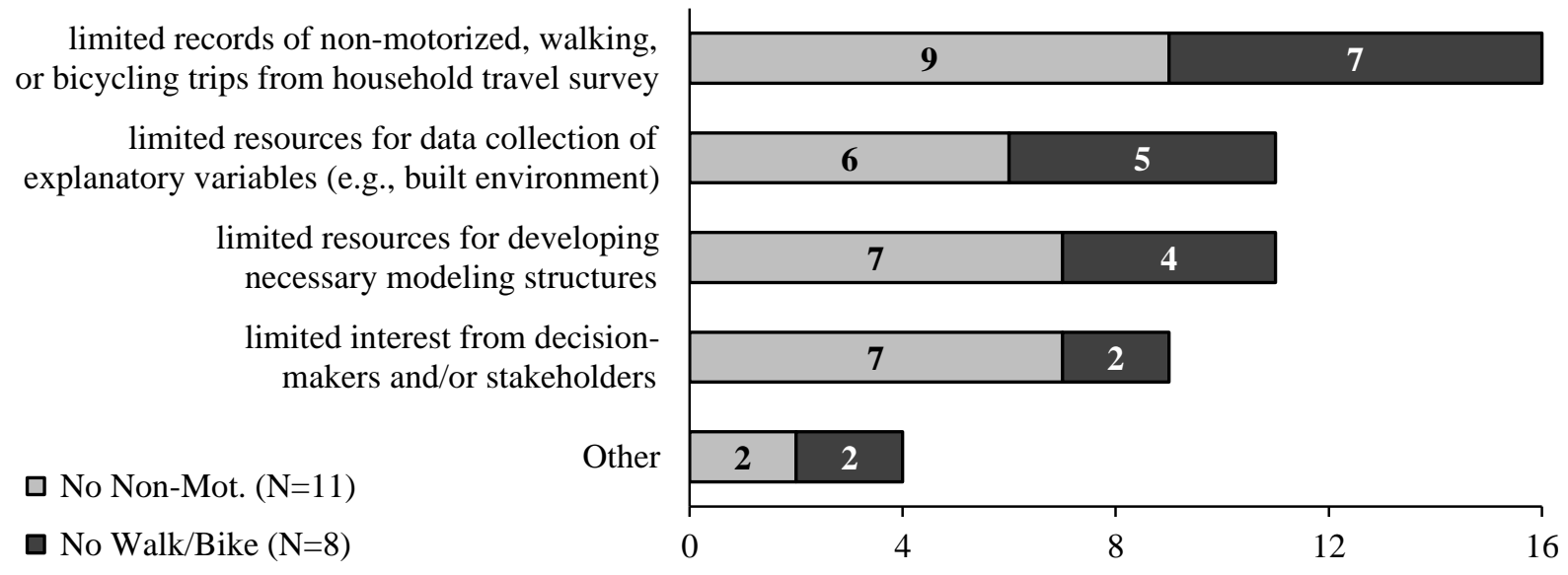

Figure 8-2 Barriers to Representing Non-Motorized and/or Walk Travel 


\section{B.4.1 Travel Survey Records}

Insufficient non-motorized travel survey records is a primary barrier for many MPOs (84\%). Household travel surveys must contain a large enough sample of walk and bicycle trips for each trip purpose from which to estimate statistically valid models. MPOs that face non-motorized survey record limitations may be able to transfer models/coefficients from other regions, or borrow parameters from national research reports (Cambridge Systematics Inc. et al., 2012). Alternatively, they may supplement walk records with standardized data from the National Household Travel Survey (NHTS) or purchase add-on NHTS samples for their regions. More standardized data collection of regional travel surveys will increase the potential transferability of non-motorized trips (Mohammadian and Zhang, 2007).

\section{B.4.2 Data Collection Resources}

Limited environmental data collection resources also constrain many MPOs (58\%). While residential, employment, and intersection densities are simple to calculate, they lack policysensitivity and act as proxy variables. Collecting data and forecasting disaggregate and manipulatable pedestrian environment measures for an entire region, while of interest, are still expensive and time-consuming tasks. One MPO responded: "We would like to assemble information on pedestrian environment (e.g., presence/absence of sidewalks, width of sidewalks, landscape/buffer treatments outside the curb, presence/absence of on-street parking lanes, traffic volumes at crossing, etc.) but the cost and difficulty of doing so has so far been prohibitive."

\section{B.4.3 Model Development Resources}

Adding non-motorized or walk modes to regional travel models requires a corresponding increase in staff modeling abilities, a challenge for some MPOs (58\%). Budgets for model improvement programs are tight, non-motorized modeling is often of lesser importance, and staff members may not feel comfortable developing walk models in-house.

\section{B.4.4 Decision-Maker Interest}

The time and effort to develop models sensitive to non-motorized policy, planning, and investment decisions will not be expended if decision-makers do not value such characteristics. This survey suggests that some metropolitan transportation planning institutions place little value on regional non-motorized travel modeling (47\%); the majority of these MPOs do not include non-motorized travel. If lack of interest is a barrier for some large MPOs, it is likely to be a major barrier for many smaller MPOs.

\section{B.4.5 Other Considerations}

Other responses followed consistent themes. A common thread mentioned how the large regional zonal and network scales of travel demand models are incompatible with the smaller scale at which non-motorized travel takes place. One MPO modeler said that pedestrian and bicycle infrastructure projects and concerns "are addressed in small funding or by city governance rather [than] the regional planning agency." Another response suggested that including non-motorized trips is little more than an accounting mechanism to better estimate motorized travel. 


\section{B.5 CURRENT AND FUTURE INNOVATIONS}

Regional travel demand forecasting models are rarely static entities. Even while one model version is in use, subsequent versions are typically in development. For example, several ABMs are now being sequentially adopted, replacing trip-based model components one at a time. In addition, some MPOs are surging ahead with innovative modeling developments, pushing the boundary of best-practice regional travel models. With these thoughts in mind, the survey of MPO modelers also asked all respondents to select from a list of planned modeling changes. Figure 8-3 shows the frequencies of responses $(\mathrm{N}=29)$.

\section{B.5.1 Adding Modes or Modifying the Mode Choice Model}

Some MPOs suggested they plan to add walk or non-motorized modes to their regional models (17\%) or change the structure of their mode choice models (38\%). Four MPOs of the first type do not currently include non-motorized modes, indicating that MPOs are interested in being better able to represent regional walk and bicycle travel.

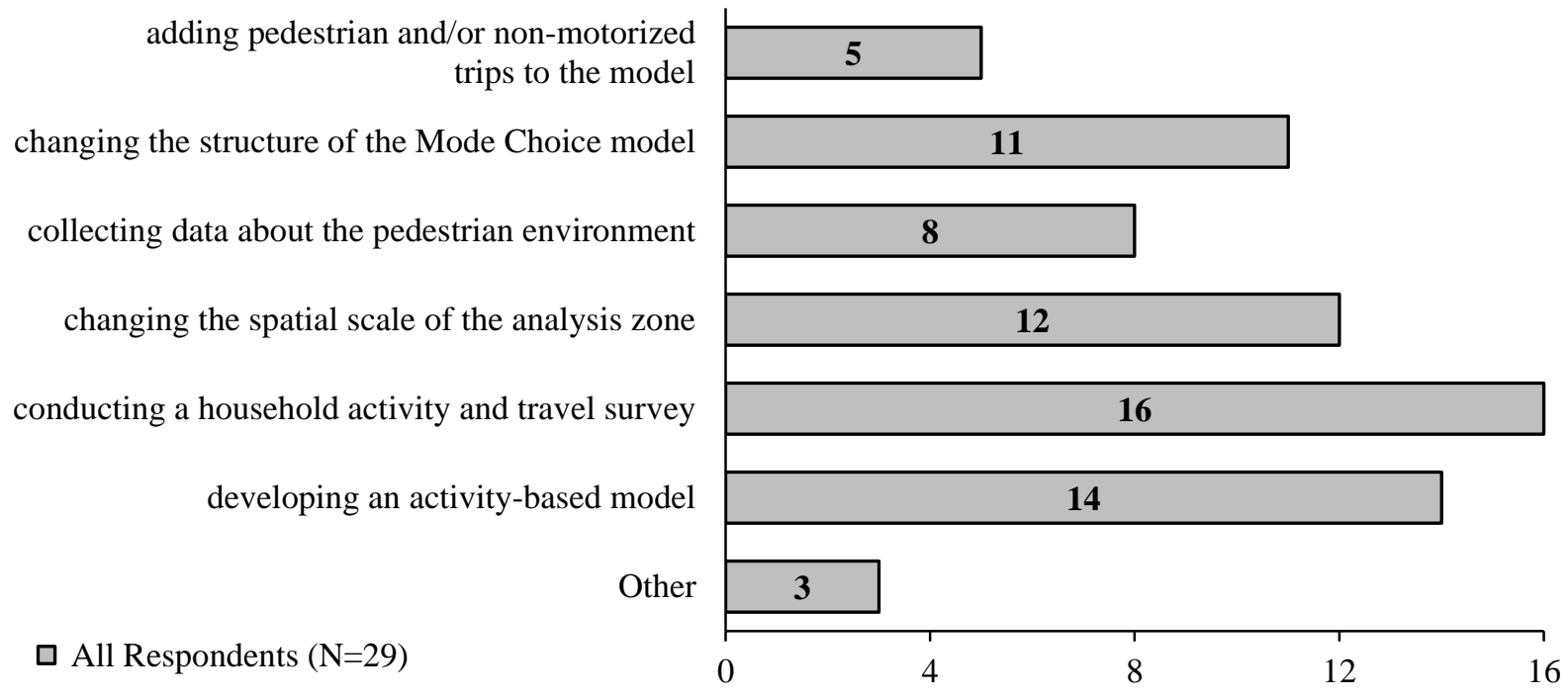

Figure 8-3 Current and Future Innovations in Representing Non-Motorized and/or Walk Travel

\section{B.5.2 Pedestrian Environment Data}

Many MPOs plan to collect better pedestrian environment data (28\%). For some this means gathering pedestrian facility information to calculate sidewalk availability or street crossing variables. For others this means compiling new measures of the pedestrian-scale street environment (sidewalk width or roadway buffers, among others) or pedestrian-attractive land uses, such as "urban amenity" businesses (Johnson Gardner, 2007). Design variables need no longer be limited to those that can be calculated using a GIS-based street network. 


\section{B.5.3 Smaller Spatial Analysis Units}

A number of MPOs reported planning to change their zonal structure (41\%), while others have already done so. These smaller spatial analysis units are being used for disaggregate land use and demographic forecasts, walk trip distance estimates, and walk accessibility calculations. Atlanta is in the process of more than doubling the number of zones in its trip-based model to 5,000+. Chicago's trip-based model has more than 16,000 sub-zones for trip generation. Los Angeles's trip-based model uses two tiers of nested TAZs, with the lower tier containing over 11,000 zones. San Diego's trip-based model (and ABM in development) similarly has nearly 5,000 TAZs and over 21,000 master geographic reference areas (MGRAs); non-motorized trips shorter than 1.5 miles use MGRA-to-MGRA network skims. Such TAZ-parcel intermediaries are stepping stones toward the more disaggregate spatial units (parcels) at which synthetic populations are generated in some ABMs.

\section{B.5.4 Activity-Based Modeling Activities}

The most frequently selected responses related to ABMs. Over half of MPOs indicated conducting activity and travel surveys (55\%), while ABMs are in progress or planned by 14 (54\%); three responding MPOs already use ABMs. It is notable that five MPOs planning ABMs do not currently model non-motorized travel. These results confirm that an increasing number of regions are turning to $\mathrm{ABMs}$ and tour-based travel frameworks for their travel demand forecasting needs (Donnelly et al., 2010). One advantage of ABMs is that the typically smaller spatial scale is better able to represent the shorter distances over which walk trips occur and the localized nature of the influences on walking travel behavior. Also, tour-based frameworks can allow for a clearer and more realistic representation of modal options and intra-household interactions.

\section{B.5.5 Non-Motorized Network Assignment}

Although not a survey question, this study found two regions (Portland and San Francisco) that have completed and at least two other regions (Philadelphia and San Diego) that are currently engaged in the development of network assignment processes for bicycle and/or walk trips. Nonmotorized assignment can improve estimates of actual walk and bicycle travel times to feed back into earlier modeling stages. Past barriers, including insufficiently detailed sidewalk and bikeway networks and the lack of walk and bicycle route data, are falling. In recent years, GPS-based travel surveys and GPS trace analyses have made possible the creation of bicycle route choice and network assignment models (Broach, Gliebe and Dill, 2011; Hood, Sall and Charlton, 2011). It is only a matter of years or even months before the first walk trip network assignment process becomes operational in a regional travel demand forecasting model.

In the meantime, aspects of preferred walk and bicycle routes can be incorporated into models through network skim modifications. Sacramento's bicycle skims use a network with link distances that have been adjusted based on preferences for or aversions to various cycling conditions; this generates a preferred route for which an actual distance is calculated. A similar method could be developed for walk trips, considering speed and volume of traffic, sidewalk buffer or exposure, and grade, among other variables. 


\section{B.6 CONCLUSION}

The stage is set for significant improvements in the regional modeling of pedestrian travel that will make travel forecasting tools more sensitive to policy concerns, such as evaluating the congestion and emissions effects of mode shifts resulting from smart-growth land use scenarios. At the same time, these models should become more useful for pedestrian planning purposes. The application of travel demand forecasting techniques to synthetic populations at disaggregate spatial scales, alongside non-motorized network assignment, would provide a wealth of detailed walking demand data that, even if crudely estimated, rivals the product of other pedestrian aggregate demand and sketch planning tools. Even if walking trips are not carried through the entire demand modeling structure, they can be spun off to create a stand-alone pedestrian demand tool.

This paper fills a gap in the literature by documenting the development and current state-of-thepractice of representing pedestrian travel in MPO regional travel demand forecasting models. It comprehensively describes and discusses the modeling frameworks, model structures, and variables used, providing a snapshot of how large MPOs currently account for walk and nonmotorized trips. This review also identifies best-practice regional pedestrian modeling techniques and suggests opportunities for improvement.

MPO staff members can use this review to identify how their models compare to other modeling techniques, select those methods that are most applicable to their organization's planning needs and modeling capabilities, and/or identify the practices that will provide the greatest return on investment. Other parties interested in predicting pedestrian demand can reference this paper when borrowing or developing forecasting procedures of their own. Future researchers can also use this paper as a benchmark upon which to evaluate the progress of representing pedestrian travel in regional demand forecasting models. 
B-18 



\section{GOTREC \\ AND EDUCATION CONSORTIUM}

P.O. Box 751

Portland, OR 97207

OTREC is dedicated to stimulating and conducting collaborative multi-disciplinary research on multi-modal surface transportation issues, educating a diverse array of current practitioners and future leaders in the transportation field, and encouraging implementation of relevant research results. 